\title{
balikbayan blues
}

\section{Unfolding a Collective Consciousness}

Neither "Here" Nor "There"

by

Anne Camille Baello

A thesis submitted to the Faculty of Graduate and Postdoctoral Affairs

in partial fulfillment of the requirements for the degree of

Master of Architecture Professional

Carleton University

Ottawa, Ontario

(ㄷ) 2017

Anne Camille Baello 
balikbayan blues

unfolding a collective consciousness

neither here, nor

there. 
:

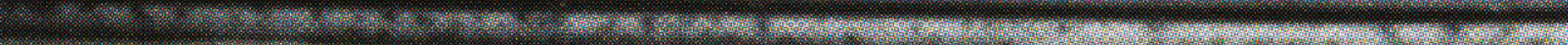

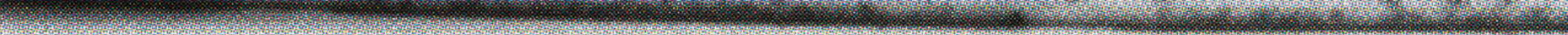
(2)

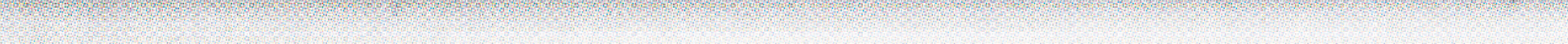

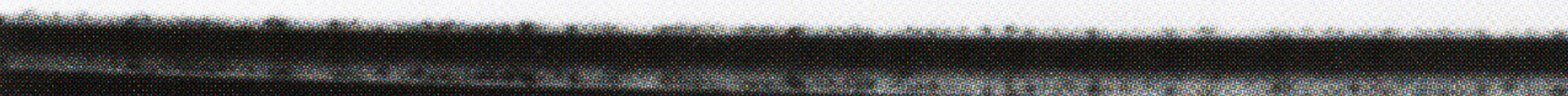
- 


\section{abstract}

Top image

View down 6th Street, San Francisco

Bottom image

Bessie Carmichael Filipino Education Centre
The term diaspora has proliferated the dialogue surrounding Filipino migrancy and has become a strategic discourse in mediating the collective consciousness between homeland and hostland. While a global phenomenon, diaspora also connotes a dynamic spatial negotiation within the host localities. The 21st century city has been and will continue to be re-shaped and redefined by the socio-cultural factor of international migration and the accompanying politics of ethno-cultural difference. Balikbayan Blues: Unfolding A Collective Identity Neither "Here" Nor "There" will set out to examine the implications of the politics of difference and the persistence and plasticity of culture through the context of the SoMa district in San Francisco - a city home to the second largest community of Filipinos in America.

A study of such dynamics - of diaspora, the "Other", and the inbetween - will frame an analysis of the Filipino balikbayan box ritual, utilized as a metaphorical tool in exploring new methods of building, situated within the negotiation of a collective memory of the homeland and responsive adaptations to the host locale, in the 21st century multi-cultural, multi-ethnic cities. The architecture that emerges is neither here, nor there and neither completely fiction or faithful. Instead, the spaces that materialize are something in-between; in perpetual mutation. 


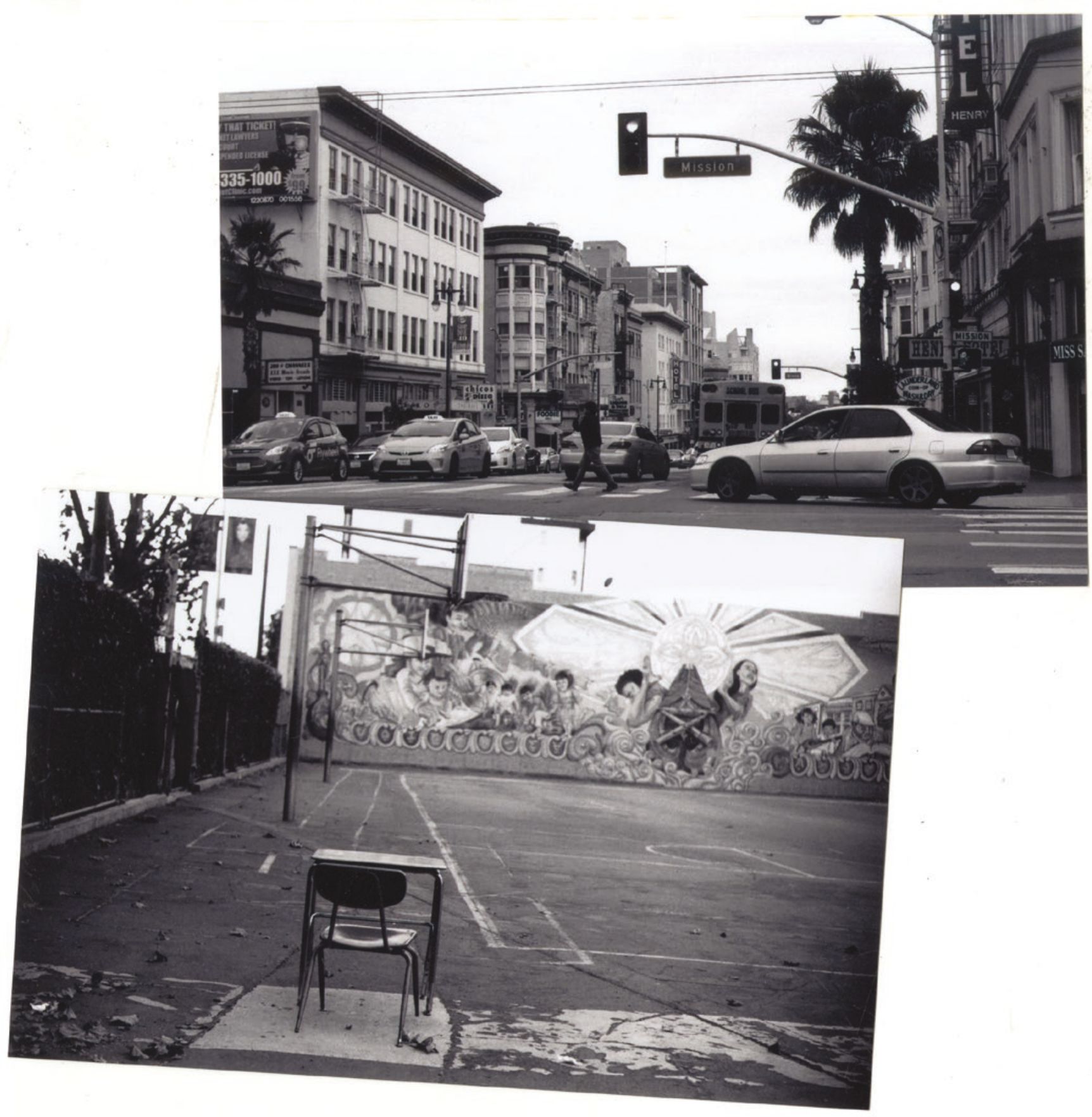




\section{Acknowledgements}

Thank you to my advisor, Yvan Cazabon (\#cazaboss)

For your guidance and always reminding me to never lose confidence in my ideas.

\section{Thank you foremost to my parents}

My dad, for always encouraging my sense of curiosity and the use of my imagination.

My mom, for sharing with me your resilience, strength of will and undying dedication.

\section{Thank you to Thompson Nguyen}

For sharing the podcast that helped to frame my thesis topic early on. You are one my biggest inspirations.

\section{Thank you to Desi Danganan}

For sitting down with me and sharing the stories of your community. 


\section{table of contents}

Abstract

Acknowledgments

List of Illustrations

List of Filipino Terms

List of Appendices

Stories From A 1.75

Diaspora Blues [so, here you are -]

001

Act I: too foreign for [home,]

009

Culture of Migration

Origin of Balikbayan

Myth to Homeland

Act II: too foreign for [here.]

Living as A Spectacle

Core Story

Not Home, but Here

Act III: never ever for both [both.]

San Francisco Bay Blues

Unpacking the Balikbayan Box

Proposal for the Liminal State
011

017

023

027

029

043

053

068

070

078

081 


\section{List of Illustrations}

All images not noted within this list were made by the author

\section{Page 019}

“FM Declares Martial Law". 1978. Newspaper cover. Philippine Sunday Express. Accessed on March 30, 2017, http://www.gov.ph/featured/declaration-of-martial-law/.

\section{Page 020}

Mari Vargas. Protester slashing an oil painting of Philippines dictator Ferdinand Marcos.

1986. Manila: AP Photo. Accessed on March 30, 2017. https://assets.bwbx.io/images/users/ iqjWHBFdfxIU/i25dZHvJp4dA/v0/1000x-1.jpg.

\section{Page 021}

Cover of Balikbayani Program brochure (Department of Tourism - Los Angeles. Aug. 1999).

\section{Page 022}

"Bring Home a Friend" raffle coupon (Department of Tourism - June 1999).

\section{Page 024}

Cover page of "Rediscovery Philippines" tour brochure (Department of Tourism - Los Angeles. Aug. 1999)

\section{Page 025}

Vintage Philippine Airlines Advertisement, 1977. http://www.vintageadbrowser. com/airlines-and-aircraft-ads-1970s/7.

\section{Page 041}

Arnold Genthe. San Francisco's Ross Alley, Chinatown. 1898. Library of Congress. http:// mashable.com/2015/11/10/arnold-genthe-chinatown/\#NCs0fBP.kgqu

Arnold Genthe. After the Earthquake, Chinatown. 1906. Library of Congress

\section{Page 042}

William W. Harts. Map of San Francisco, California. Showing limits of the Burned Area destroyed by the Fire. 1906. Lithograph. San Francisco: U.S. Army via UC Berkeley. Accessed on April 1, 2017. https://www.hjbltd.com/antiquities/images/antq/aq19334a.jpg.

\section{Page 045}

"Bataan Completely Occupied by Japan". 1942. Newspaper cover. The Tribune. Accessed on March 30, 2017. https://static.rappler.com/images/bataan-fall-tribune.jpg.

\section{Page 046}

White Mobs Attack Filipino Farmworkers in Watsonville, California. 1930. Photography. Stockton: The Culture Project-SoHo. Accessed on April 1, 2017. http://www.nytheatre-wire. com/co07051b.jpg.

\section{Page 049}

Photography of the 1-Hotel. 1978. Photography. San Francisco: Freedom Archives. Accessed on March 30, 2017. https://freedomarchives.org/images/IHotel.photo.jpg.

\section{Page 050}

Calvin Robertson. Sheriff Richard Hongisto stands outside the evicted I-Hote. 1977.

Photography. San Francisco: Found SF. Accessed on March 30, 2017. http://www.foundsf.org/ images/c/c1/Hongisto-at-I-Hotel-by-Calvin-Roberts-Granmas-Camera-1977.jpg. 
Chris Huie. Sheriff Deputies and San Francisco Police confront demonstrators. 1977.

Photography. Accessed on March 30, 2017. Sheriff_deputies_and_San_Francisco_Police_ officers_confront_demonstrators.jpg

\section{Page 056}

Janet Delaney. Greyhound Bus Depot, 7th St. between Mission and Market Street. 1982. San Francisco: de Young Museum.

\section{Page 057}

Janet Delaney. People's Constructions, 30 Langton Street. 1980. San Francisco: de Young Museum.

\section{Page 058}

Janet Delaney. 10th at Folsom. 1982. San Francisco: de Young Museum.

\section{Page 097}

Google Maps. 2017. "4th Street and Folsom Street" Google. Accessed May 2, 2017. https:// www.google.ca/maps/@37.7818816,-122.401375,3a,75y,319.09h,88.78tdata=!3m6!1e1!3m4! 1sNUIdWcYkDKQhpU43kzBhXg!2e0!7i13312!8i6656.

\section{Page 099}

Google Maps. 2017. "Yerba Buena Lane" Google. Accessed May 2, 2017. https://www.google. ca/maps/@37.7850742,-122.4034476,3a,75y,312.36h,83.14tdata=!3m6!1e1!3m4!1ssyc3GdEH 3K1k5buvrzo5PQ!2e0!7i13312!8i6656.

\section{Page 101}

Google Maps. 2017. "Bayanihan Centre." Google. Accessed May 2, 2017. https://www.google ca/maps/@37.7805906,-122.4091508,3a,75y,316.64h,88.25t/data=!3m6!1e1!3m4!1sIQ2XiTObXa9PS73sPEmbw!2e0!7i13312!8i6656. 


\section{List of Filipino Terms}

Span. = Spanish; Tag. $=$ Tagalog; var. = various

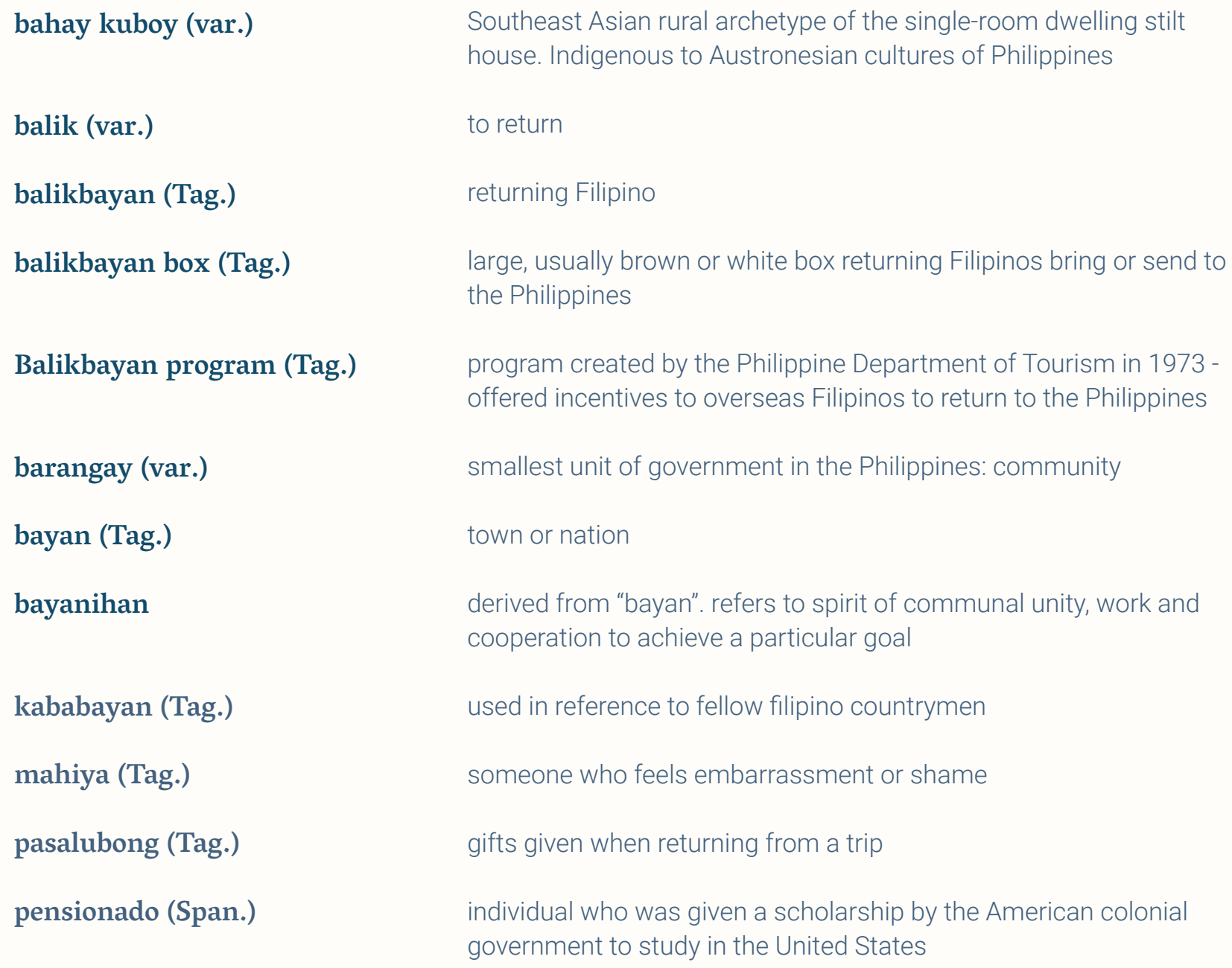




\section{List of Appendices}

Appendix A

Appendix B
Definitions of selected terms

\#

Process Images 


\section{stories from a 1.75}

Home has always been an abstract notion to me. As an immigrant from the Philippines who moved to Canada when I was 4, I've struggled to find footing not only in my adopted country but in my own self-conscious. As my family moved from town to town, searching for that space that could make a place - that they could make a home - the means at which I could identify with my own surroundings seemed to get more and more muddled.

Inside the walls of my house I was Filipino.

Outside, I was simply not. At least - I felt like I was not.

It was the Summer that I turned 16 - the Summer I spent a month in San Francisco with my grandparents - that home finally became a place. The internal longing that I felt to connect with something - anything - finally collided into a space that was not bound by four walls but extended outwards. I was immersed. Surrounded and connected to the community that my grandparent's had been a part of for over 18 years - a community that they helped built - I was Filipino. I was home.

And since then, it's always felt like home. 


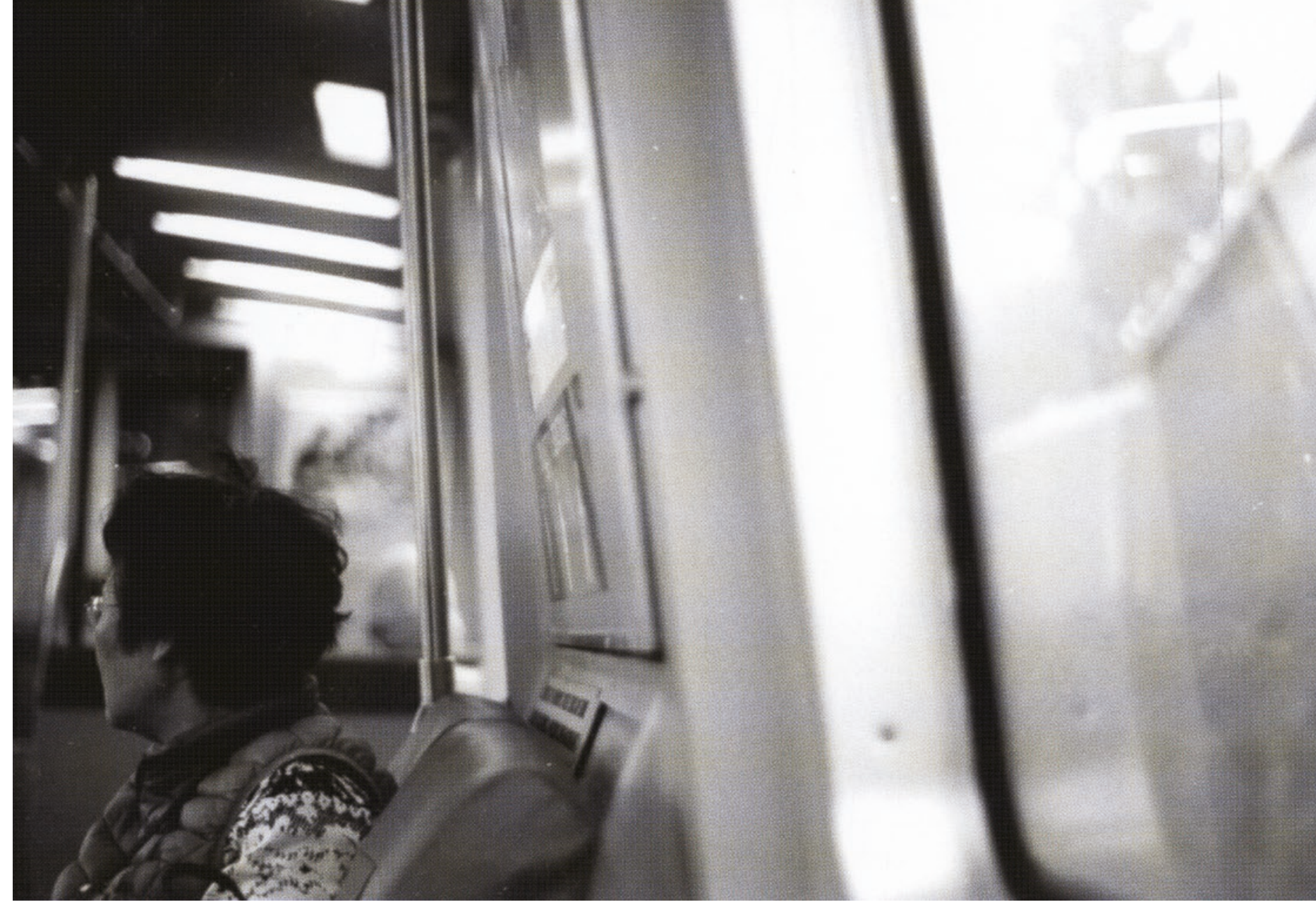

diaspora blues

so, here you are - 
di.as·po·ra $\backslash \mathrm{d} \overline{-}-'$ as-p(ə-)rə, dē- $\backslash$ :

the movement, migration, or scattering of a people away from an established or ancestral homeland.

Discourses on diaspora use the term in three distinct but related ways:

1. As a social form:

refers to individuals who live in different parts of the world but identify collectively with one another.

2. As a type of social consciousness:

refers to individuals who live in a variety of societies and cultures and who emphasize their sense of belonging or exclusion, their states of mind, and their sense of identity.

3. As a mode of cultural production:

refers to the reproduction of cultural phenomena through creolization and hybridization. ${ }^{1}$ 


\section{so, here you are -}

Preface

DIASPORA BLUES [ so here you are - ]
Within North America, the socio-political phenomena of international migration ${ }^{2}$ is so prevalent that the concept of the "Other" has come to define the multi-national identity and history of both the United States and Canada. In these movements, cultures globally are de- and re-territorialized in the demographic restructurings of 21st century cities ${ }^{4}$. The term diaspora, originally used to describe the forced dispersal of the Jewish, Armenian, and Greek peoples, has proliferated the dialogue surrounding international migration and transnationalism. ${ }^{6}$ While it expresses a social experience of displacement, diaspora is also used to refer to a transnational sense of self and an understanding of ethnicity that breaches boundaries both real and imagined. As a result, the term has become a discursive strategy in mediating the collective consciousness between "homeland" and "hostland."

In addition to being a social phenomenon born of the complex and multi-dimensional processes of globalization, diaspora also connotes a dynamic spatial negotiation within the host locales, where the transnational migrant groups 8 live in "mediated tension"9 between displacement and place-making. Through the experience of displacement the link between social identity and geographic space is disrupted..$^{10}$ Ijeoma Umebinyuo articulates the sentiment of a transmigrants ${ }^{11}$ internal struggle in Diaspora Blues: 
So, here you are -

too foreign for home

too foreign for here.

Never enough for both. ${ }^{12}$

Umebinyuo, a Nigerian poet who strongly identified with her Igbo heritage, expressed the transmigrants struggle to redefine a sense of belonging in their new society. In that process, transmigrants actively engage in the breakdown of traditional spacio-temporal conditions through the development of transnational social fields. ${ }^{13}$ As they occupy a liminal ground that is somewhere between the everyday tension of living "here" and remembering "there", it is through their formation of hybrid identities that transmigrants contribute to the spatial restructuring of contemporary cities ${ }^{14}$.

Transmigrants daily fight to exercise agency over the physical spaces in which they live, work and interact, is parallel to the their struggle of belonging. This is because the globalized localities ${ }^{15}$ are inhabited by both diasporic individuals and those who are perceived as "indigenous"16, which can create a conflict of ethnocultural differences ${ }^{17}$ and an experience of fear of "The Other"18. The neighbourhoods of the 21st century multi-ethnic, multicultural city then become the stage of contestation at which the 
"cultural politics of difference"19 plays out. Therefore, the narrative of diaspora and the project of intercultural co-existence ${ }^{20}$, is one in which architects and urban designers are deeply implicated. Transmigrants, rather than being mere victims who are acted upon by the dominant society, appear in these narratives as actors within and across space. ${ }^{21}$

In the poem "Diaspora Blues", the first lines directly refers to the transmigrant actors within the diaspora, "So, here you are", reinforcing their presence (you are) and grounding their existence through the expression space (here). Within the literature of international Filipino migrancy, these diaspora subjects are referred to as Balikbayans. ${ }^{22}$ The character of the Balikbayan and the derivative ritual of the Balikbayan box encapsulates the collective consciousness of Filipino transmigrants, occupying the imagined space between the "homeland" and the "hostland".

Balikbayan Blues: Unfolding A Collective Identity Neither "Here" Nor "There" sets out to examine the persistence and plasticity of cultural identity and the implications of the politics of difference through its relationship to place, specifically the SoMa (South of Market) neighbourhood in San Francisco. The Northern California city is home to the second largest community of Filipinos in 
America. In part an ethnographic investigation and proposal for the Filipino diaspora community in San Francisco, the thesis also seeks to present a re-conceptualization of the "ethnic enclave", not as a metaphor of exclusion but rather built on an ethos of negotiation and inter-cultural co-existence. Rather than a simple case study, the thesis is a microhistory insofar that it aspires to "[ask] large questions in small places." ${ }^{23}$ Using the poem Diaspora Blues by Ijeoma Umebinyuo as a literary device, the character of the Balikbayan and the balikbayan box ritual will be examined through the framework of "Home", "Here" and "Both".

"Home" and "Here" of the examination follows the deconstruction of the Balikbayan character in both respected contexts - as a temporal category of citizen in "Home" and as a reductive characterization as the "Other" in "Here". The character will then be reconstructed in the context of SoMA, San Francisco - a city not only significant in Filipino American history but within that of my family as well. It is within the context of this city that Balikbayan's narrative will be demarcated, simultaneously delineating the transformation of the community's "urban cultural landscape."24

"Both" includes a microhistory of the balikbayan box - a deconstruction of the artifact as a means of examining the 
sequence of the ritual. This in turn provides insight on how the process and the remittances exchanged redefines the Balikbayans relationship with their homeland - mediating the spatial abyss of the Filipino diaspora. In addition to being an index in understanding the unit of a Filipino household, the ritual is also an apparatus by which to conceptualize the everyday actions of plurality and recollection inherent in the development of a Balikbayans transnational identity.

The range of topics that are discussed in Balikbayan Blues are set within the intersection of migration, memory and urban studies. Within this context, the thesis seeks to explore architecture's role as a mediating agent. Approaching the methodology of design as a consummation of the ritual, three "pasalubongs"25 made inalienable through the Balikbayan Box ritual are redistributed within SoMA, each location integral to the neighbourhood's cultural landscape and to the larger contextual surroundings of San Francisco. The thesis then becomes an examination of these "pasalubongs" as lens into the evolving ties of kinship embedded within the action of the exchange and the changing dynamic transnational migrant communities have to their homeland.

Public space, a tool of governmentality ${ }^{26}$ to propagate fear of 
difference can be reclaimed to exercise the right to difference, which is essentially a right to the city. Representative of the Balikbayans ties of kinship - adapted meanings and memory reified - the interstitial social narratives that emerge from the action of exchange will provide the formal tactics for the urban landscape and to facilitate the design process of the micropublics $^{27}$ - the sites of everyday social contact and encounter.

The proposal will be a means to integrate the narrative of diaspora into the planning of a 21stcentury multi-ethnic, multi-cultural cities - allowing the liminal state to inform the process of designing an urban-scale architecture based upon the mediation of belonging and inclusivity of difference. The spaces that materialize will then be something in-between; in perpetual mutation. 


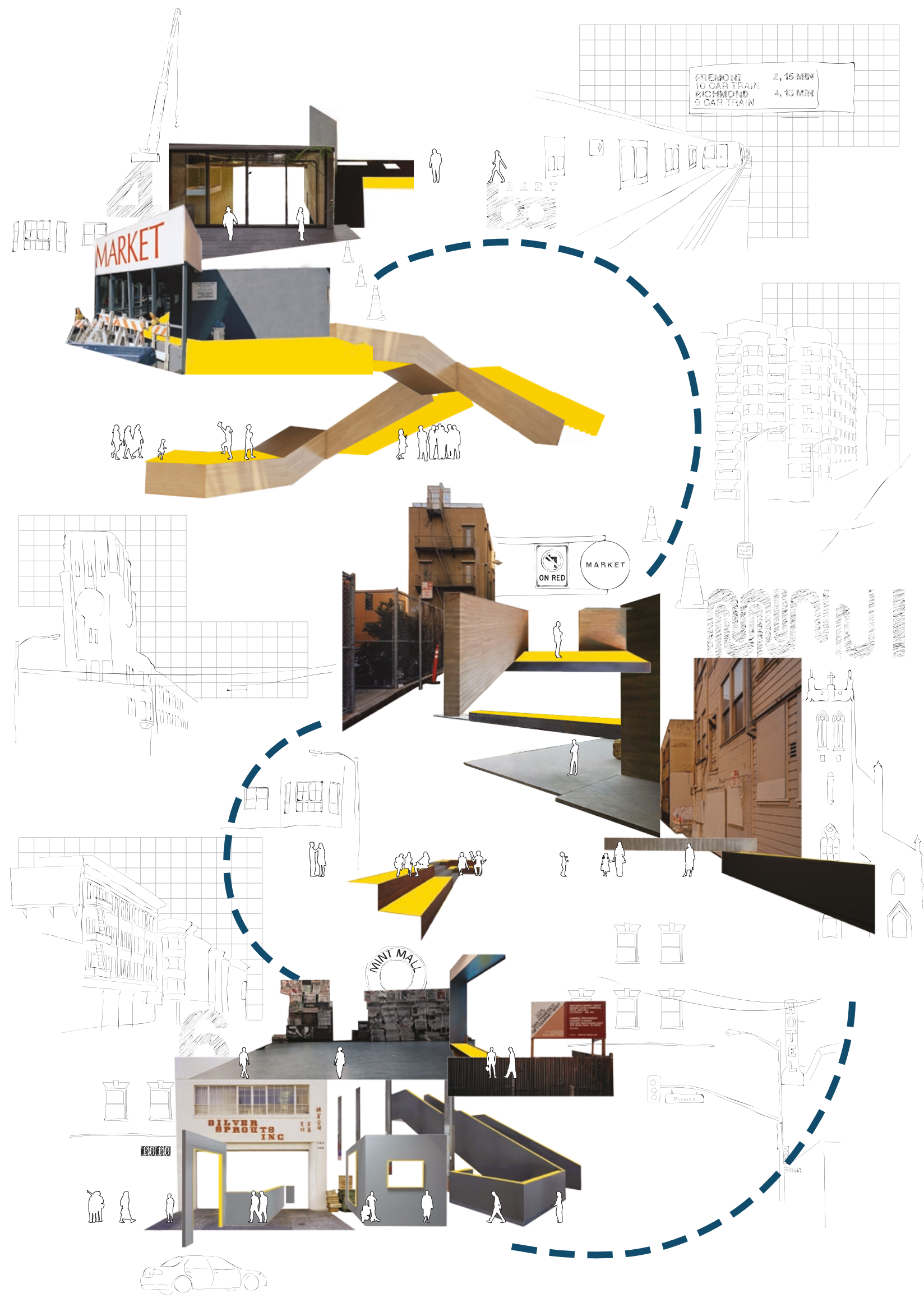




\section{Endnotes}

01. Vijay Agnew, Diaspora, Memory and Identity: A Search for Home, (Toronto: University of Toronto Press, 2005), p.5

02. Refer to Appendix A

03. Refer to Appendix A

04. Leonie Sandercock, Cosmopolis II: Mongrel Cities in the 21st Century, (London: Continuum, 2003), p.92.

05. Agnew, Diaspora, Memory and Identity, p.3.

06. Refer to Appendix A - Definition of transnationalism

07. Refer to Appendix A

08. Refer to Appendix A

09. Agnew, Diaspora, Memory and Identity,p.193

10. Philip Chang, Claire Dwyer and Peter Jackson, Transnational Spaces, (London: Routledge, 2004),

11. Refer to Appendix A

12. Ijeoma Umebinyuo, Questions for Ada, (CreateSpace Independent Publishing Platform, 2015), p.

13. Chang, Dwyer and Jackson, Transnational Spaces, p. 13.

14. Sandercock, Cosmopolis II: Mongrel Cities, p.20.

15. Refer to Appendix A

16. Chang, Dwyer and Jackson, Transnational Spaces, p.11. Excerpt taken from Cartographies of Diaspora by Avtah Brah (1996)

17. Sandercock, Cosmopolis II: Mongrel Cities, p.4

18. Refer to Appendix

19. Refer to Appendix A

20. Refer to Appendix A

21. Ayse Caglar and Nina Glick Schiller, Locating Migration: Rescaling Cities and Migrants (London: Cornell University Press, 2011), p.3

22. Refer to Appendix A

23. Charles Joyner, Shared Traditions: Southern History and Folk Culture, (Urbana: University of Illinois, 1999), p.1.

24. Sandercock, Cosmopolis II: Mongrel Cities, p.223

25. Refer to Appendix A

26. Michel Foucault, Power, Michel, James D. Faubion, and Robert Hurley, eds. (New York: New Press, 2000), p. $219-220$

27. Refer to Appendix A 
too foreign for home,

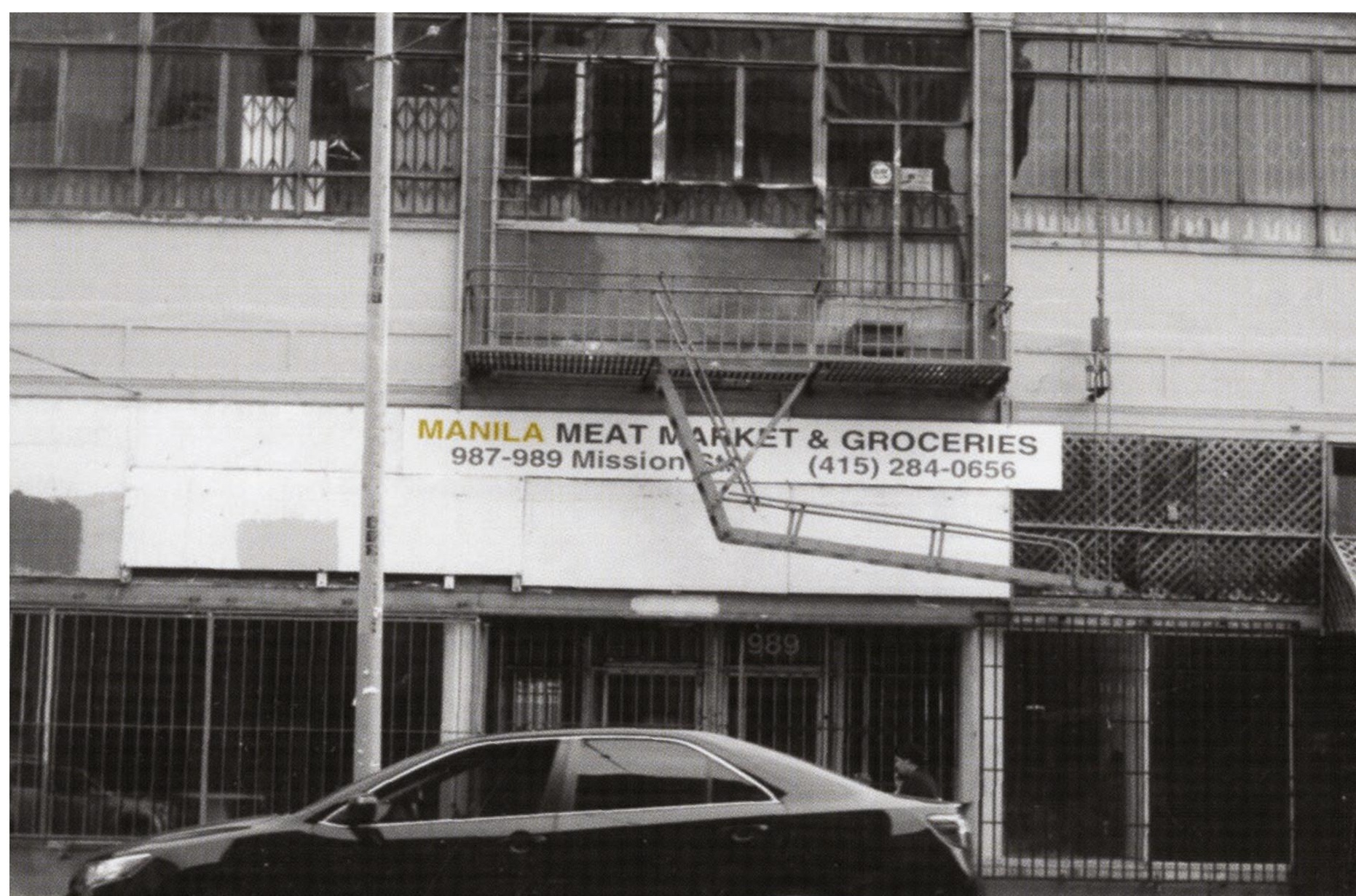




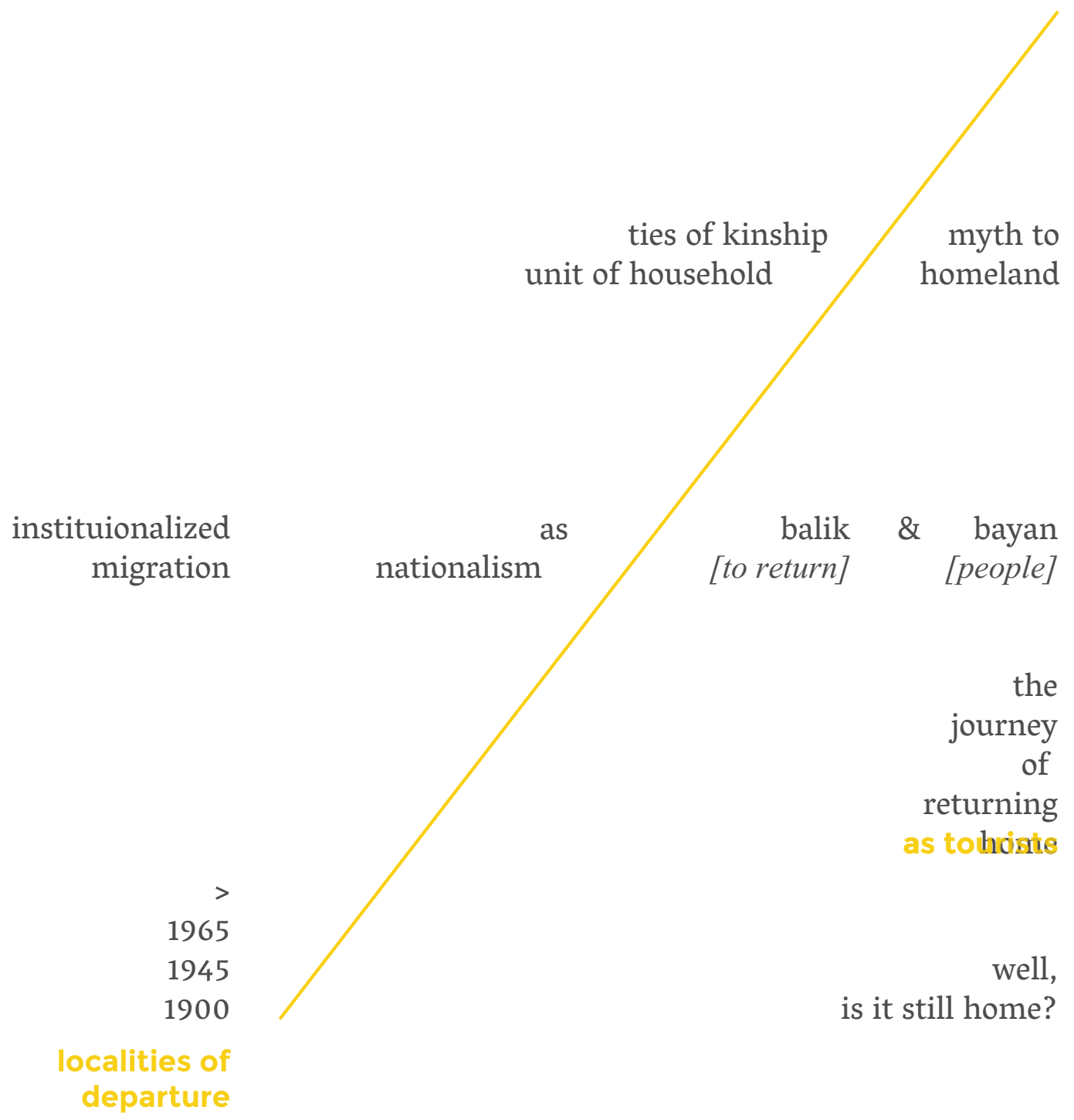




\section{home,}

Culture of Migration

\section{Culture of Migration}


definition of a "household" is not limited to a physical dimension of a domestic unit, but can include consanguineal, affinal and fictive ties of kinships within and across space. This meso-level form of analysis of migration can be utilized as a tool to contextualize the transmigrants relationship to the localities of departure (home) and frame their experiences within the localities of settlement (here).

The unit of a household does not only reflect cultural values and builds upon the history of the people who make them, but is also critical in the creation, negotiation and maintenance of identity over time. The cultural model of migration is compatible in analyzing the character of the Balikbayan, as the Philippines as a kinship-oriented society; a direct influence of the ancient barangays (or villages) which were the dominant organizational pattern in the pre-colonial history of the country. These social structures, derived from the spatial organizations of the barangays and the traditional housing archetypes, continue to act as the precedent for social and political interactions within Filipino culture $^{6}$. The concept of bayanihan, of which modern Filipino proxemics ${ }^{7}$ is based from, is evident of the barangays continuing cultural influence. 


\section{Bahay Kubo}

The traditional Filipino home, "bahay kubo" (nipa hut) has no physical boundaries that seperate the rooms. The interior of the "bahay kubo" is multipurpose, functoning as "receiving room, sleeping room, kitchen, dining room.

The space constantly adapts to allow for whatever activity needs to be accommodated at any particular moment during the day.

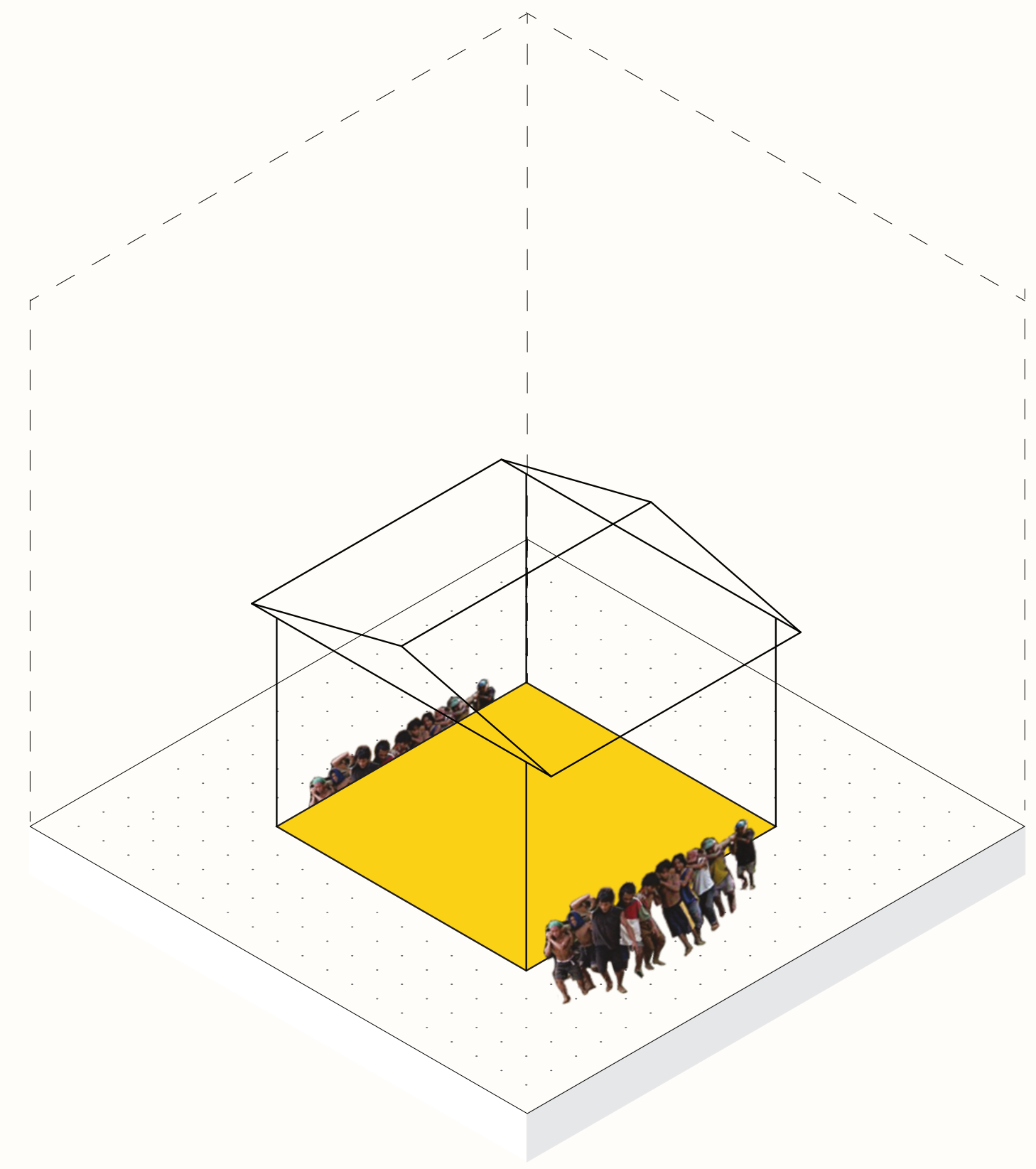




\section{Bahay Kubo}

Bayanihan is a Filipino value system that encompasses a spirit of kinship and camaraderie. The Bayanihan system is characterized by communal work towards one goal. This is commonly examplified through the action of community members volunteering to help carry a Nipa hut when a family needs to move to a new place.

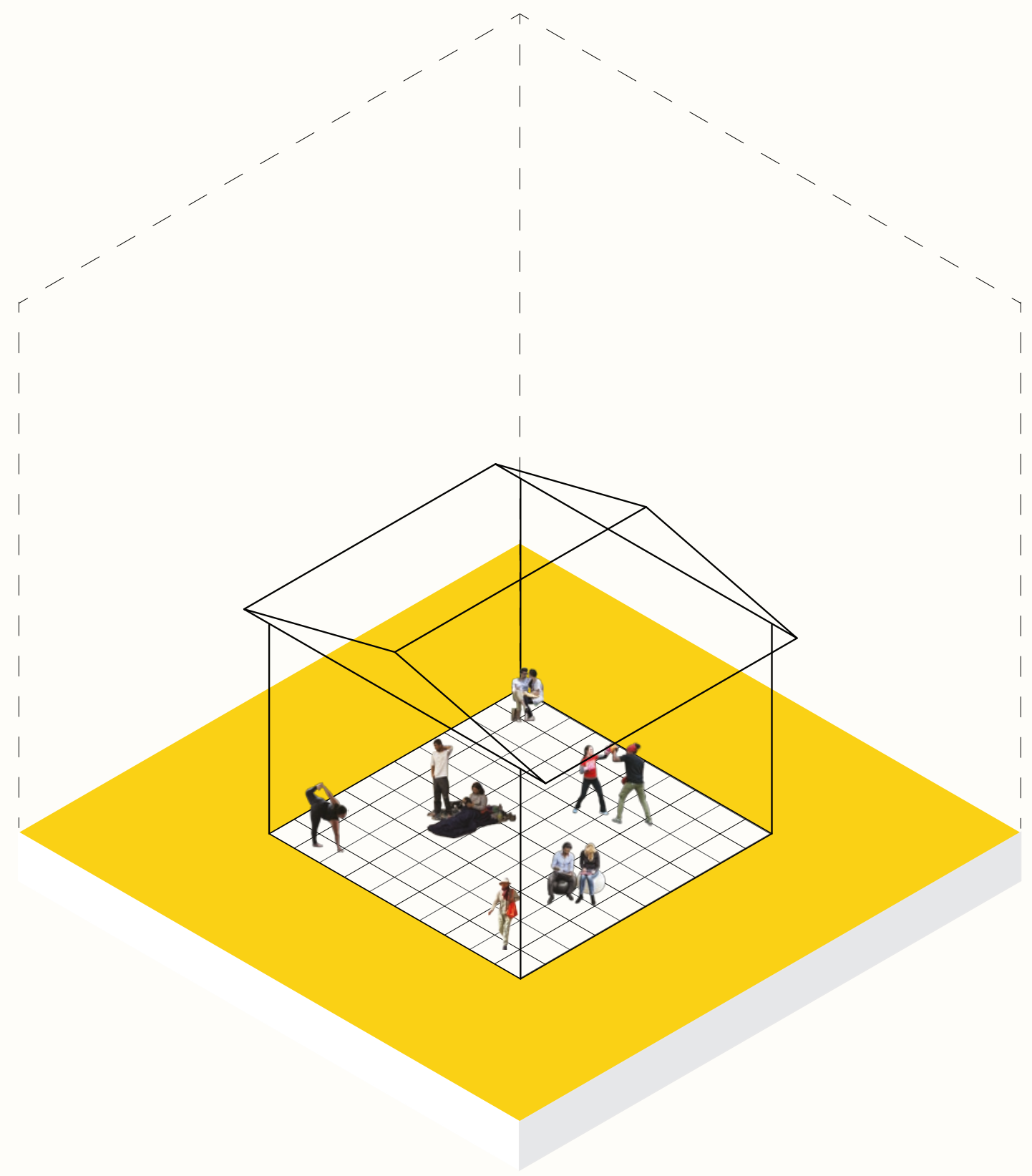


Whereas the contemporary manifestations of barangays represent a territorial entity - the pre-colonial barangays were a representation of loyalty to a particular head (or datu). ${ }^{8}$ The datu and their families were considered members of the nobility, the highest category in the "barangay" status system. However, the social structure was by no means rigid and beholden to the three broad classes (nobility, freeholders and dependants). Instead, the "barangays" were defined by a bilateral kinship system, which saw descent and inheritance passed equally through male and female lines. This is represented within modern Filipino household units as unequivocal loyalty to both the matriarch and patriarch of the family.

Within the contemporary context of migration, the Filipino "household" has become predominantly transnational. However, the loyalty towards the modern equivalent of a Filipino household's "datu" and their associated "barangay" has not wavered. Instead, the fervor of loyalty has manifested itself within the character of the Balikbayan. An understanding of the sociocultural ideals, norms and history of "home", framed through a mesolevel deconstruction of the Balikbayan, provides a contextual comparison to the experience of "here", (South of Market, San Francisco). What this facilitates is an discernment of the plurality 


\section{Filipino Proxemics}

Philippine concept of space is boundless and communal. The Filipino people have little or no sense of personal space or personal boundaries.

Although most social interactions occur comfortably within the Intimate and Personal Space distances, spatial attitudes towards strangers are erratic and unpredictable.

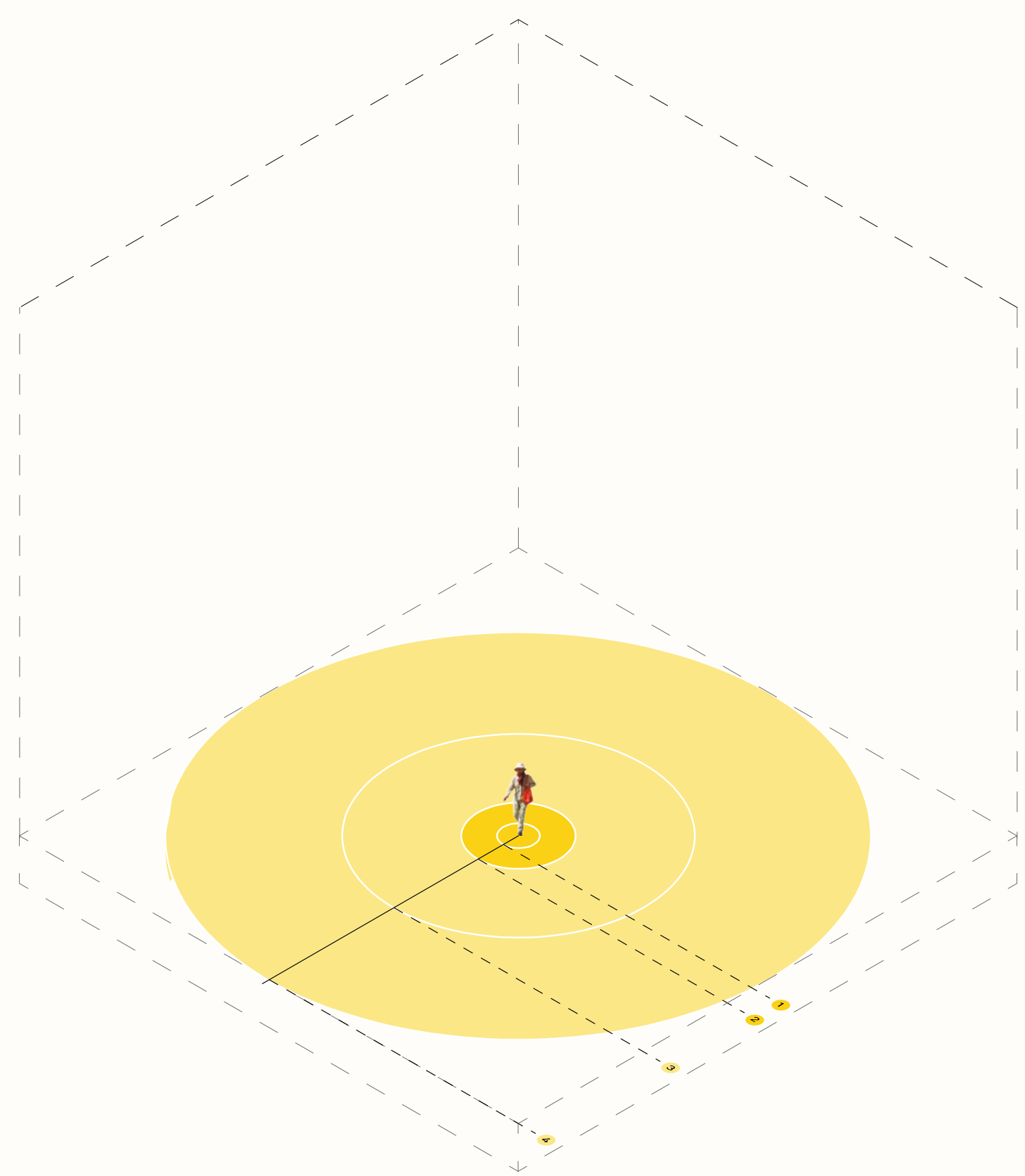


a Filipino transmigrant's identity, through the ties of kinship that encompass the unit of a household.

"The journey creates us [...] and we become the frontiers we cross."

\section{- Salman Rushdie9}

To contextualize the collective consciousness of a specific diaspora, the global and local dynamics within the localities of departure (home) must be addressed in relation to the trends of emigration and the localities of settlement (here $)^{10}$. Within Filipino migration literature, the character of the Balikbayan is the mechanism by which to clarify and understand these nuances, as its origins are directly related to the Philippine's colonial history and emigration trends, especially in relation to the United States.

The contemporary Filipino household unit became transnational due in large part to the United States aims of becoming a Colonial power. Although the Philippines had been subjugated to Western colonization by Spain for 300 years, it was the acquisition of colonial rule in the Spanish-American war of 1898 that defined future emigration trends. Prior to the country's colonization by Spain in 1565 , it had not yet developed a centralized government 
ruling ${ }^{11}$. The Spaniards introduced a political bureaucracy to the archipelago, making it the only Southeast Asian country that was not able to do so independently, hindering its ability to create an indigenous dominant culture ${ }^{12}$.

Though eventually finding solidarity through shared grievances which led to an organized opposition against the Spaniards, complete independence was usurped by the arrival of the Americans, who disguised their imperialist intentions by feigned generosity. Immediately after the Spanish were defeated by the combined Filipino and American forces, the Treaty of Paris was signed in December of $1898^{13}$, ceding the Philippines to the United States. Over the next 50 years, the Americans continually promised the Philippines complete independence while simultaneously ensuring its lasting dependence. While the country was formally granted independence on July 2, 1946 $6^{14}$, colonization left indelible imprints on Philippine politics, culture, and most significantly economy, contributing to the nation's persistent underdevelopment ${ }^{15}$.

This near century's trend of economic struggle influenced by the United States interference in Filipino politics, was the impetus for the country's large scale migrations - an effort to protect themselves from declining real incomes and standards of living ${ }^{16}$ - to search for opportunities of upward social mobility. Over the 2oth century, there were three major waves of Filipino emigration: 190o's, postwar 1940's and the late 1960's. Although the migrational trends were at very different points in history, there were two pervasive trends: 1 . They were all driven by the desire for the acquisition of education, property and money, 2. The majority of the migrants traveled to the United States.

The third major wave of Filipino emigration in the late 1960's was spurred by the election of Ferdinand Marcos in 1965 and his violent and fraudulent re-election in 1969. This was also the same year the 


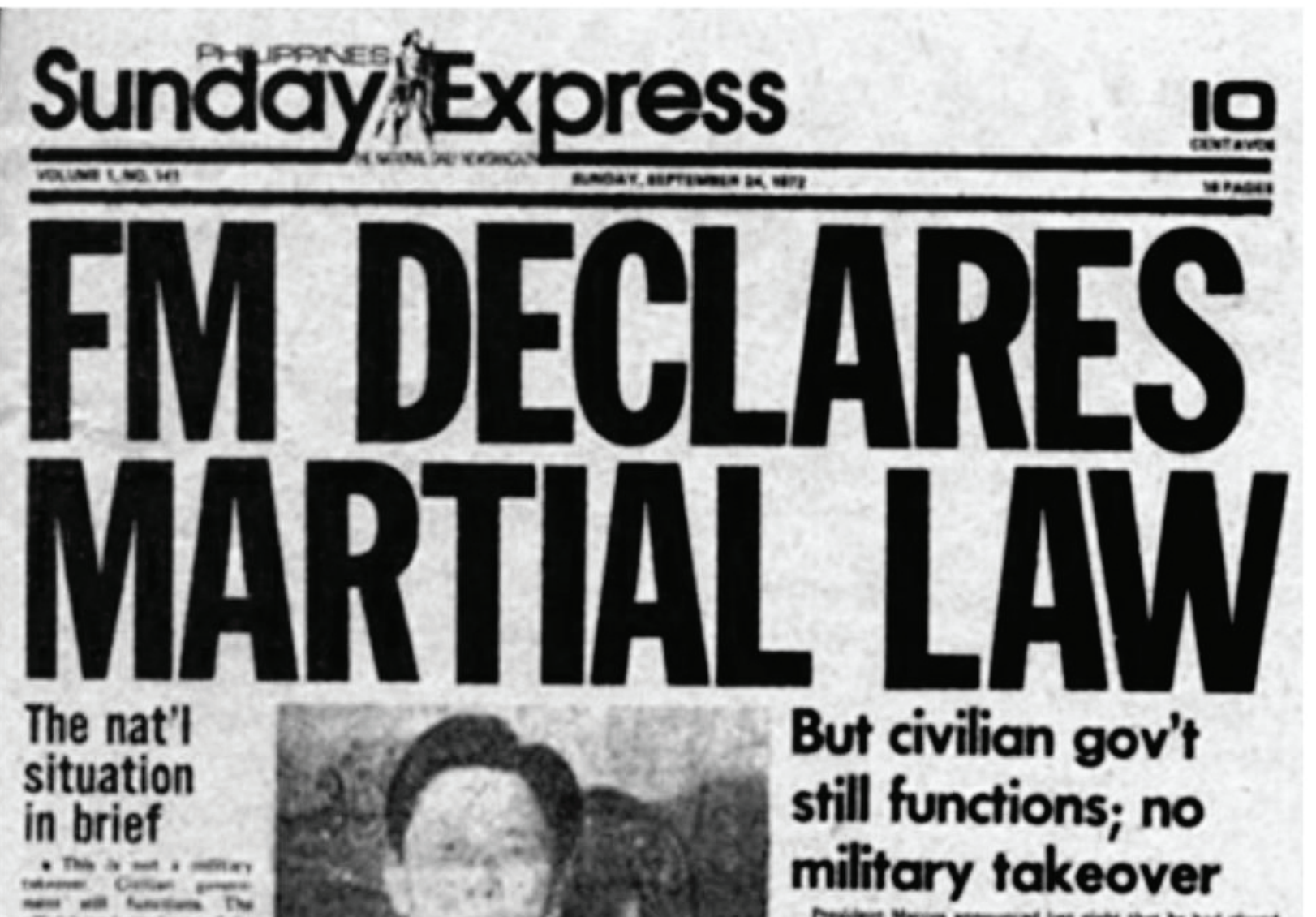

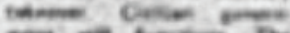

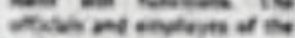

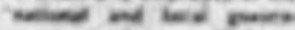

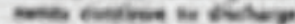

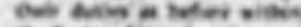

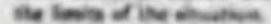

- Al nisure Anes

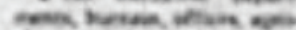

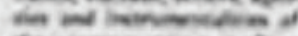

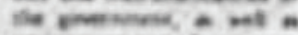

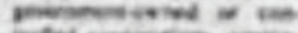

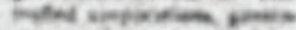

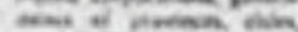

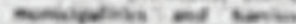

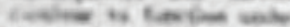
No mon athers a knolisen is nimbies oily wives wers

- is hadiring ball ines

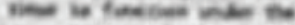

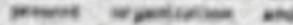

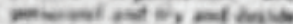

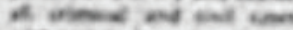

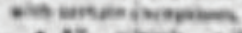

- ar vions cia ke

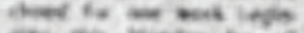

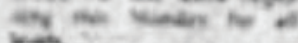

- Camiar al cravera

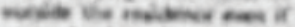
wowed by heres he

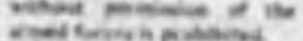
- Colles wa in inosed

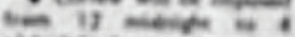

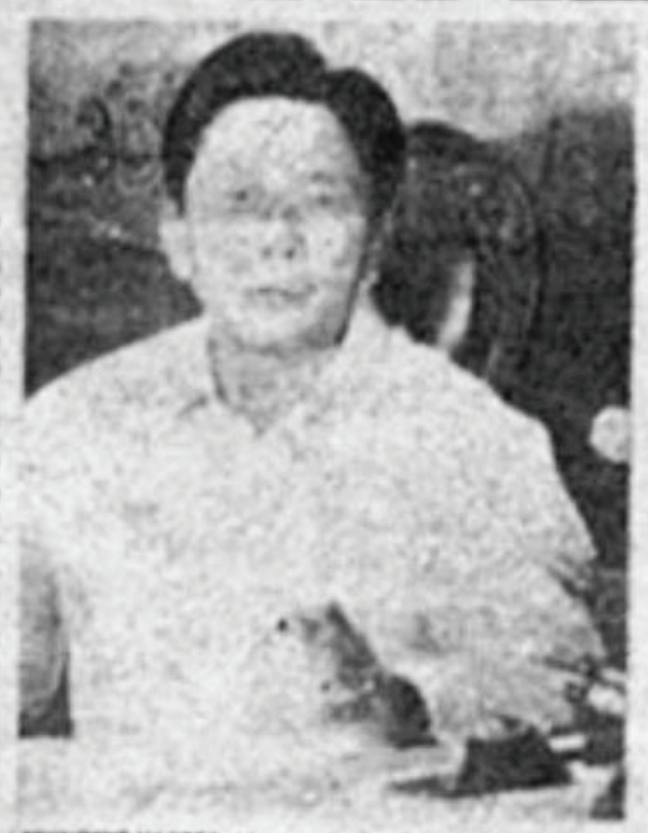

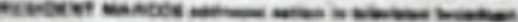

But civilian gov't still functions; no military takeover

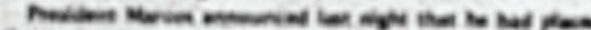

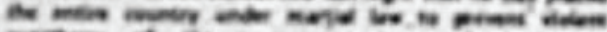

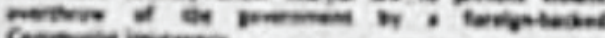

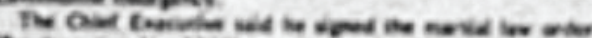

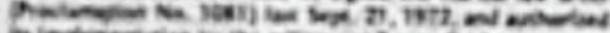

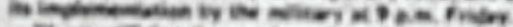

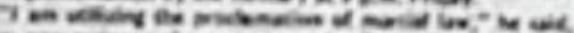

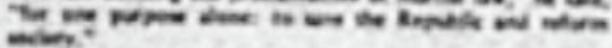

-To save the Republic and form a new society

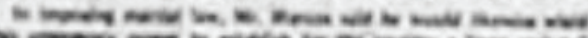

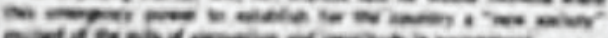

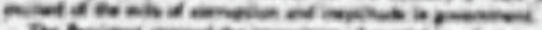

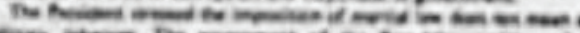

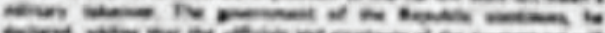

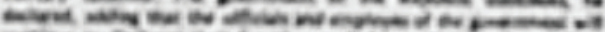

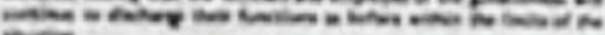

Nation is calm; business, life go on normally

The selies las tobes Her

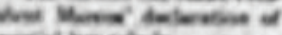
nerat bo sallob

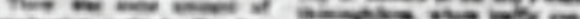
-

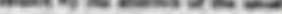

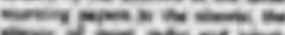

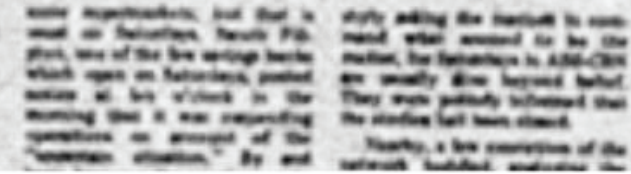


Protester storming the Presidential Palace in Manila - March 25th (1986)

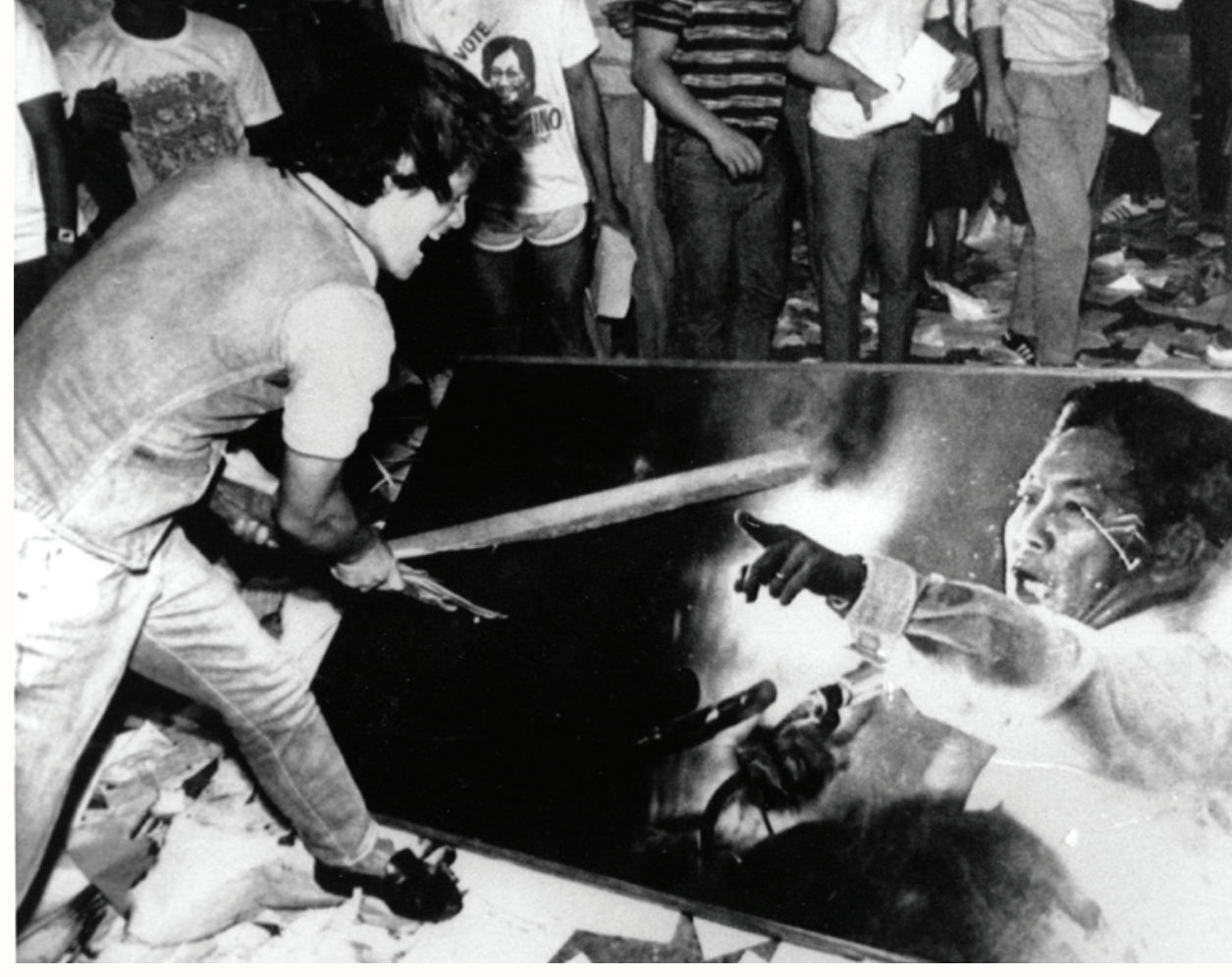

United States Congress introduced changes to immigrantlaws with The Immigrant and Nationality Act, which led to a highly visible increase of the Filipino American population. It continued into the 1970's as President Marcos declared Martial Law, in reaction to the increasing disorder brought on by violent student demonstrations and threats of resistance from opposing political forces. However, his declaration of a "state of rebellion"17 was primarily to override the imminent approach of his presidential two-term limit - extending his authoritarian rule for another decade. The authoritarian era, deemed by Marcos as the "New Society"18 was publicly criticized for its increased corruption, reported excesses and continued repression of rights and freedoms, which Marcos attempted to curtail with the introduction of the Balikbayan program on September 1, 1973.

As an effort to publicize the achievements of his regime and promote tourism, Marco's Department of Tourism designed the Balikbayan program to encourage Filipino migrants, primarily those residing in the United States, to return (balik) to the their homelands (bayan) to observe the benefits of the regime's "New Society" ${ }^{\prime \prime}$. By offering incentives such as reduced airfare, travel tax exemptions and generous baggage allowances, the government capitalized on the emotions of the expatriates and their sentimental 


\section{Invite Your Friends to Rediscover the Philippines}

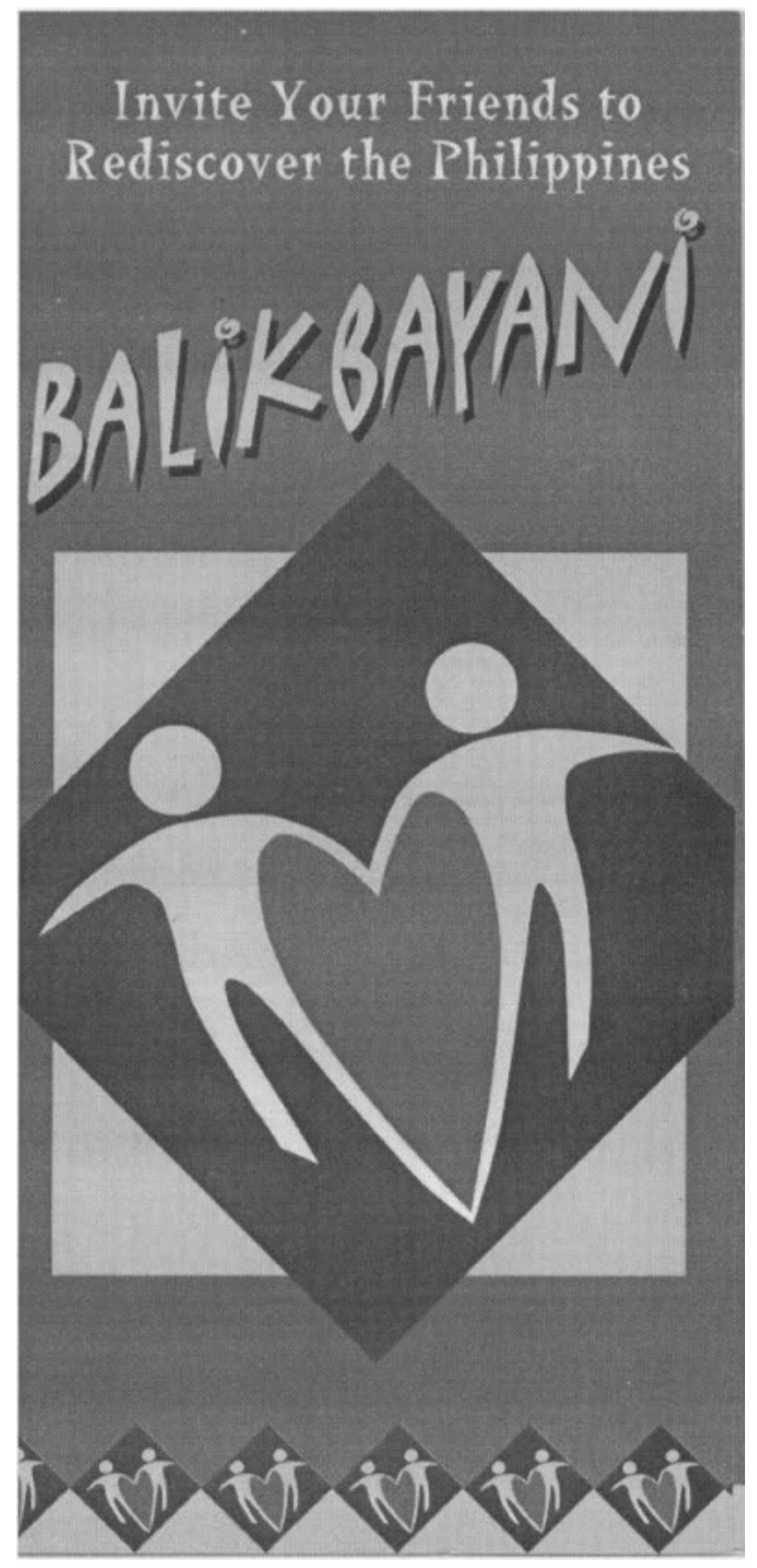



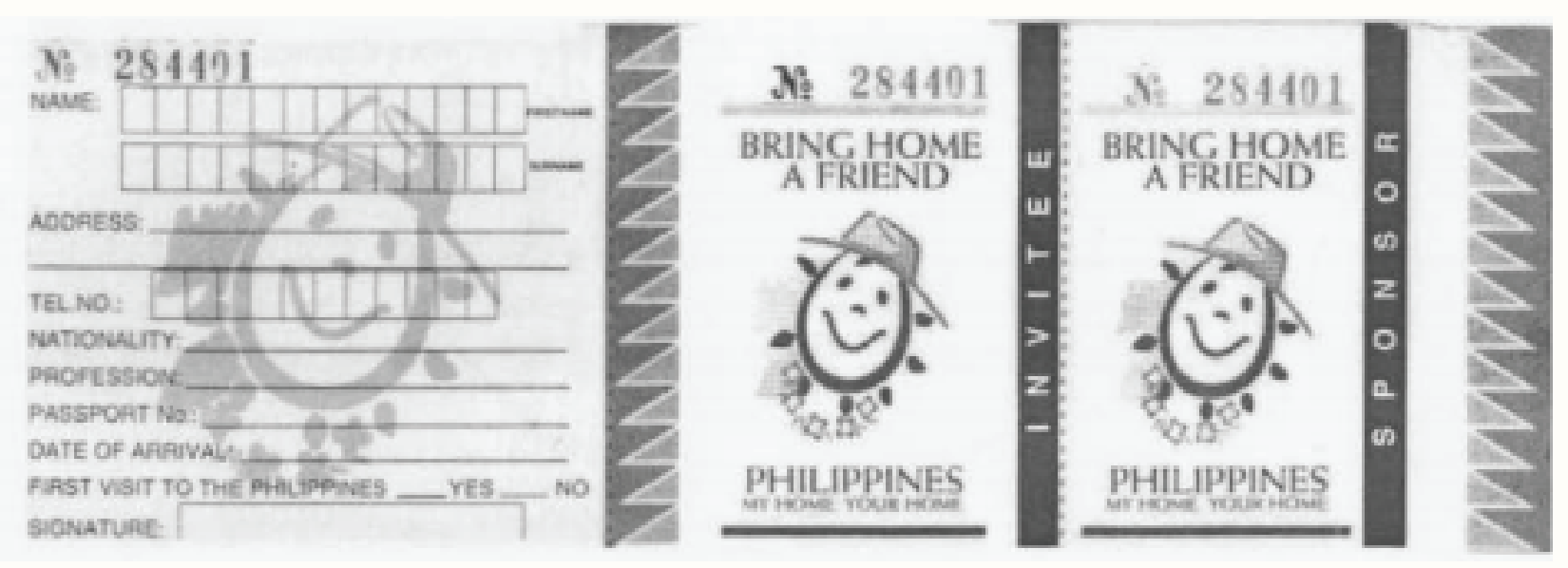

"Bring Home a Friend" raffle coupon (1999)

ties to their homelands to generate income and a positive public perception for the Philippines and the Marcos government. Although, the promotion was meant to be a temporary exercise, the Balikbayan program was extended indefinitely after the end of the third phase on February 29, 1976 after generating over \$4) million dollars ${ }^{20}$ for the Philippine economy.

The Balikbayan program transformed the identity of the returning Filipino expat, which was now characterized by their political credibility in contrast to that of "ordinary tourists." ${ }^{21}$ During the temporary return to their homelands, they were in a position to compare Marcos' "New Society" to that of their "Old Society", which they had opted to leave despite their strong familial ties. The positive feedback provided by the returning migrants to the local press and the world, was of significant political value to the longevity of the Marcos regime. From these circumstances, the character of the Balikbayan emerged. Originally a political tool to serve the purposes of the President Ferdinand Marcos, the invented term, now deeply embedded in Filipino popular vocabulary, has become subservient to a new, temporal category of the populace. 
In Diaspora Blues, the subject of the poem is described to be "too foreign for home". Implying a change in the diaspora subject or a change in their perspective of self in relation to home, or home in relation to self. With the introduction of the Balikbayan Program in 1973, the nature of the Filipino migrant's relationship to their homeland was redefined, as migration, memory and nostalgia became institutionalized as an economic generator for the country. Presently, the "other"-ing of Filipino migrants in their own home-land has become so normalized in local popular culture that Philippine citizens typically describe Balikbayans as "gikan sa gawas", or "from the outside"22 despite being of the same ethnicity.

The development of what was initially meant to be a temporary tourism promotion into a formalized decree - by the inclusion of the Balikbayan Program into law - altered perceptions of Filipino migrants even more so than distance created by miles and years. The adapted Western behaviours only further perpetuated the divide between Balikbayans and the "kababayans" (countrymen) left behind.

Upon arrival on their pilgrimage to the homeland, Balikbayans are immediately ubiquitous figures. Their identification as Balikbayans 


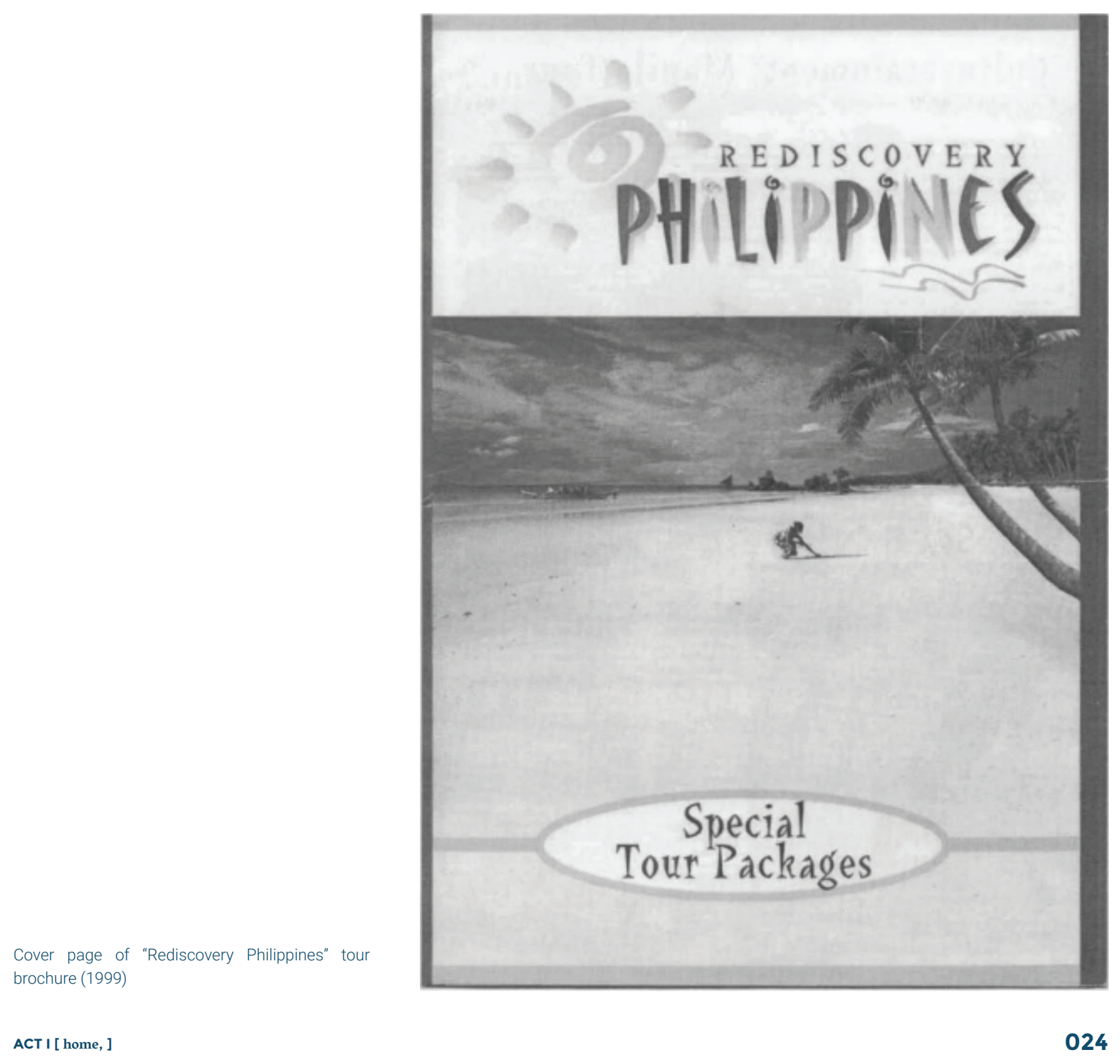




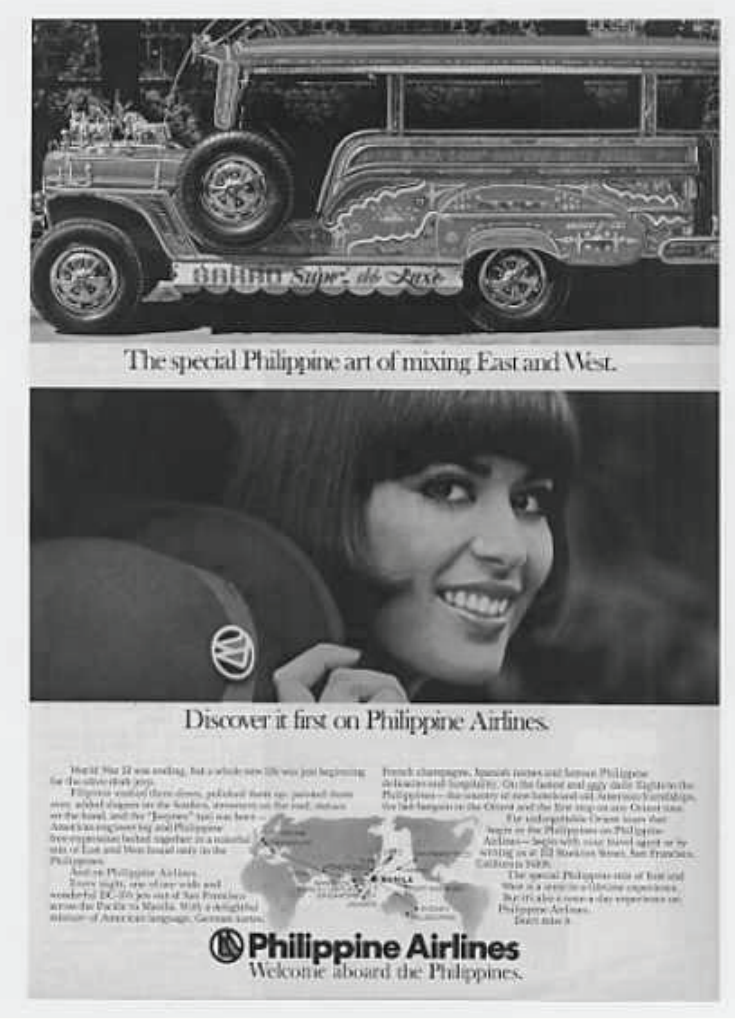

Philippine Airlines advertisement (1977) immediately associates them with a certain position of wealth, and therefore a higher level of status relative to the locals perception of themselves. The perception of affluence that a Balikbayan exudes commodifies them into objects of financial expectation, despite their personal economic realities.

Although the status of Balikbayan immediately adorns migrants with the heightened consideration of Filipino locals, there is an associated assumption to entreat "kababayans" with "pasalubongs" as a reparation for their position of privilege and an expression of nationalistic allegiance. This impression is only further sustained by the economic underdevelopment and the wealth disparity that has consistently affected the Philippines, when compared to that of the migrants hostland. Balikbayans are therefore unable to fully return "home" to the Philippines - as from the moment of their departure, they are perceived to now be from somewhere else. The diasporic location does not promise "neither transcendence nor return"23 to the original comprehension of the "homeland". Instead, it now only exists as an imagined construct and a product of nostalgia, separate from the reality of the actual geography. Within a diasporic consciousness, "home" is now positioned at the intersection of displacement, cultural hybridity and transnational connections ${ }^{24}$. 


\section{Endnotes}

01. Hamid Nacify, Exile, Homeland Film, Media, and the Politics of Place, (New York: Routeledge, 1998), p.5-6

02. Nina Glick Schiller and Ayse Caglar, Locating Migration: Rescaling Cities and Migrants (London: Cornell University Press, 2011), p. 63

03. Yen Le Espiritu, Home Bound: Filipino American Lives across Cultures, Communities, and Countries, (Berkeley and Los Angeles: University of California Press, 2003), p. 2

04. Jefferey H. Cohen and Ibrahim Sirkeci. Cultures of Migration, (Austin: University of Texas Press, 2011), p. 17 Refer to Appendix A

05. Ibid, p. 11. Refer to Appendix A

06. Alice Jade A. Alburo. Box Populu: A Socio-Cultural Study Of The Filipino American Balikbayan Box, (St John's: Memorial University of Newfoundland, 2002), p.189.

07. Refer to Appendix A

08. Alburo. Box Populu: Study Of Balikbayan Box, p. 25

09. Vijay Agnew, Diaspora, Memory and Identity: A Search for Home, (Toronto: University of Toronto Press, 2005), p. 11.

10. Caglar and Schiller, Locating Migration, p. 80

11. Gregorio C. Borlaza and Caroline G. Hernandez, "Philippines: Pre-Spanish History”, Encyclopaedia Britannica (Encyclopaedia Britannica, inc, 2016), March 20, 2017, https://www.britannica.com/place/Philippines/PreSpanish-history.

12. Ibid

13. Alburo. Box Populu: Study Of Balikbayan Box, p. 27.

14. Alburo. Box Populu: Study Of Balikbayan Box, p. 45. Notes: The United States reasons for granting Independence to the Philippines were financially motivated; as a means to evade obligations to assist in repairing extensive damages from World War II.

15. Ibid, p. 37.

16. Cohen and Sirkeci, Cultures of Migration, p. 20.

17. Alburo. Box Populu: Study Of Balikbayan Box, p. 32.

18. Ibid, p. 64

19. Ibid, p. 65

20. Ibid, p. 66

21. Ibid.

22. Alburo. Box Populu: Study Of Balikbayan Box, p. 82.

23. Agnew, Diaspora, Memory and Identity, p. 3.

24. Ibid, p. 15 
...where?

the "Other" the thalticultural city
spaces of struggle
a landscape

of postmodernity

marked by difference

conceptualization

rationalization

and management

of culture

"living together"

a cultural container

for [ ]-ness

history of struggle

a landscape

negotiated

claimed

imprinted

an atmosphere

of relationships

sacred spaces

the history

$\&$ poetics

occupied. 


\section{here.}

Living As A Spectacle

ACT II [ here. ]

\begin{abstract}
"Difference defined as that which is outside, in opposition to the congealed norms of any society, is constituted by/against hegemonic identity. Identity and difference than are an intertwined and always historically specific system of dialectical relations, fundamental to which is inclusion (belonging), and its opposite exclusion (not belonging)."
\end{abstract}

\section{- Leonie Sandercock}

In the opening line of Diaspora Blues the narrator introduced the place of "here", as their present location, a delineation from the location of "home" in the second line. However, in the context of both "here" and "home", their existence within either location is addressed as being too "foreign". In comparing their journey from "home" to "here" as a ritualized practice, transmigrants embark upon a "rites de passage" marked by three phases: separation, margin, reaggregation ${ }^{2}$. From a Balikbayan's point of arrival within the host society (here), they then transition from the margin state to the reaggregation state, in which afterwards the passage is then consummated. The reaggregation state, and the extent to which the completion of the ritualized practice is achieved, is however prescribed in direct correlation to the perception of difference in the host society. 


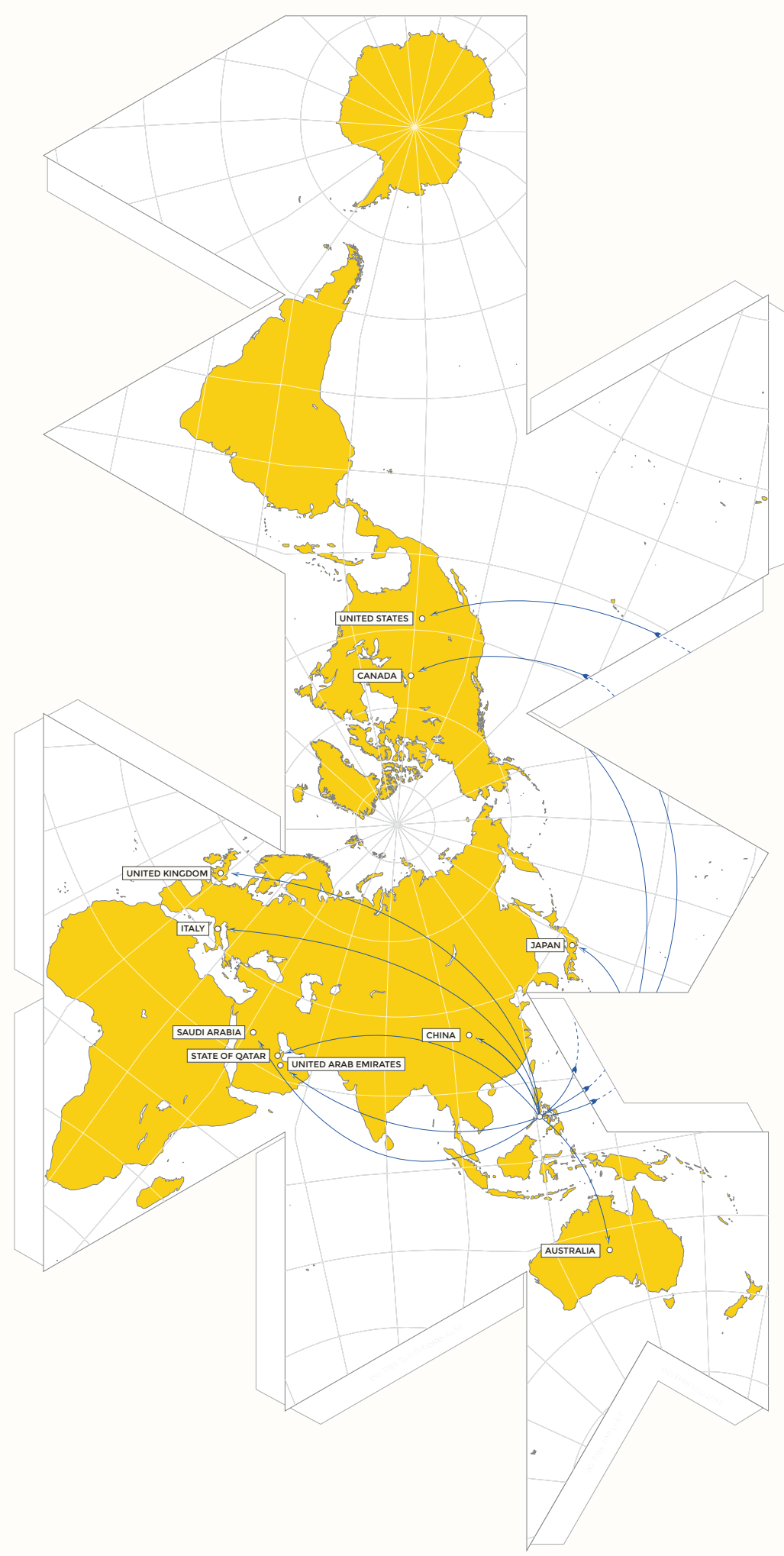


The condition of being "too foreign for here", as described in the third line of Diaspora Blues, is a comparison of ethno-cultural differences to an understanding of "Self" defined by the dominant society, the result of which is a reductive characterization of transmigrants as "The Other" in their localities of host societies. This construction of "The Other" has challenged the integration of Balikbayans into their host societies as it has created an environment of fear, conducive to the exacerbation of ethnocultural difference and bias. Much of contemporary scholarship surrounding the process of migration has developed to address the presumed threat transmigrants bring to their host society ${ }^{4}$.

Due the demographic restructurings of "the rational city"s within the postmodern "age of migration", the multi-ethnic and multicultural neighbourhood has become a site of struggle, where the rights of transmigrants to exercise agency over the physical spaces in which they live, work and interact are challenged daily. Capitalist space ${ }^{7}$ a reflection of the politique of the state and centres of power that functioned to negate differences, is "pushed toward ... explosion" "by these spatial negotiations of transmigrants and is transformed "spaces of insurgent citizenship" - a landscape marked by difference.

In an effort to manage, rationalize and conceptualize ethnocultural difference spatially, it is commonly abstracted into a notion of "national cultural difference" 10 in host societies. This term speaks of processes of categorization, based on the understanding that the nation state function as a fundamental cultural "container" is then reduced to "markings of difference"12, such as national costume, cuisine or decorative styles, presented as spectacle. These spatial contestations occur in parallel to the transmigrants personal journey of redefining the conditions of belonging within their host societies.

This commodified packaging of ethno-cultural difference is a 


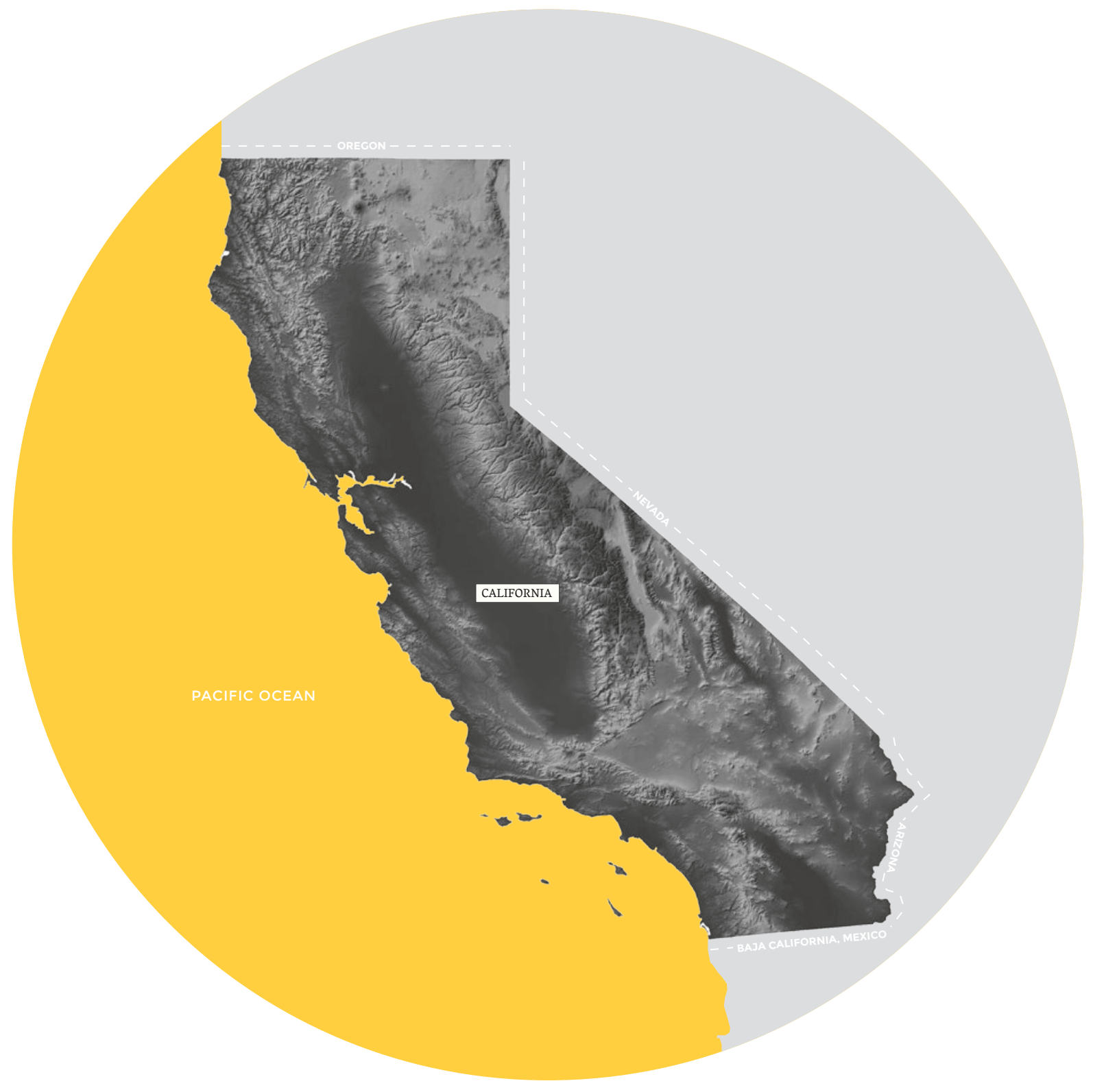


by-product of the civic ideology of "living together"13 encouraged by a top down policy declaration of multiculturalism. ${ }^{14}$ British theorist James Donald describe this version of cultural pluralism as an "ethical need for an openness to unassimilated otherness"1s. Although virtuous in its intentions, peaceful coexistence requires broad social participation, banal intercultural interaction and dialogue - the basis of which is pre-existing trust. This is difficult to achieve with a top down bureaucratic approach, common in many settler countries that claim an ideology of multiculturalism, and instead results in a society of cultural enclaves and "de facto" separatism ${ }^{16}$

As an exercise of agency, It is common for many transmigrant communities to mobilize the production of differentiation to their advantage through economic means. An example of this would be the urban archetype of the cultural corridor or street, which commonly indicates the commercial centre of an ethnic enclave, but also serves as a stage for the performance of cultural difference. In their role as designers and actors across this space, transmigrants participate in the commodification and marketing of their own "culture", which only perpetuates an attitude of selfinterest and indifferent, which assumes that nothing is be gained from intercultural discourse.

The civic ideology of "living together" is framed by commercial interests and a symbolic understanding of "Other"-ness, and rather than functioning as a social equalizer that empowers migrants alike, it tends to exacerbate inequalities of difference ${ }^{17}$. This is because the politics of "pure identity"18 and assimilation, which seeks to eliminate The Other, is the basis of this civic ideology.

For transmigrants to reaggregate into the their host societies and complete the rites de passage of migration, a vocabulary of spatial and social accommodation must be incorporated into 
public culture. As a foil to the modernist politics of pure identity, the politics of difference focuses on the paradigm of "intercultural co-existence", which is defined by actions of local recognition and inclusion. ${ }^{19}$ However, the active construction of living together in difference is a long term process, that cannot ignore any fears or anxieties surrounding the construct of "The Other".

Instead, the inherent inequalities and challenges of integrating migrants from different cultures must be addressed through the deconstruction of community as neither identity or place, but as a productive process of social interaction ${ }^{20}$. More so than a matter of bureaucratic management or of citizen legislation, it is the "lived, everyday, sociological expression"21 of urban citizenship and the willingness to work together across differences that is necessary. In these interactions and in the building of a cosmopolis ${ }^{22}$, the mediation of collective memories of identity and belonging are essential, and can be achieved through the inclusion of story, metaphor and ritual. 

modernist notions as providing order, coherence, regulation and homogeneity, was at the expense of experiential, intuitive, and local knowledges based on the capacity of narrative. In the post-war rush to construct the Rational City, practices of talking, listening, seeing, contemplating, sharing, as expressed by visual, symbolic, ritualistic and artistic means ${ }^{23}$ were ignored. Instead, modernist city-building professionals relied in the liberating potential of their technical knowledge to arrive at an objective assessment of "the public interest."24

However, the new cultural politics of difference undermines the modernist paradigm and brings upon the death of the Rational City. It is with the rise of spaces of insurgent citizenship, that the importance of place, the art of placemaking and the role of narrative return to prominence.

Within the process of the deconstructing of "The Other", stories can provide a far richer understanding of the human condition, and concurrently the urban condition, than traditional social science. This is because it allows the unrepresentable space, life and language of the politics of difference to be made imaginable. Narrative then is conducive to the productive process of social 
interaction, as it serves as an aid to critical thinking and a means of mediating collective memory and identity.

How cities are then narrated are then constitutive of urban reality; stories are not merely told but are actively created within the daily lives of the cities inhabitants. Culture then is the creation and expression of stories that bind communities. Transmigrants, rather than being mere victims who are acted upon by the dominant society, also appear and construct these narratives as actors within and across space. ${ }^{25}$ However, the cultural narrative of an urban landscape is one of continual negotiation and it is the stories of the dominant society that are often times represented spatially, revealing structures of inequality inherent in the building of the Rational City.

The culture of the politics of difference is then the creation and expression of stories centered on the power inequalities that define diasporic identities, consciousness, and solidarity. Although these narratives of difference may not have always found a place in history, it does not mean their stories are necessarily erased. The localities of the host society - the socio spatial dimension of human experience - do contain the transmigrant narratives of both the "home" and the "here". However, they are relegated to 
appropriate or occupy interstitial ground. Behind the edifice of buildings and embedded within the urban landscapes are traces of collective social memories of difference - a transnational cultural urban landscape.

It is these accumulative memories that create a diasporic community's "core story" ${ }^{26}$, which lend meaning to collective life and connect the history of struggle over urban space with the "poetics of occupying particular places" ${ }^{27}$. An understanding of the local context of migration, and the way that transmigrants organize themselves within their host societies and new translocal ${ }^{28}$ spaces is as significant as knowledge of their traditions and customs. ${ }^{29}$ For the Filipino diasporic community in San Francisco, the core story is one defined by displacement, disenfranchisement, and perseverance, stemming from the near century long colonial legacy that defines the relationship between the United States and the Philippines. As the only former colony of the United States, the Philippines' disadvantaged position is indoctrinated in the nation's psyche. The vision of America as a golden land of opportunity was imposed by the colonial curriculum ${ }^{30}$, which instilled a binational loyalty to both home and the country of their colonizers.

This unequal dynamic can be traced throughout the three major waves of immigration from the Philippines to San Francisco, a city significant within the narrative as it served as the key gateway passage into and throughout the greater United States..$^{31}$ Their core story then is inherently transnational. Therefore, the urban reality of that narrative - and in consequence the productive processes of social interaction it would constitute - would be transnational as well. 


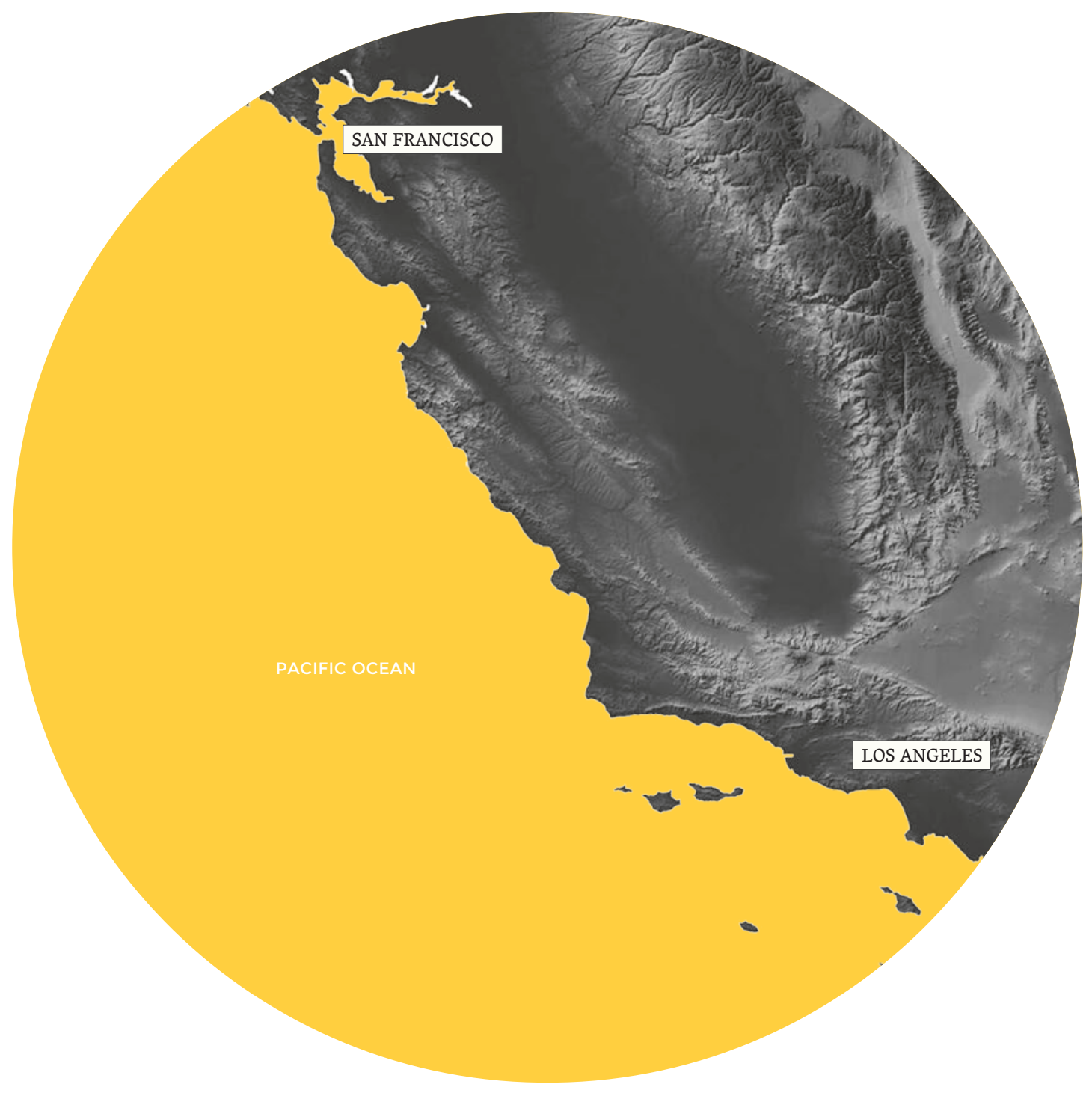


Anti-Asian laws that discriminated against the entry of other "Orientals" did not apply to those arriving from the Philippines due the country's status as a "territorial protectorate" ${ }^{2}$ of the United States. Early Filipino migrants included members of the mestizo (mixed-race) aristocracy, single men brought to fill agricultural labour shortages, Navy veterans and governmentsponsored scholars, known as pensionados (or pensionadas) ${ }^{33}$. The earthquake of 1906 resulted in the displacement of many Filipinos residing in the downtown core. They found refuge in such towns as Daly City ${ }^{34}$ which would become a cultural stronghold for the transmigrant community. By the 1910 s to the early 1920 s those that preferred employment near the urban centre situated themselves in such areas as Kearney Street (or Manilatown) adjacent to Chinatown and in the South of Market area. Early immigrants were however blocked from becoming naturalized citizens and instead were categorized as "nationals" 35 - an indeterminate status that subjected them to racial discrimination and exclusion. As a result, Filipinos were prohibited to rent or purchase home in exclusively caucasian neighbourhoods. Anti-Filipino sentiment only continued to increase into the Depression when they were then barred from entry into the United States by the TydingsMcDuffie Act in $1934^{36}$. 


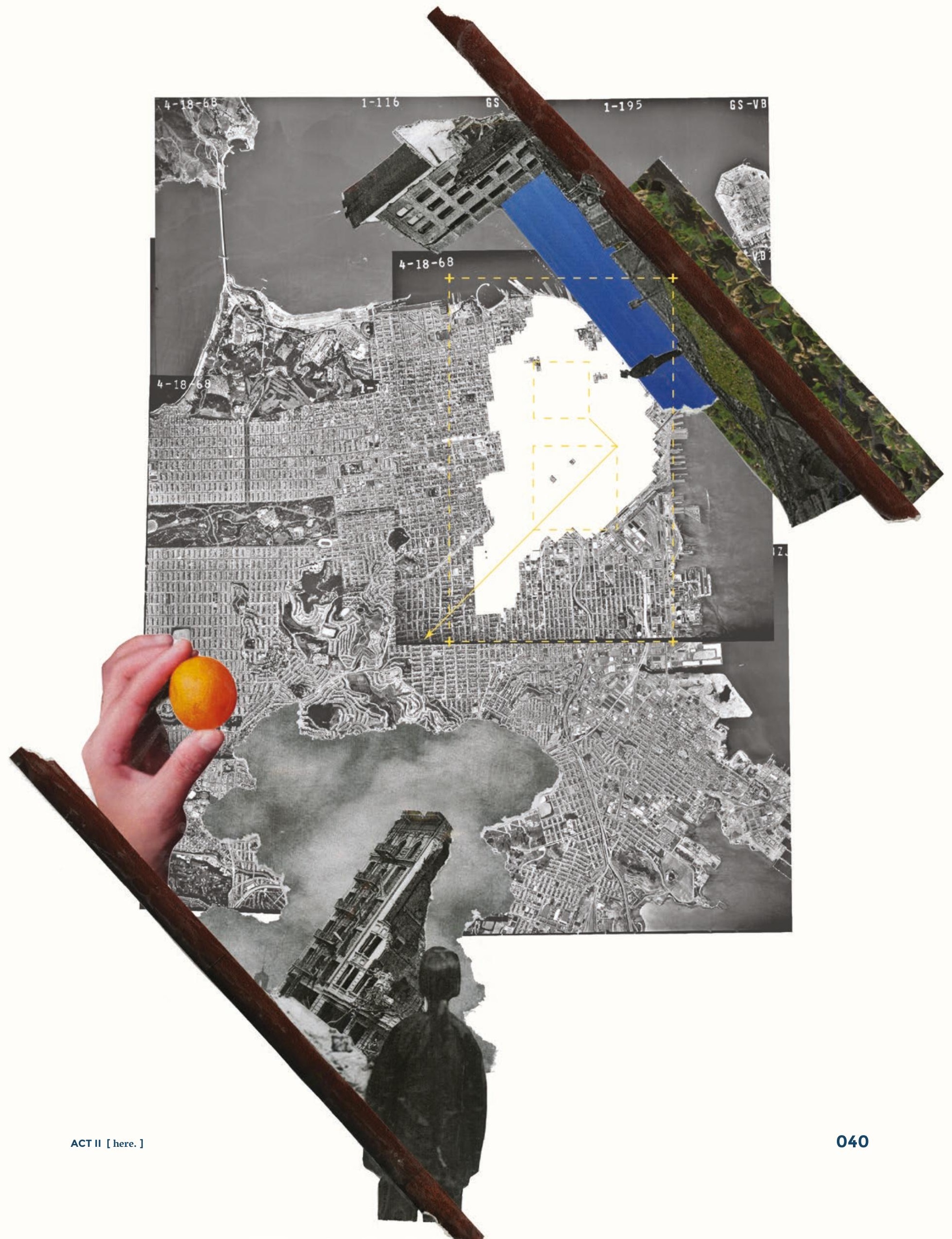




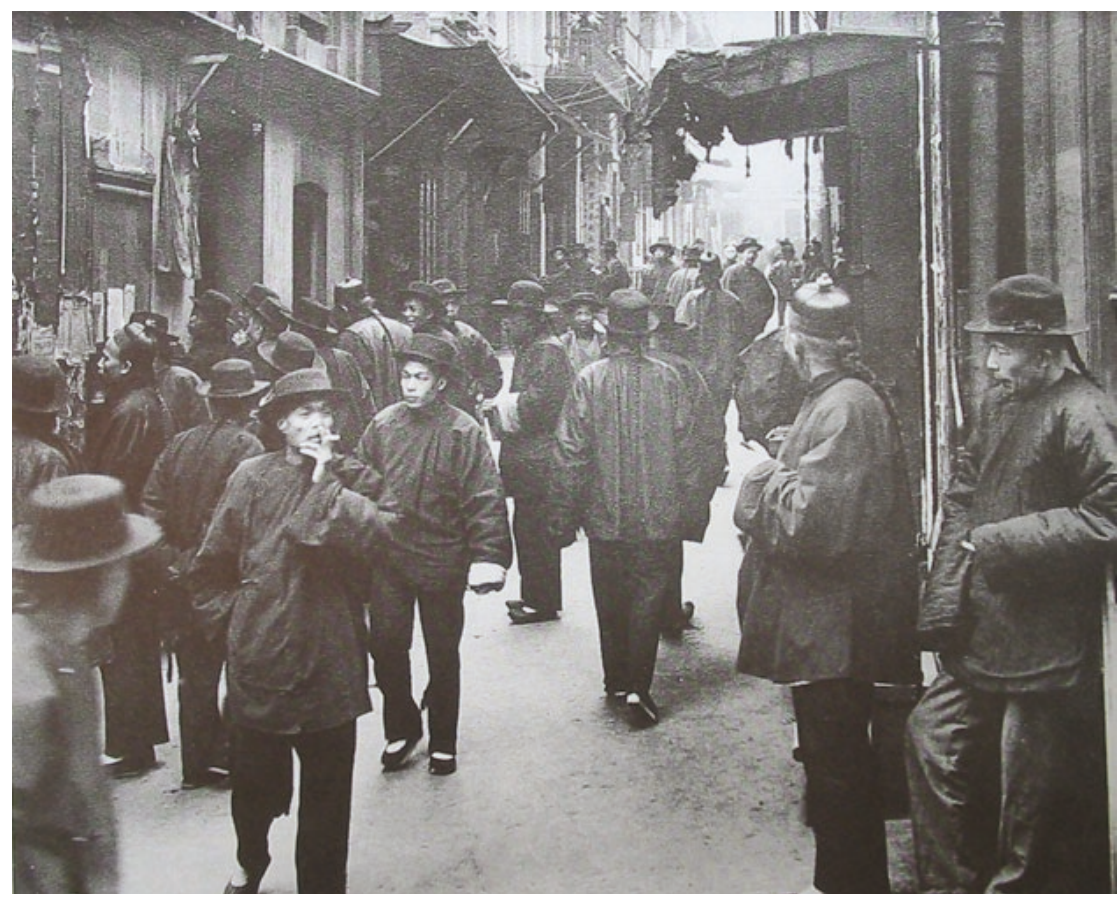

San Francisco's Ross Alley, Chinatown (1898)

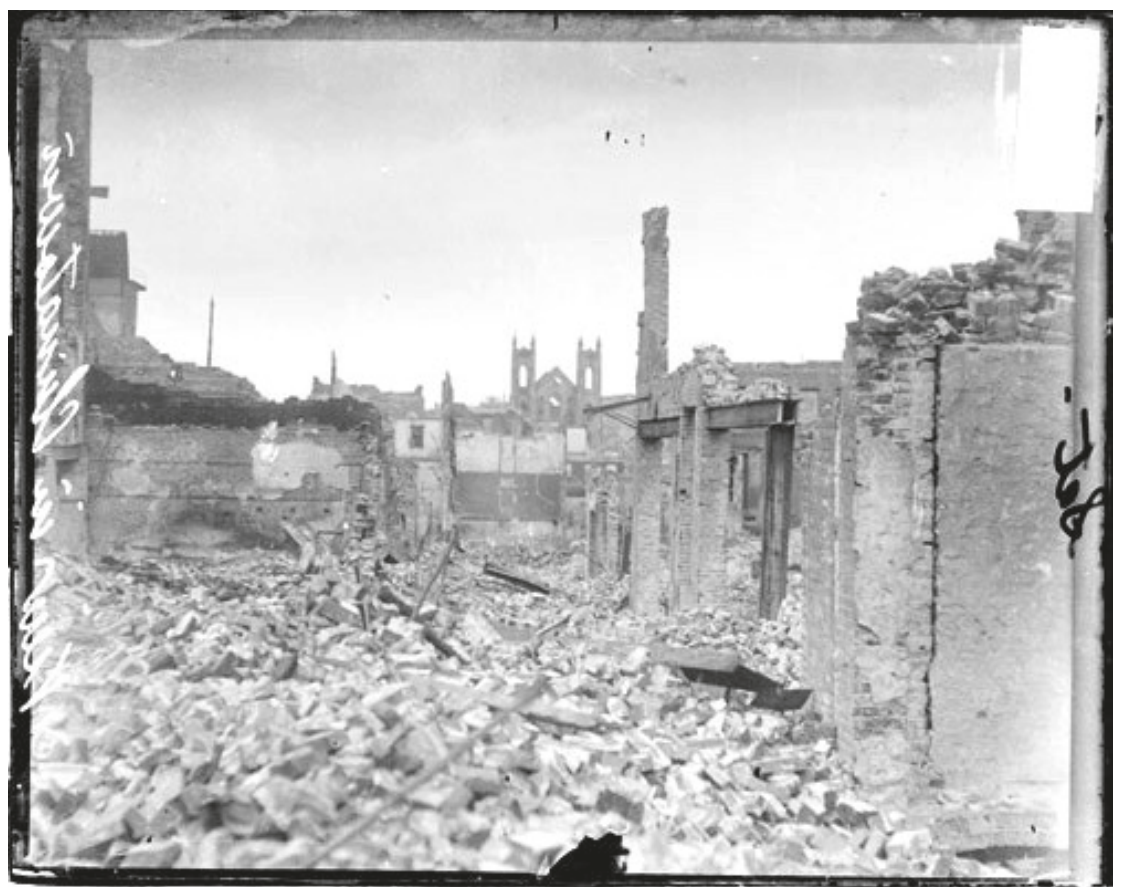

After the Earthquake, Chinatown (1906) 


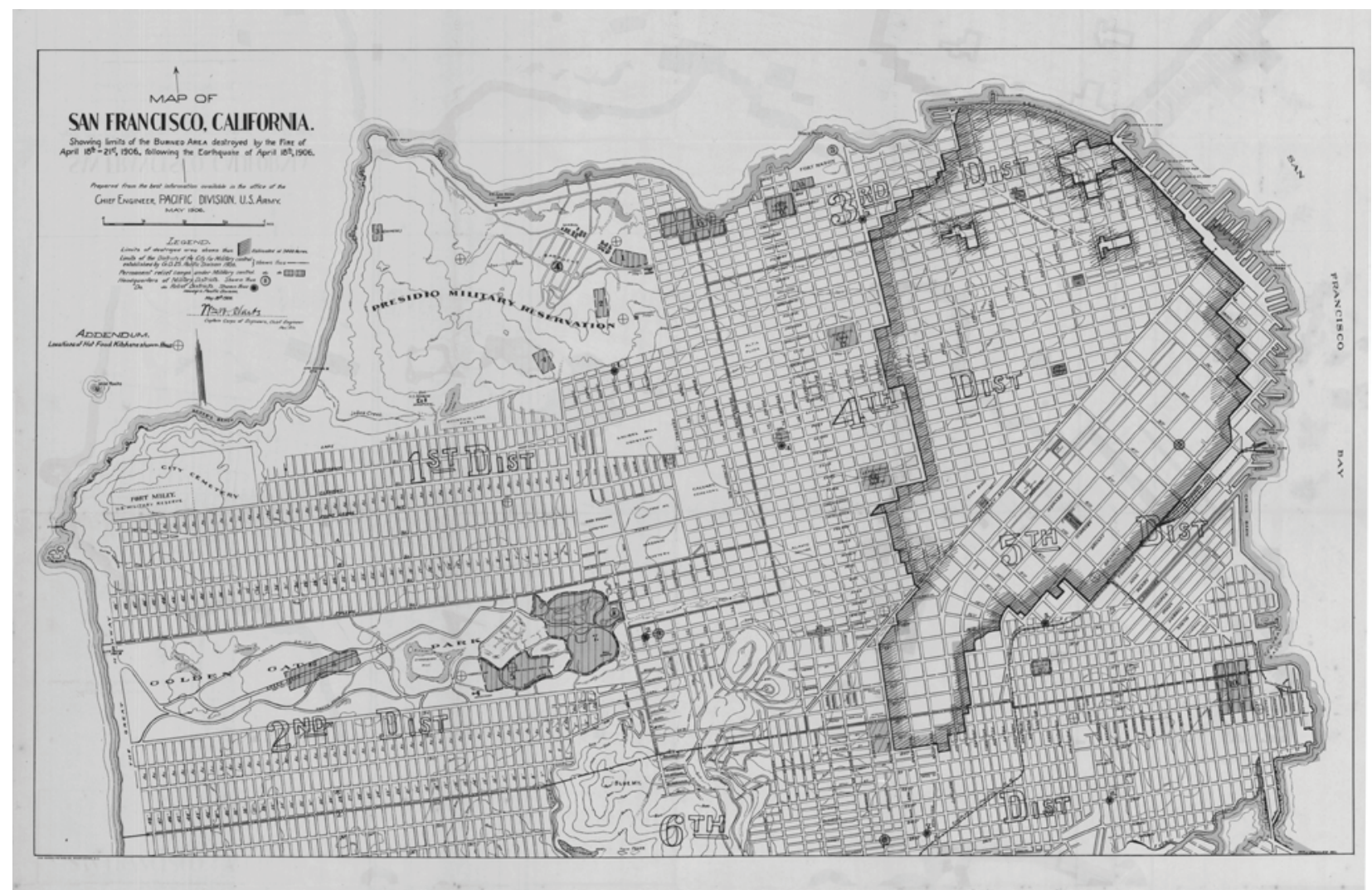

Limits of the Burned Area destroyed by the Fire. (1906, Lithograph) 
Triptych [ 1945+ ]

ACT II [ here. ]
Despite the obstacles faced in the transition to their hostland, Filipinos were still able to establish a unique Filipino American culture and community in San Francisco. As highly talented musicians, writers, artists and journalists, first-generation immigrants found their place among other Latino and black immigrants in such neighbourhoods as the Fillmore, the Mission, and on Kearny Street. They also excelled in such sports as basketball, baseball, softball, and volleyball, despite limited access to public facilities because of racist prohibitions. Upon the beginning of World War II in 1942, Filipinos were made eligible to draft and volunteer for service in all branches in the United States military - which granted them the opportunity to also become citizens. By the end of the war, Filipinos were now viewed as loyal allies which contributed to a positive shift in public sentiment. Parallel to an increase in immigration quotas, the War Brides Acts $(1945)^{37}$ was also passed, which allowed veterans to bring their wives and children to the United States. The postwar period saw the Filipino community make great strides in socio-economic mobility and a rise of insurgent citizenship. The GI Bill gave veterans access to higher education, well-paying civil service jobs and low-interest home loans - the outcome of which was the intercity migration from SOMA and Kearney Street into such areas as the Richmond and Sunset district to the west (despite white-only racial covenants), and the Mission, Bernal heights, Outer Mission, Crocker Amazon and Visitacion Valley neighbourhoods to the south. 


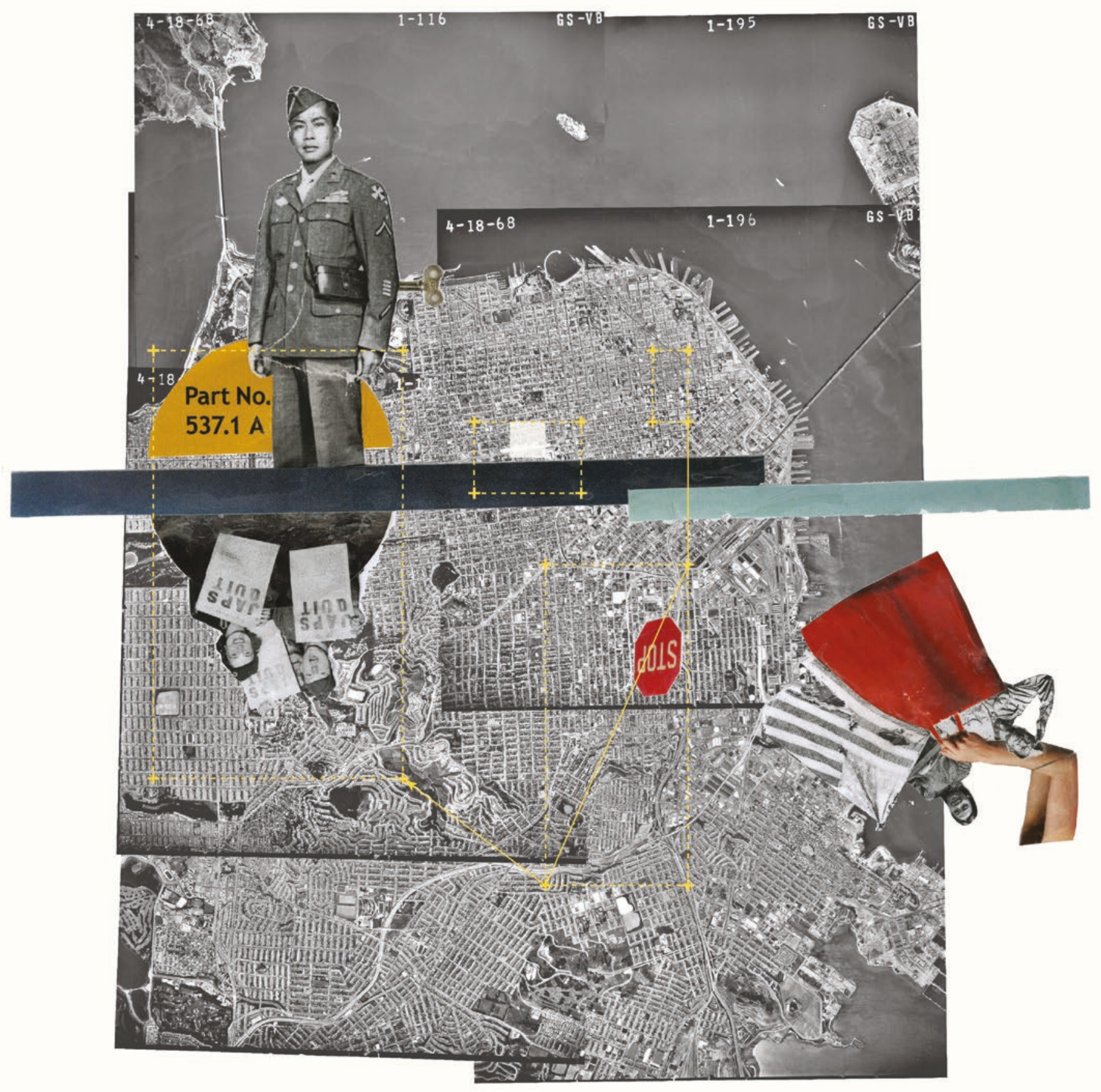



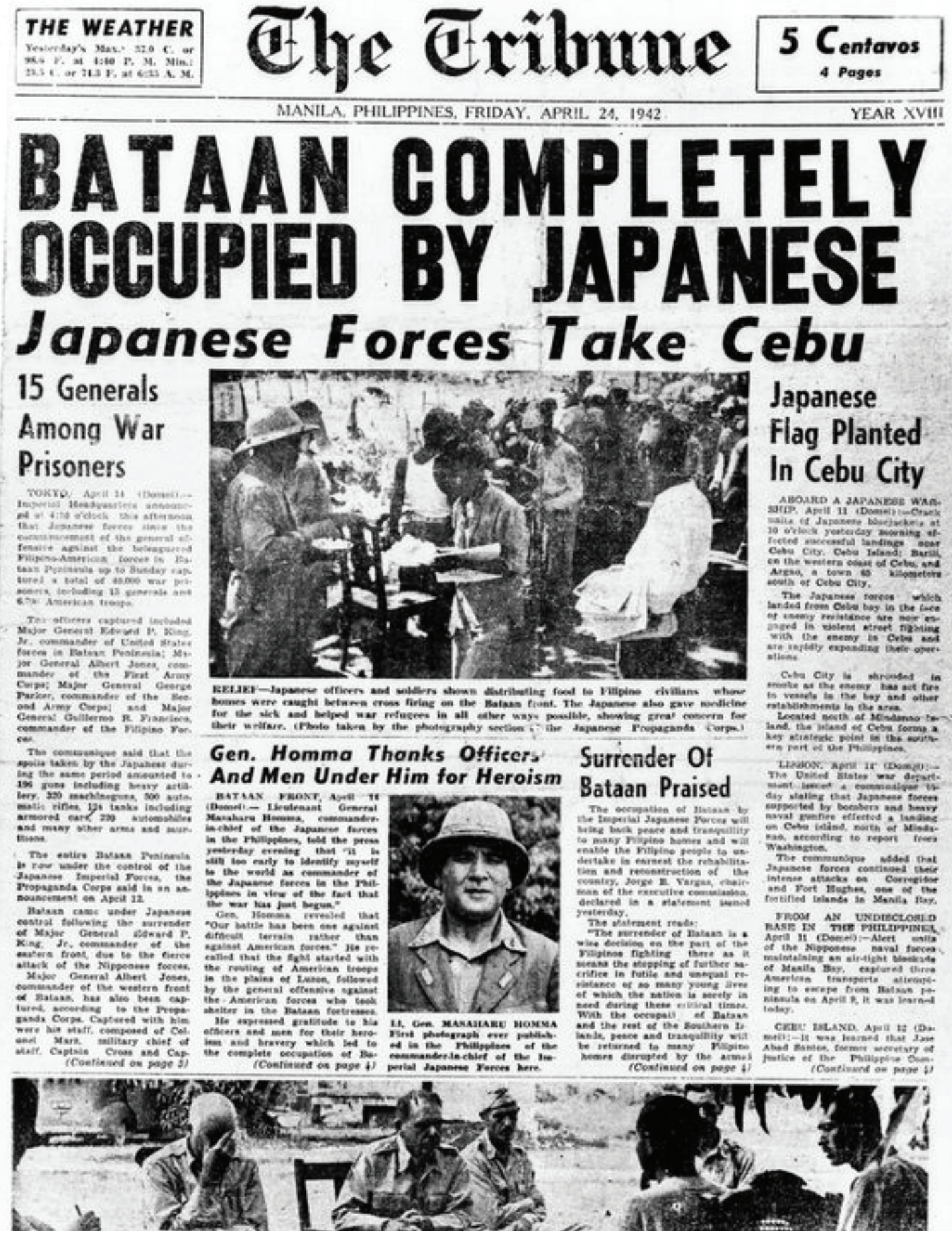

Cover of The Tribune - September 24th (1942) 


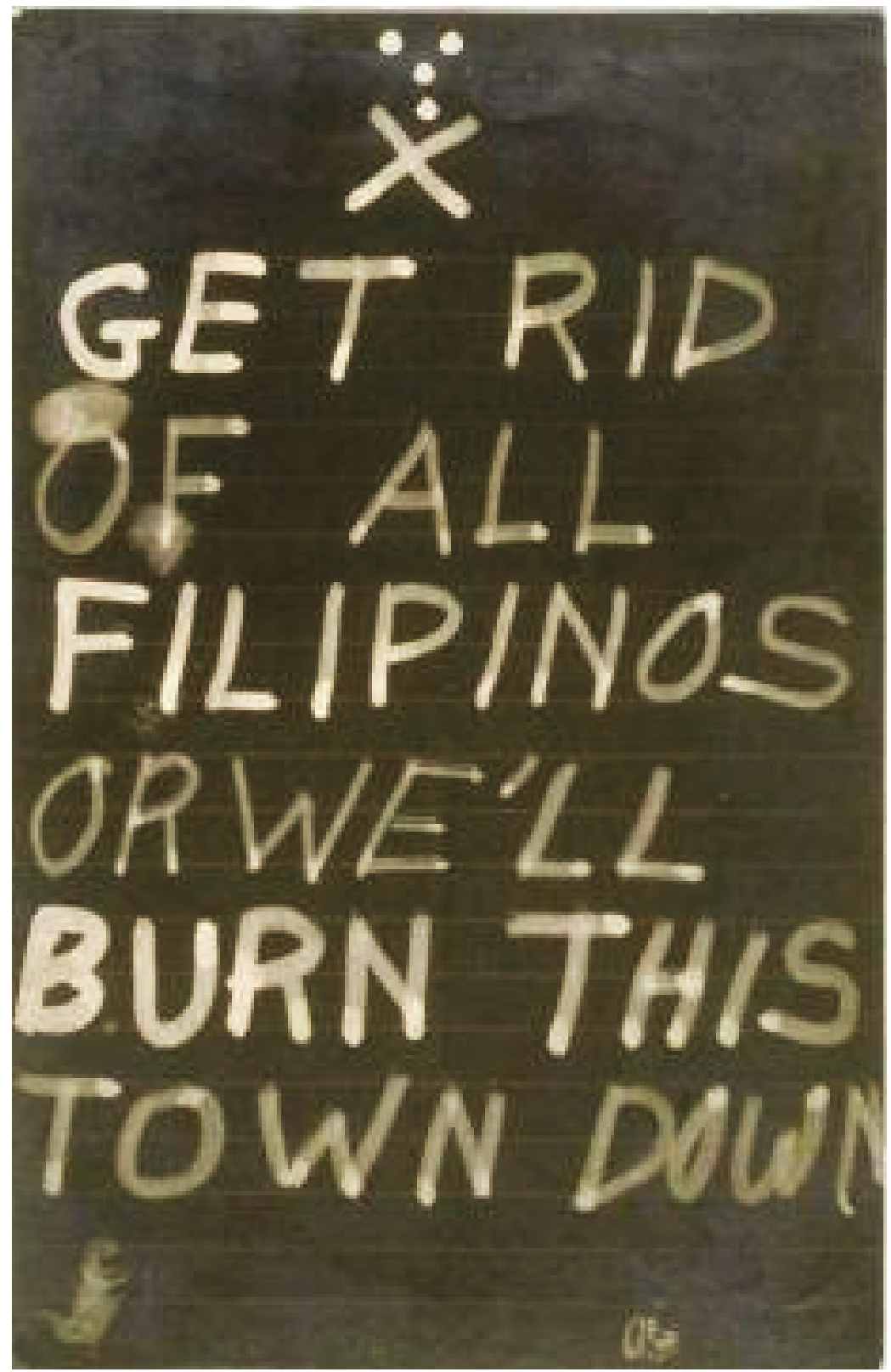

Sign posted on front door of hotel in Stockton,

California (1930) 

wave of Filipino immigration to the United States, which welcomed the arrival of university-educated technicians and professionals. Welcomed by an expanding economy, new Filipino immigrants were provided a higher level of socio-economic mobility than prior generations, driven by democratizing effects of the GI Bill and the Civil Rights Act ${ }^{3}$. The "Cold War" era saw increased political participation from Filipino immigrants as they established political clubs and became leaders in their local communities. While engaging in various cultural movements such as the Beat, jazz and rock-n-roll scenes, Filipino American youth were also involving themselves in the goals and methods of the Civil Rights movement, which caused a divide amongst the community's more conservative members ${ }^{39}$. The Vietnam war only deepened the estrangement. In 1968 the legacy of Manilatown was threatened to be erased from history as the last institution of the neighbourhood, the International Hotel came under duress by the purveyors of Urban Renewal. Despite resistance from the elderly tenants and the larger San Francisco Community, the tenants and their supporters were violently evicted on August 4, 197740. The "I-Hotel Struggle" became a defining moment in both Filipino American and San Francisco culture. 


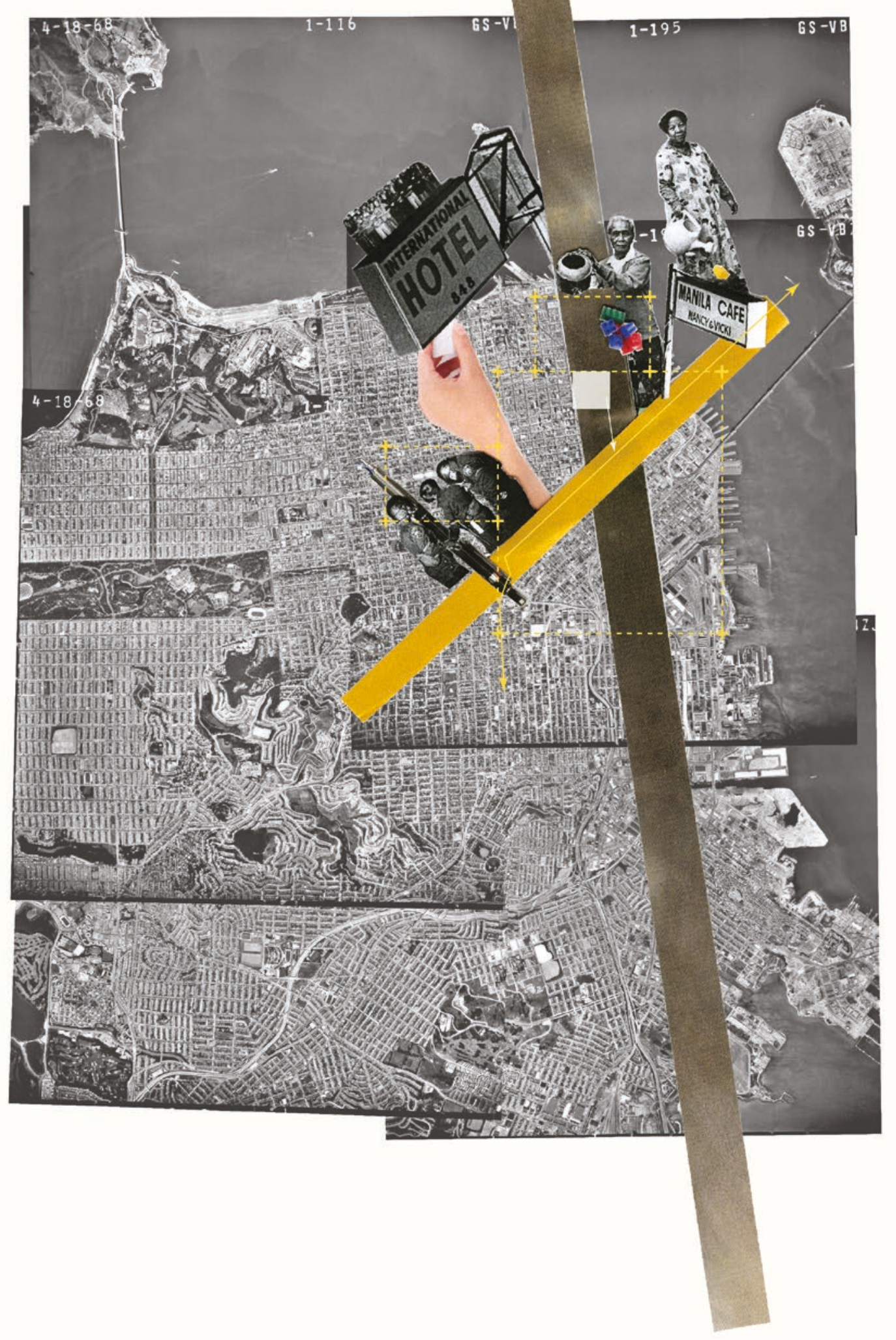




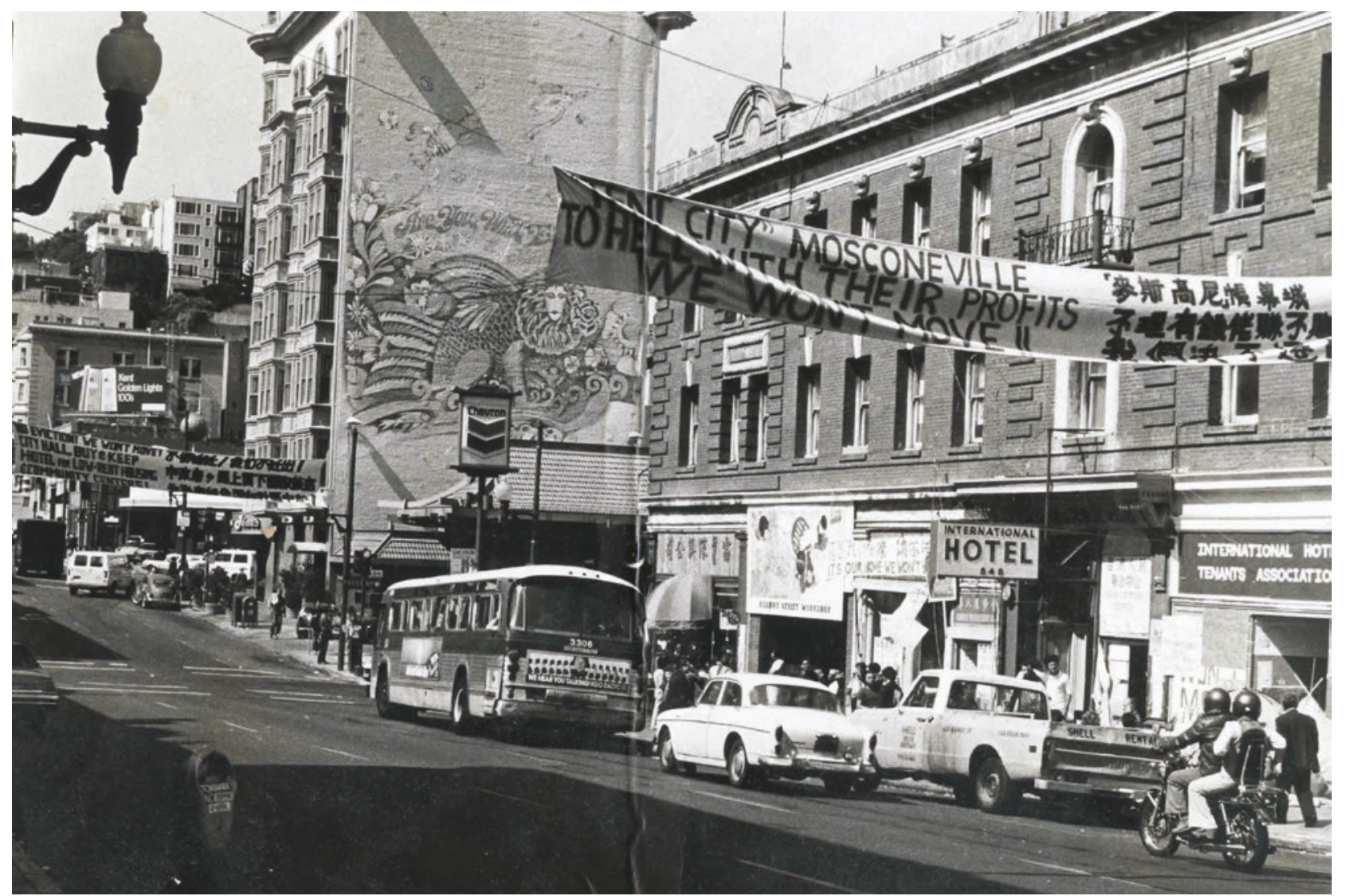

Photograph of I-Hotel with banner that reads "To hell with your profits! We won't move!" (1977) 


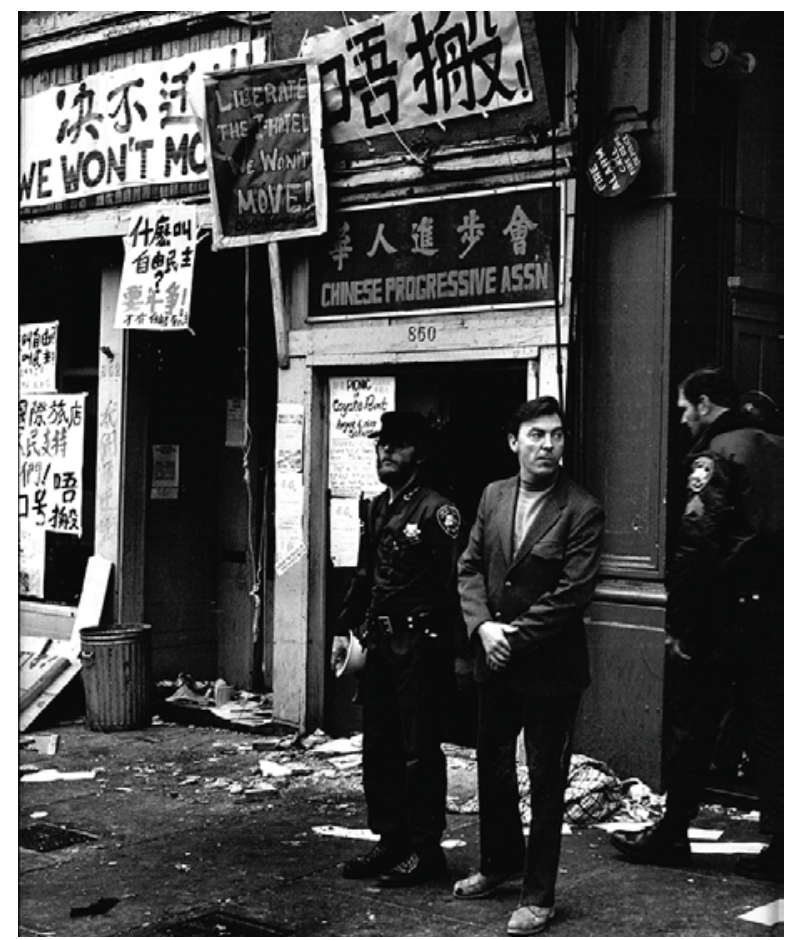

Sheriff Richard Hongisto stands outside the evicted I-Hotel (1977)

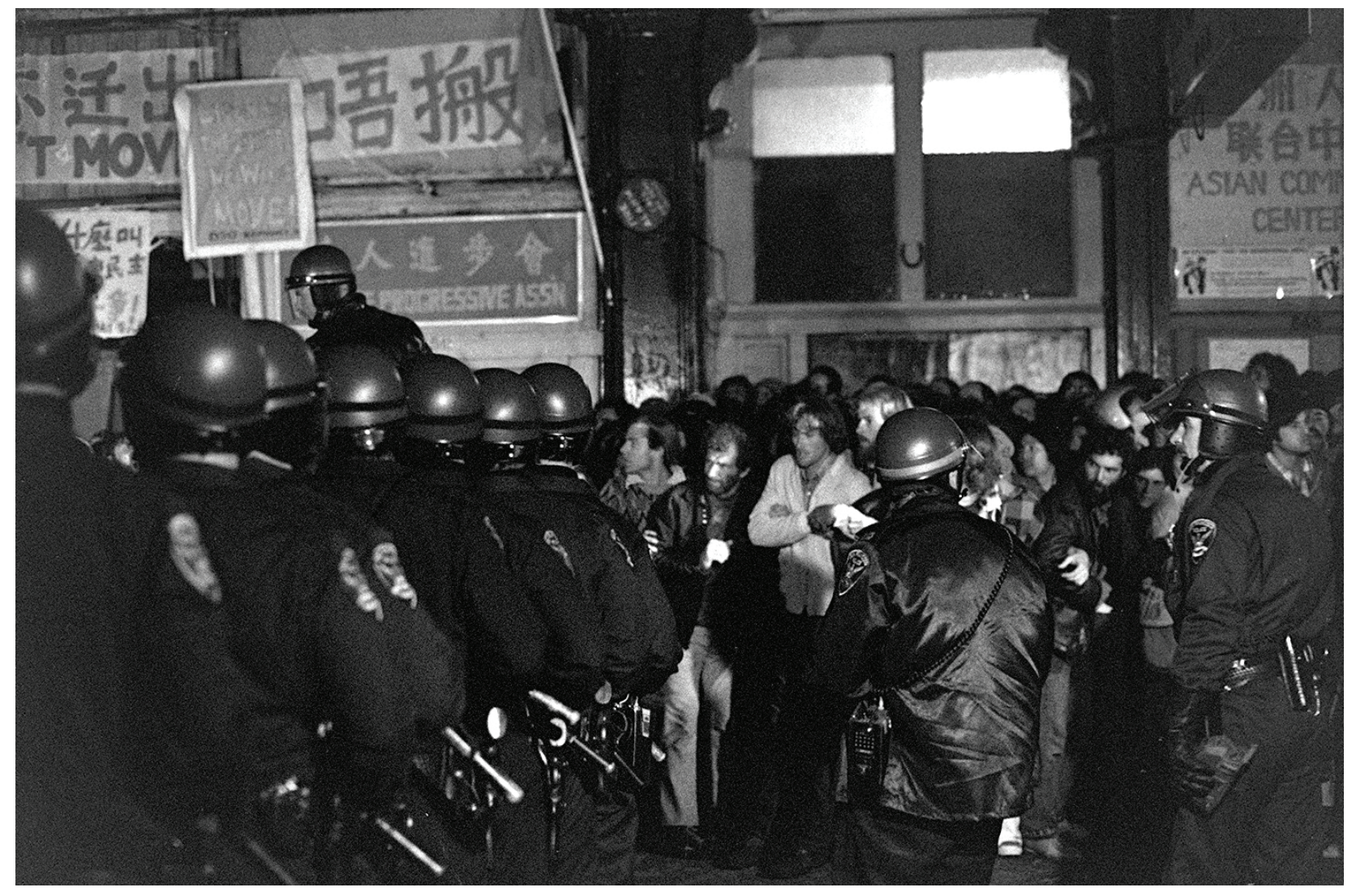

Sheriff Deputies and Police confront demonstrators (1977) 
By engaging with a deeper understanding of the entire urban cultural landscape, agency is returned to the communities whose histories were made invisible. Through the process of spatially reciting a transmigrants community's core story, the "sacred spaces"41 within the urban cultural landscape are then able to be discerned. Refined through processes of reinvented ritual, sacred spaces are formed between the static state of nostalgia and the transformative action of remembering. ${ }^{42}$ What is revealed through a network of sacred spaces are the connections between place and collective identity - a fundamental component of "The Other's" experience of the city. ${ }^{43}$

The clarity gained through the process of nurturing a transmigrant community's public memory can incite moments of grief and empowerment, which then consequently prompts the experience of healing. A new narrative arc - one not based on spectacle, commodification or "Other-ing" - within a transmigrant community's core story cannot be stimulated without this explicit moment of lamentation. However, for this course of renewal and redemption to move forward, not only must there be collective will to do so but it must involve an ongoing process of atonement, negotiation, ritual, acknowledgement and trust. 44

Presently, the Filipino diasporic community in San Francisco is currently facing a pivotal point in their history. Earlier in April of 2016 the San Francisco Board of Supervisors unanimously passed legislation zoning 9 blocks of the South of Market neighborhood as a Filipino-American cultural district. Through the layers of cultural memory and meaning, it is made evident that a large portion of the Filipino diasporic community's narrative is centered on the SoMA neighbourhood. Now they have been given opportunity to actively participate in the building of their core story. 


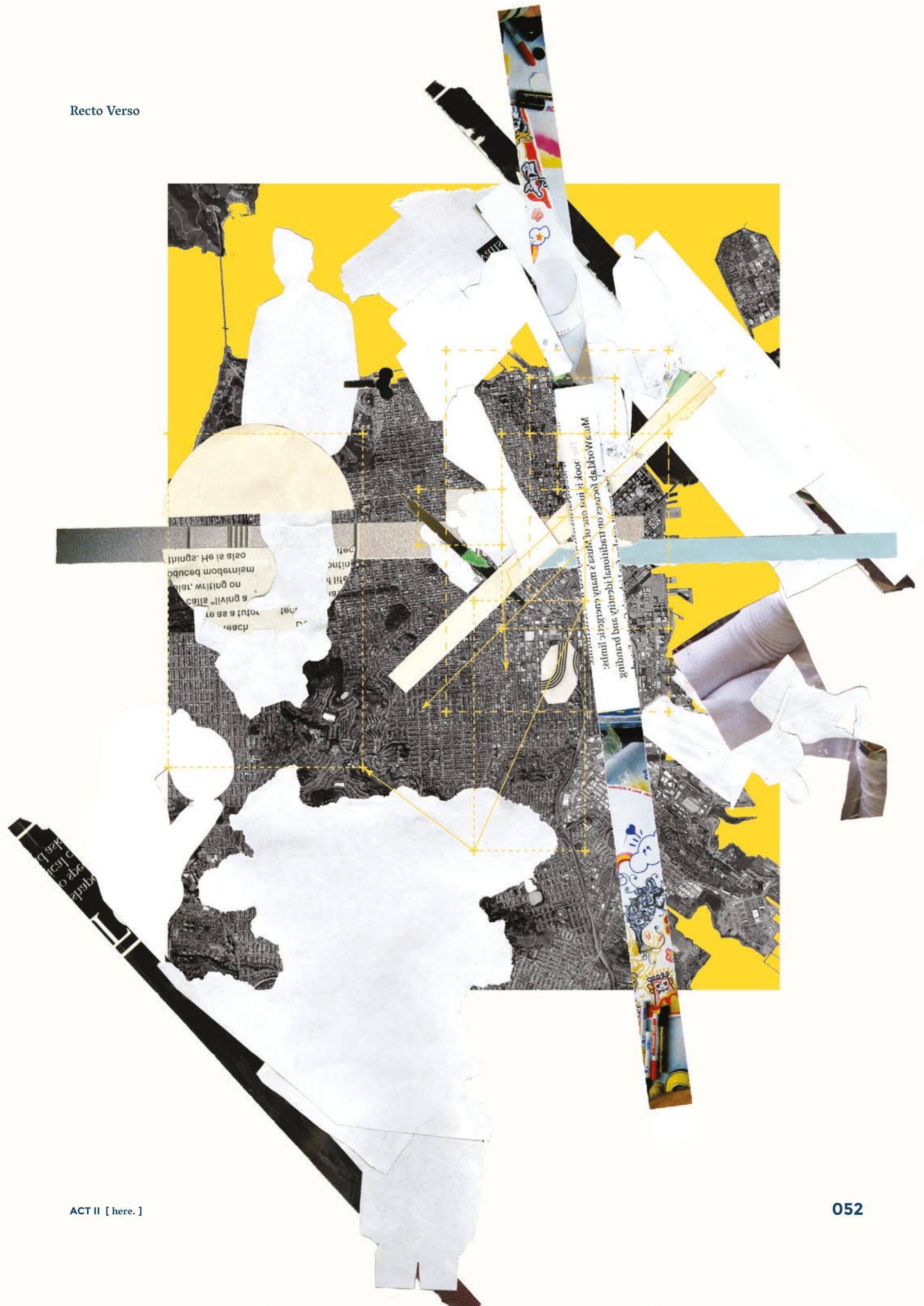


"...the role played by migrants and their local and transnational practices of incorporation in the rescaling and restructuring of cities', calls for an understanding of historical processes underlying (and constraining) the making and re-making of localities and regions."

- Nina Glick Schiller and Ayse Caglar ${ }^{45}$

Located in the Northeast corner of the San Francisco peninsula, the South of Market ${ }^{46}$ neighbourhood is part the sixth supervisorial district of the city proper, which is also commonly called South of Market. However, the district also contains the neighbourhoods of Mission Bay, Financial District, South Park and the Tenderloin. In contrast to the rest of the peninsula SoMA is characterized for its low lying topography and low scale built environment ${ }^{47}$. Bordered North by Market Street and the BART subway line, the Caltrain railyard and King Street to the South, Highway 101 to the West and the San Francisco Bay to the East (U.S. Route 101), it is placed at a fair distance from clusters of tall buildings and hills.

The built morphology of the neighbourhood speaks of a history that reflects the transformative influences that have shaped the 


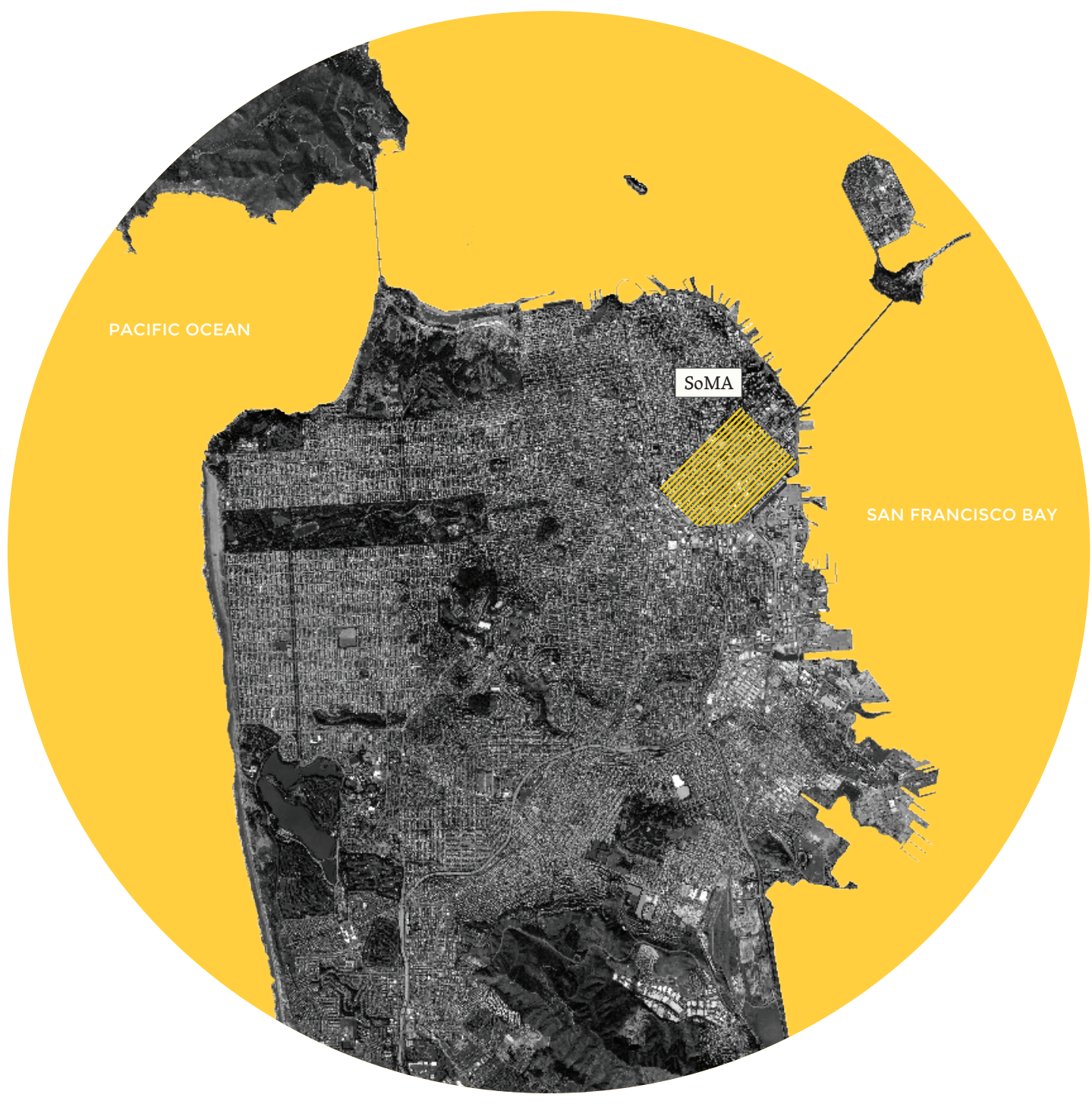

ACT II [ here. ] 
rest of San Francisco. Initially a burgeoning pioneer community, SoMA was primarily dedicated to heavy industrial development by the 2oth century due to its proximity to the San Francisco Bay ${ }^{48}$. Although the earthquake of 1906 completely destroyed the area, SoMA was again rebuilt to house the city's industrial manufacturing. Simultaneously, the neighbourhood became "home" for many low-income Filipino immigrants, in light of SoMA's loose zoning requirements and lower than average rental costs. In addition, SoMA welcomed a sizeable population of working-class individuals, transients, the incipient gay community and a community of artists and craftspersons, who thrived in the flexible nature of the environment.

The 1980's marked a shift in the area's history due to ambitious redevelopment plans targeting central SoMA. Yet, it the influx of young tech-minded entrepreneurs - attracted by the low-rent and the proximity to downtown - who inhabited the empty warehouse spaces that incited substantial change in the area. Developers, seeing the opportunities within the area's flexible zoning, empty warehouses and lots, soon followed and began building high-rise apartment and office buildings ${ }^{49}$.

While the Bay Area and SoMA quickly established themselves 


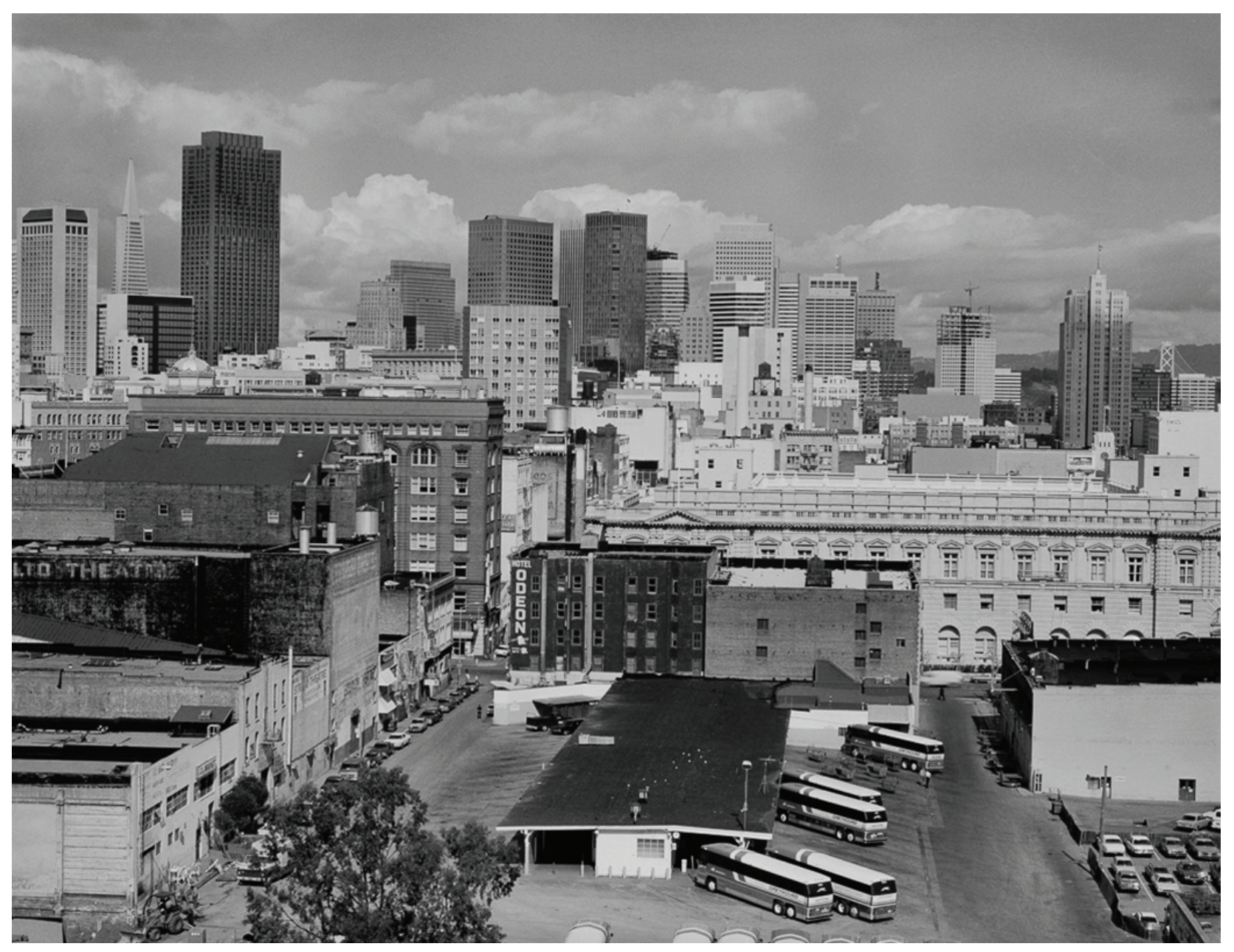

Greyhound Bus Depot - a photographic narrative of SoMA by Janet Delaney (1982) 


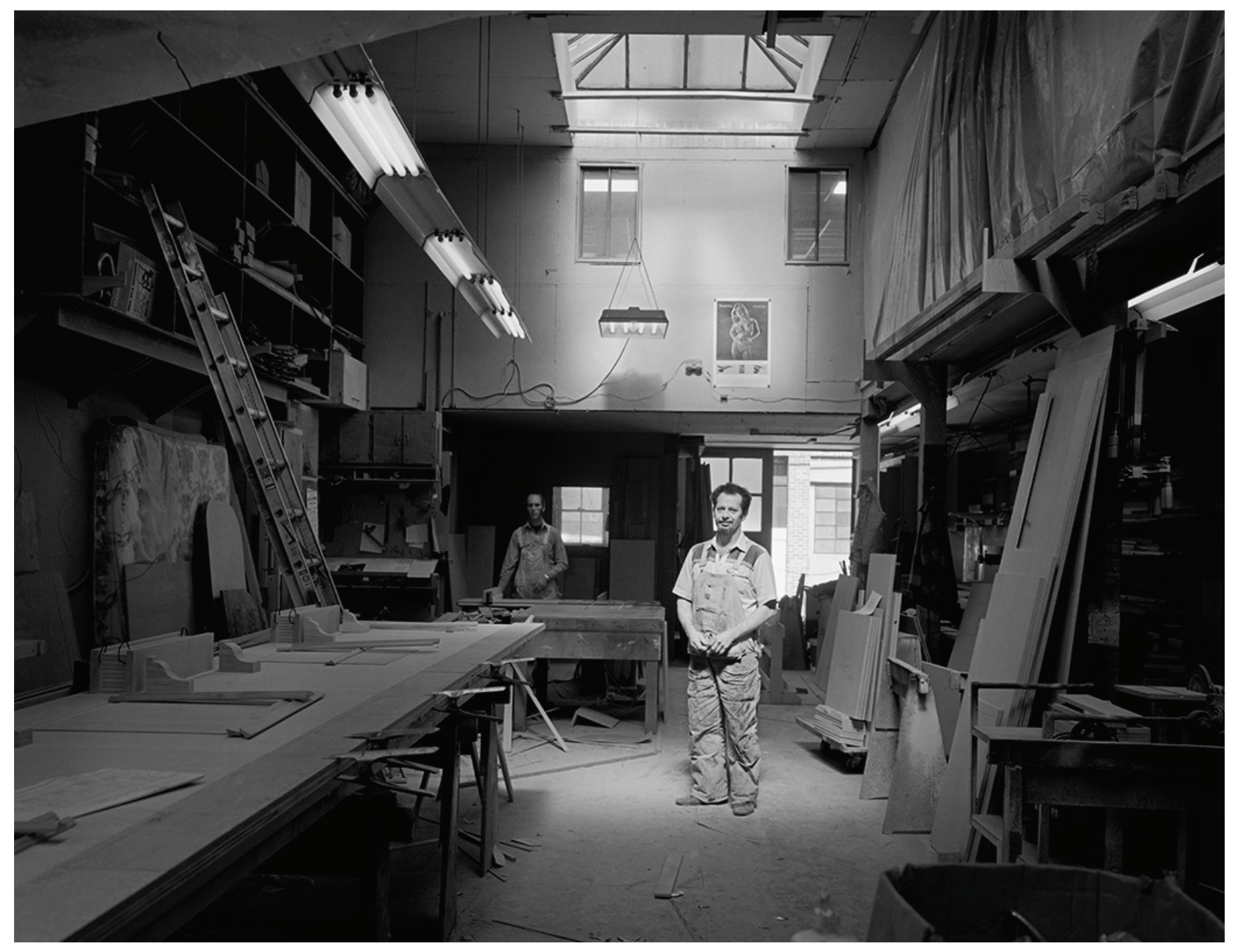

People's Construction - a photographic narrative of SoMA by Janet Delaney (1980) 


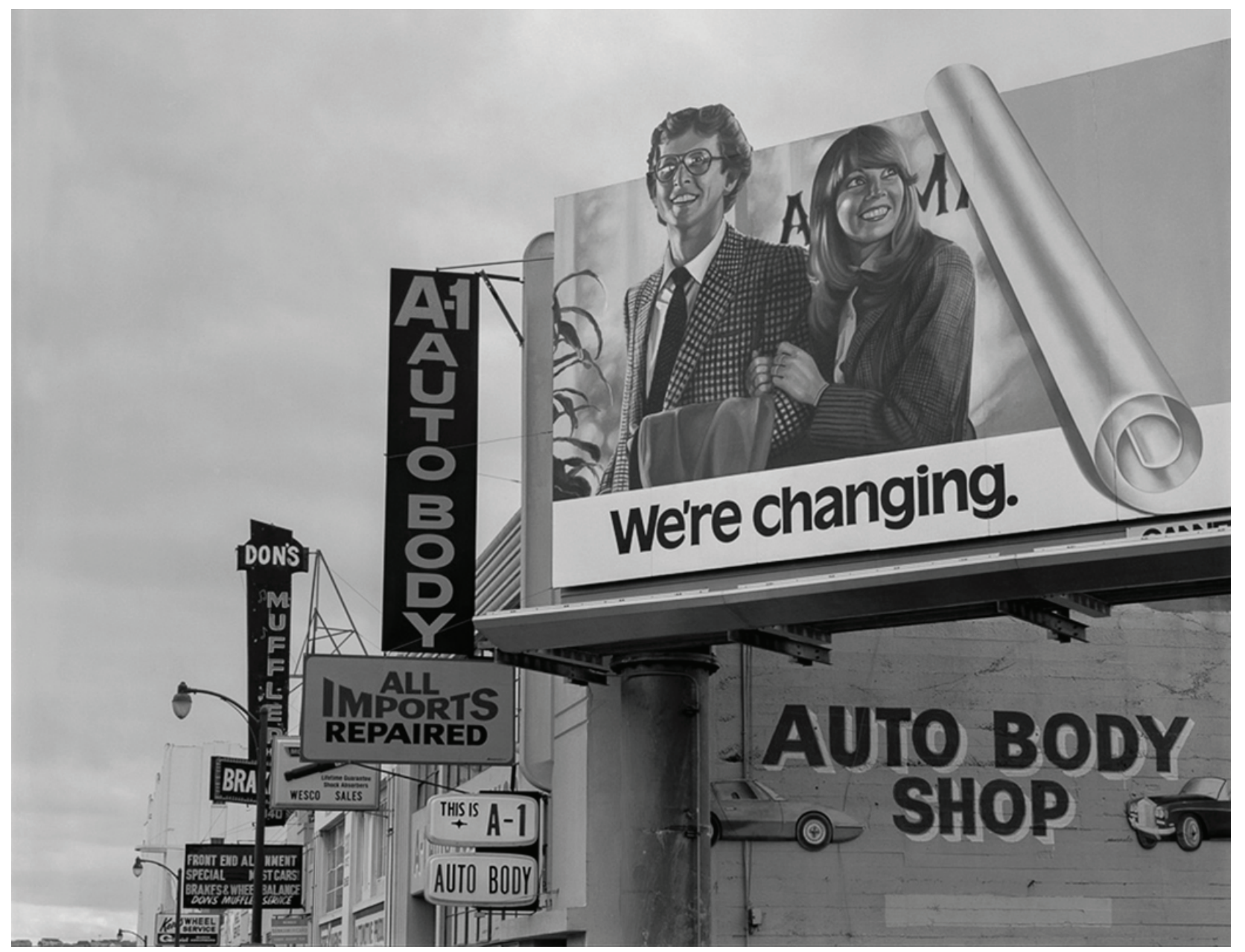

"We're Changing!" 10th at Folsom - a photographic narrative of SoMA by Janet Delaney (1982) 
as the hub of the tech industry during the mid 1990's dot com boom ${ }^{\circ}$, many of the area's original populace were driven out of the neighbourhood due to increasingly expensive property prices and decreasing availability in space. Prior to the dot com boom of the 1990's, Filipinos accounted for more than 30 percent ${ }^{t 1}$ of the population in SoMA. However, for those who had established a measure of prosperity and more or less settled into a comfortable stasis, continued demolition of SoMA did not ignite a movement like the threat of Urban Renewal did on Kearny Street during the 1970's. Instead, many Filipinos, took advantage of the wild Bay Area housing market, sold their downtown properties and moved to larger residences in Daly City, the East Bay and further down the peninsula..$^{22}$

Regardless of these factors, the next two decades saw immense growth in the sixth supervisorial district's population - doubling from 11,560 to 20,488 in the ten years between the dot com boom and the early 2000's.3 By 2010, the U.S. census recorded 40,451 residents living in the area. ${ }^{54}$ However, the majority of the population can still be described as characteristically transient as 71 percent of the SoMA's residents are renters and unmarried, suggesting that there is less interest in the long-term development of the area.s 
Despite the surrounding upheaval and the exodus of a significant percent of the Filipino population elsewhere in the Bay Area, SoMA still remains a cultural foothold of Filipino American culture. Even after experiencing a substantial decrease since the early 1990's, 5,100 individuals that identify as Filipino still reside in the sixth supervisorial district, according to the 2010 U.S. census. ${ }^{56}$ At $13 \%$ of the overall population, Filipinos still comprise the majority of the neighbourhood's Asian community, which represent 33\% 37 of SoMA’s population.

Within SoMA's existence as a mixed-use and heterogeneous neighbourhood defined by its tentative identity, the Filipino population has remained a resilient presence. Balikbayans have been significant contributors to the neighbourhood's evolution through their coherent and cohesive social capital, civic engagement and position as scale-makers by their reconstruction ofglobal processes that are substantiated locally. ${ }^{5}$ However, despite their impassioned history of civic involvement, the endurance of community landmarks and the recent success of contemporary Filipino-run businesses in the area, the presence of the Filipino community in the public realm has remained largely minimal. 59

This is due in large part to the neighbourhood's severe deficiency 
in both private and public open space resources, with only four public parks in the neighbourhood - Yerba Buena Gardens being the only one periodically associated with the Filipino community. In addition, the Filipino community is characteristically insular or "mahiya." ${ }^{\circ}$

In the mid 2000's, the Filipino community in SoMA organized a local coalition with the goal of receiving recognition for their role in the neighbourhood's history, making visible the contemporary Filipino community, safeguarding from the area's rapid development and guaranteeing the community is able to thrive into the future. ${ }^{61}$

After finding themselves dispassionate within the complacency of the 1990's, the Filipino community in SoMA once again returned to their legacy of activism. They organized around the vision of delineating the neighbourhood as SoMA Pilipinas - a "Cultural Heritage District". The nomenclature indicates it as an active community, rather than a fossilized one - which is what the use of the word "historic" would have suggested ${ }^{62}$. By using the plaza, the framework of the social nucleus of any Philippine town ${ }^{63}$, as a guide, SoMA Pilipinas is envisioned as a "center of gravity" for all Balikbayans. 
However, a challenge in the development of SoMA Pilipinas was its location at the intersection of three different planning ordinances: The Western SoMA Area Plan, the Eastern SoMA Area Plan and the Central SoMA Area Plan. Although the Central SoMA Area Plan comprised the majority of the SoMA Pilipinas and a proposal of an associated new Central Subway line did demarcate a proper gate into SoMA and served as a connection for the neighbourhood to the rest of San Francisco, it did not the absolve the complexity of the circumstances.

What further adds to the difficulty of the site is the controversy of the proposed $5 \mathrm{M}$ real estate development, it's approval of which has caused a division in the SoMA community. This only intensified when a group of SoMA activists sued the City and County of San Francisco to challenge their decision to approve it ${ }^{64}$. Those that disapproved predicted the construction of the development will come at the expense of the surrounding working-class community, who will be pushed out once the project is completed, forcing rental prices to rise as a result. In contrast, those that approved recognize dthat the development was planned with hyper-localized benefits in mind and understood the value it would bring to the immediate neighbourhood ${ }^{6 s}$, even if it not centered on the SoMA Pilipinas. 
SoMA Pilipinas Map \& Central SoMA Plan

Central SoMA Plan Boundaries

SoMA Pilipinas Borders \& Sacred Spaces (Compared to Central SoMA)

Proposed Central Subway Stations \& BART Subway Stations

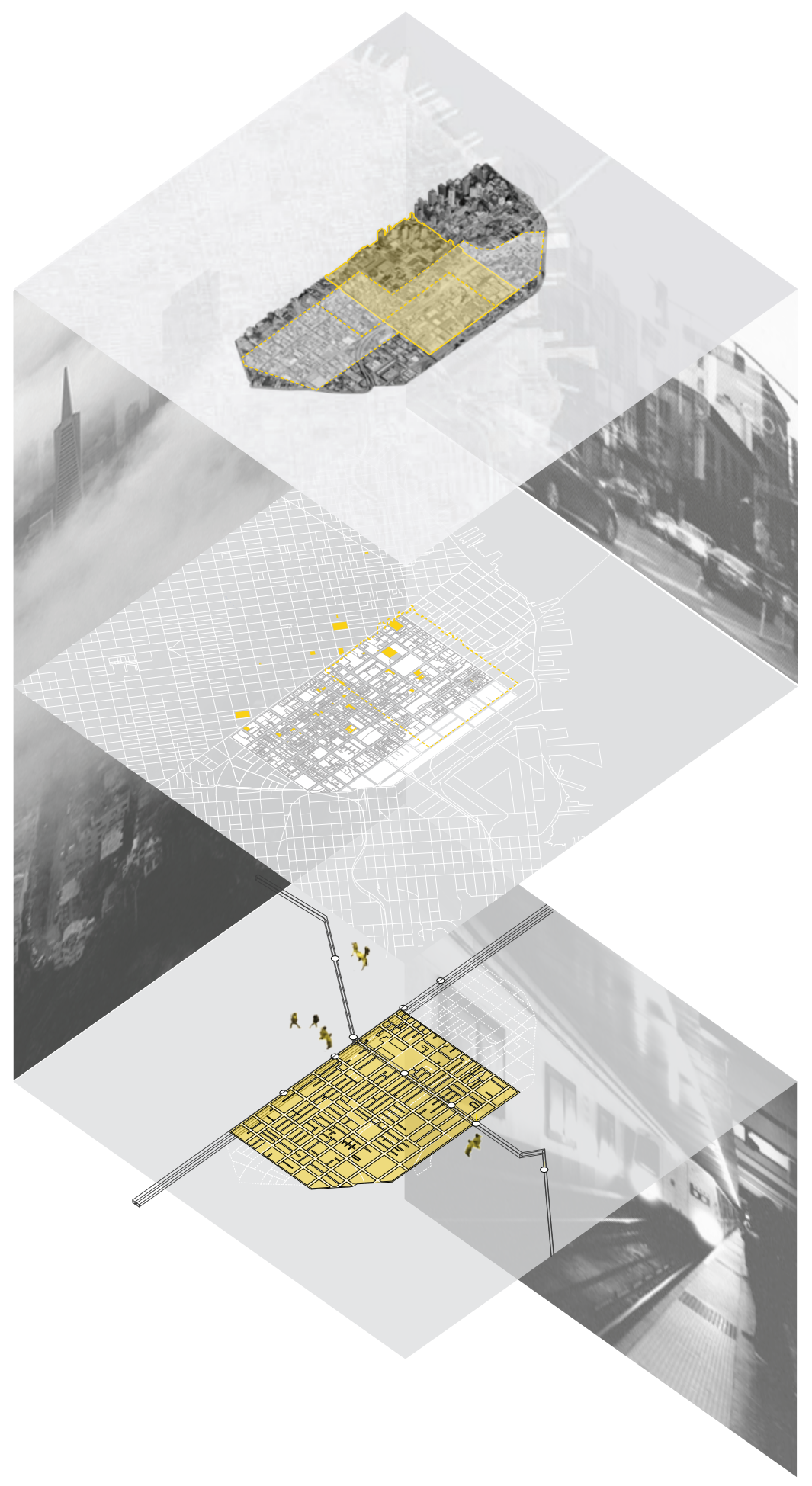




\section{Balikbayan Generations}

Generation 1.0

Filipino transmigrants that were born in the Philippines and emigrated from the country well into their adult lives. Most likely to retain cultural proxemics and beliefs from their homeland while living in the hostland. Strongly associate "home" with the Philippines.

Generation 1.5

Filipino transmigrants who have spent equal parts of their lives in both the homeland and hostland. Although they do retain cultural proxemics and beliefs from the Philippines, they are more adaptable to hostlands prescriptions than the 1.0. Have a flexible and more abstract notion of "home".

Generation 2.0

Although culturally Filipino, they have little or no physical relationship to the country itself. Most likely born in the hostland or immigrated at a very young age. Most associations with Filipino culture obtained from Gen 1.0 or 1.5. Perceive the hostland as their primary "home".
The schism within the community was rooted in the dispute of mediating a collective Filipino American culture vision. In the process of making what was referred to as "forgotten and invisible" now "visible", deciphering a common conclusion was a challenge. This is because a transmigrants relationship to home was not rigid or homogeneous. ${ }^{66}$ Instead diasporic identities are fluid and heterogeneous and not confined to definite understanding as race, ethnicity, nationality and citizenship. ${ }^{67}$ In result, the role of transmigrants as actors within a city is constantly changing in parallel to their evolving forms of place-making. Between the three generations of Balikbayans (Generation 1.0, 1.5, 2.0) who identify as Filipino American, each negotiate the idea of "home" and "here" differently, as a collective and as individuals.

However, what these conflicts emphasized was that although the systematic oppression of difference was rooted in city governance, it could not simply be dismantled through an empowered citizenry. What must simultaneously occur is the development of new narratives and symbols in regards national and local identity and belonging. ${ }^{68}$ Within the context of this thesis, this will be absolved through the deconstruction of the Balikbayan box ritual - extracting these narratives and symbols through the negotiation of the diasporic or liminal condition. 

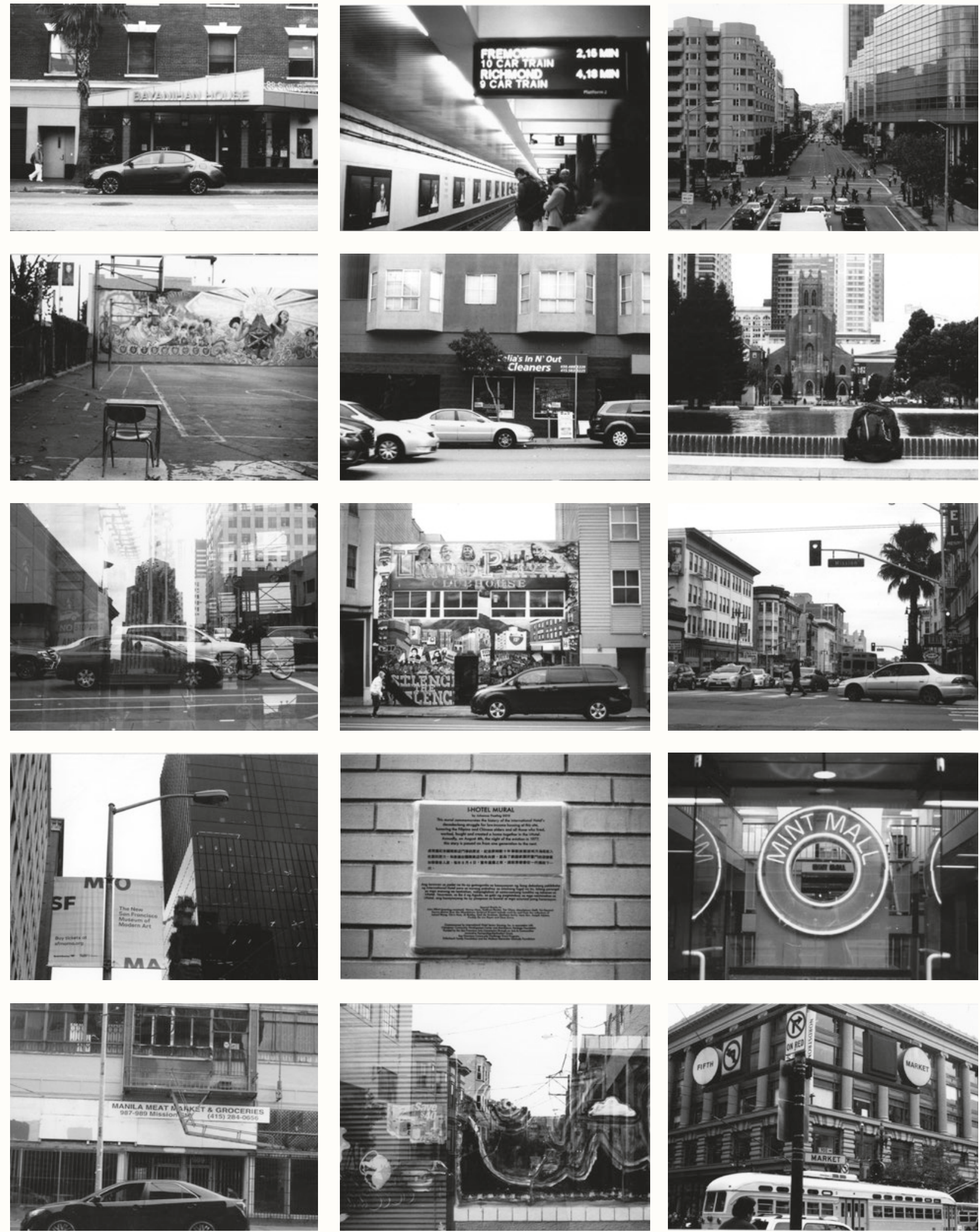
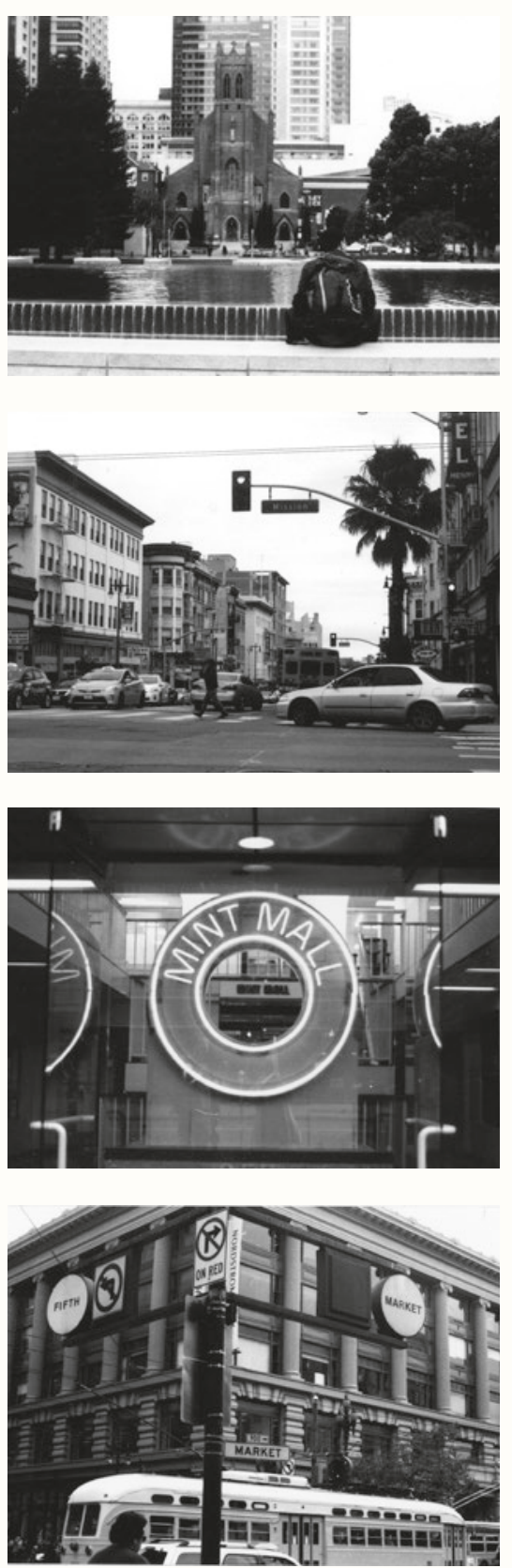


\section{Endnotes}

01. Leonie Sandercock, Cosmopolis II: Mongrel Cities in the 21st Century, (London: Continuum, 2003), p. 98.

02. Victor W. Turner, Ritual Process: Structure and Anti-Structure, (New Jersey: Aldine Transaction, 1969), p.95

03. Refer to Appendix A

04. Ayse Caglar and Nina Glick Schiller, Locating Migration: Rescaling Cities and Migrants. (London: Cornell University Press, 2011), p. 64

05. Refer to Appendix A

06. Leonie Sandercock, Cosmopolis II: Mongrel Cities in the 21st Century, (London: Continuum, 2003), p. 4 Refer to Appendix A

07. Refer to Appendix A

08. Henri Lefebvre, State, Space, World: Selected Essays, (Mankota: University of Minnesota Press, 2009), p. 189

09. Sandercock, Cosmopolis II: Mongrel Cities, p.2. Refer to Appendix A

10. Greek Colombijn and Aygen Erdentug, Urban Ethnic Encounters: The Spatial Consequences, (London: Routledge Publishing, 2002), p. 189. Refer to Appendix A

11. Ibid. Refer to Appendix A

12. Ibid.

13. Ibid, p.188

14. Refer to Appendix A

15. Sandercock, Cosmopolis II: Mongrel Cities, p.88

16. Ibid.

17. Philip Chang, Claire Dwyer and Peter Jackson, Transnational Spaces, (London: Routledge, 2004), p.149

18. Refer to Appendix A

19. Sandercock, Cosmopolis II: Mongrel Cities, p.98

20. Ibid

21. Ibid, p. 151

22. Refer to Appendix A

23. Sandercock, Cosmopolis II: Mongrel Cities, p. 76

24. Sandercock, Cosmopolis II: Mongrel Cities, p.3

25. Nina Glick Schiller and Ayse Caglar, Locating Migration: Rescaling Cities and Migrants (London: Cornell University Press, 2011), p.3

26. Refer to Appendix A

27. Sandercock, Cosmopolis II: Mongrel Cities, p.23

28. Refer to Appendix A

29. Caglar and Schiller, Locating Migration, p.171

30. Alice Jade A. Alburo. Box Populu: A Socio-Cultural Study Of The Filipino American Balikbayan Box, (St John's: Memorial University of Newfoundland, 2002), p.43

31. Filipino American National Historical Society, Images of America Series: Filipinos in San Francisco, (Mount Pleasant: Arcadia Publishing, 2011), p.7

32. Ibid

33. Ibid 
34. Benito Vergara, Pinoy Capital: The Filipino Nation in Daly City, (Philadelphia: Temple University Press), p.27.

35. Alburo. Box Populu: Study Of Balikbayan Box, p.53.

36. Filipino American National Historical Society, Filipinos in San Francisco, p.7

37. Ibid, p.9

38. Ibid, p. 11

39. Ibid

40. Reclaiming San Francisco, p.285

41. Sandercock, Cosmopolis II: Mongrel Cities, p.226. Refer to Appendix A

42. Vijay Agnew, Diaspora, Memory and Identity: A Search for Home, (Toronto: University of Toronto Press, 2005), p.9

43. Sandercock, Cosmopolis II: Mongrel Cities, p.222

44. Ibid, p.189. - four steps towards renewal of core story

45. Caglar and Schiller, Locating Migration, p.215.

46. Refer to Appendix A

47. Lucy K. Phillips, Revitalized Streets of San Francisco: A Study of Redevelopment and Gentrification in SoMA and the Mission, (Masters Thesis, Scripps College, 2012), p.48

48. Ibid.

49. Ibid.

50. Ibid.

51. Reclaiming San Francisco, p.285

52. Pinoy Capital, p. 12.

53. Katie Worth, "San Francisco Neighborhoods Have Changed Faces Over Two Decades" San Francisco Examiner (http://www.sfexaminer.com/local/development/2011/03/san-francisconeighborhoods-havechanged-faces-over-last-two-decades, 20 Mar. 2011) 20 Mar. 2017.

54. Ibid

55. "South Of Market (SOMA) Neighborhood in San Francisco, California (CA), 94103 Detailed Profile." City-Data.com, (n.d.) 20 Mar. 2017, http://www.city-data.com/neighborhood/South-Of-Market-San-FranciscoCA html.

56. San Francisco Planning Department, San Francisco Neighbourhoods Socioeconomic Profiles 2011, http:// sf-planning.org/sites/default/files/FileCenter/Documents/8501-SFProfilesByNeighborhoodForWeb.pdf.

57. Ibid

58. Caglar and Schiller, Locating Migration, p.3

59. Centre for Asian American Media, Filipino Americans Make a New Name for Their San Francisco Neighbourhood, 6 Oct. 2016, http://caamedia.org/blog/2016/10/05/filipino-americans-make-a-new-name-fortheir-san-francisco-neighborhood/

60. Refer to Appendix A

61. Ibid.

62. Ibid

63. Ibid

64. "SoMA Filipino Community Divded on Costs, Benefits of 5M Development", Hoodline San Francisco, http:// hoodline.com/2016/01/soma-filipino-community-divided-on-costs-benefits-of-5m-development, 10 Jan. 2016), 20 Mar. 20

65. Sandercock, Cosmopolis II: Mongrel Cities, p. 103

66. Agnew, Diaspora, Memory and Identity, p.193.

67. Ibid, p.15.

68. "SoMA, Tenderloin Activists Suing San Francisco over 5M Project Approvals", Hoodline San Francisco, (http://hoodline.com/2016/01/soma-tenderloin-activists-suing-san-francisco-over-5m-project-approvals, 7 Jan. 2016), 20 Mar. 20 


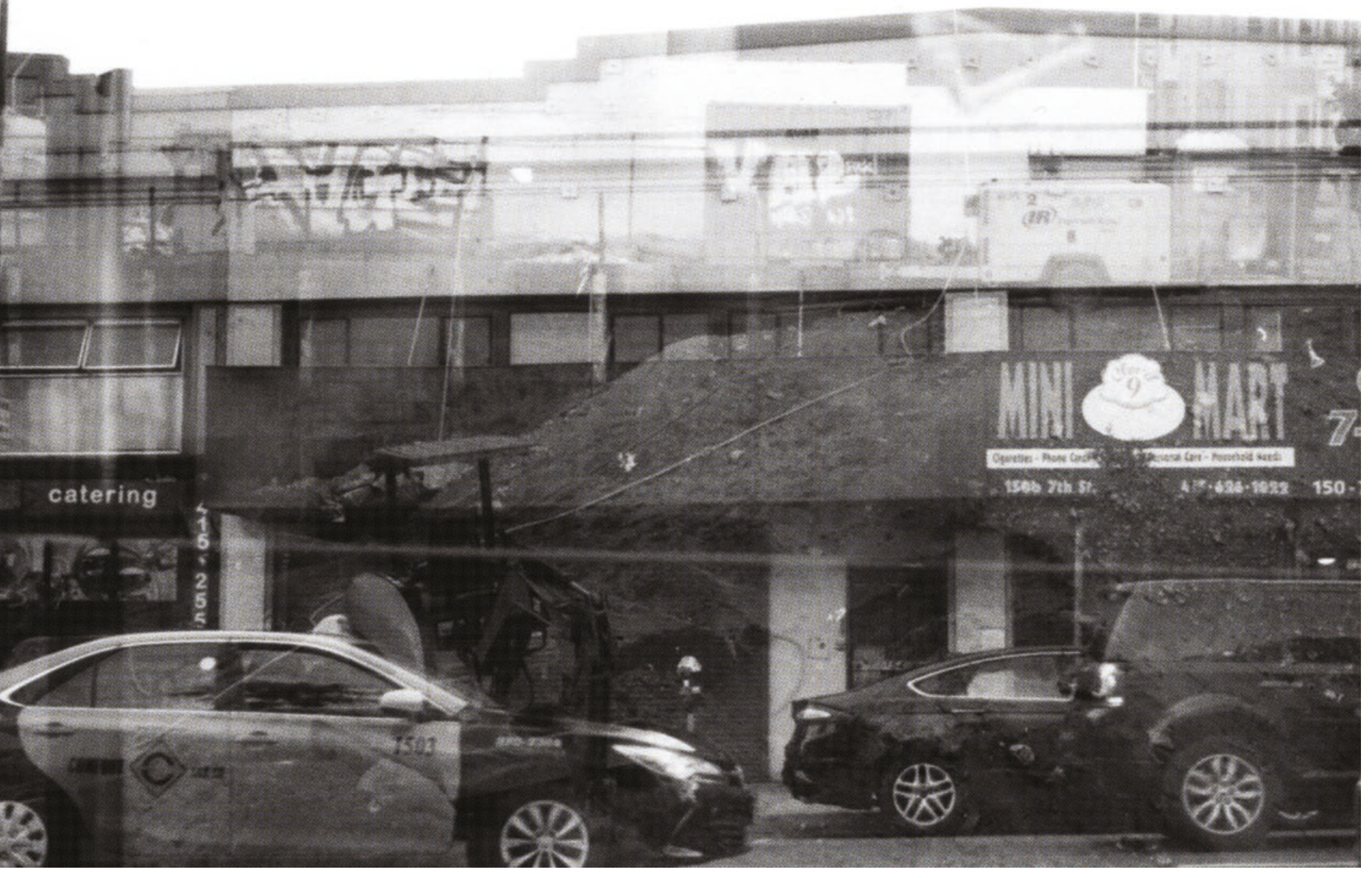

never enough for both. 


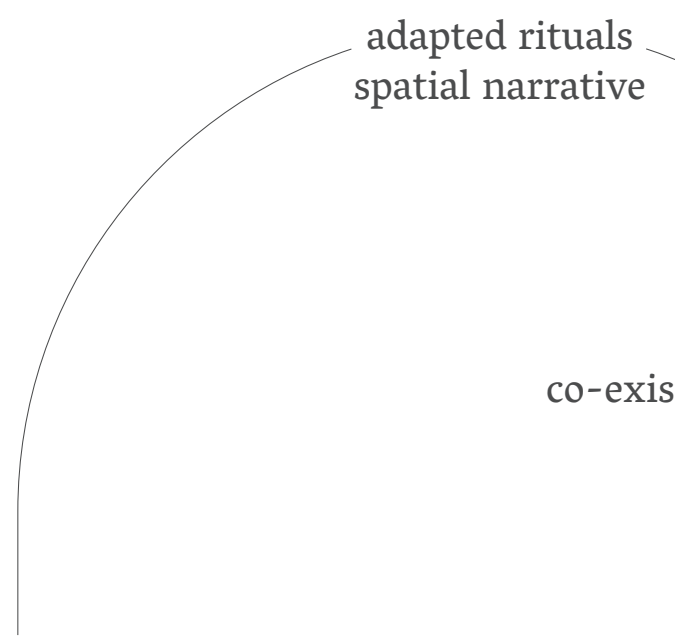

right to difference right to the city

balikbayan micro-publics

box ritual

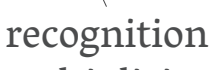

and belonging

hybridity

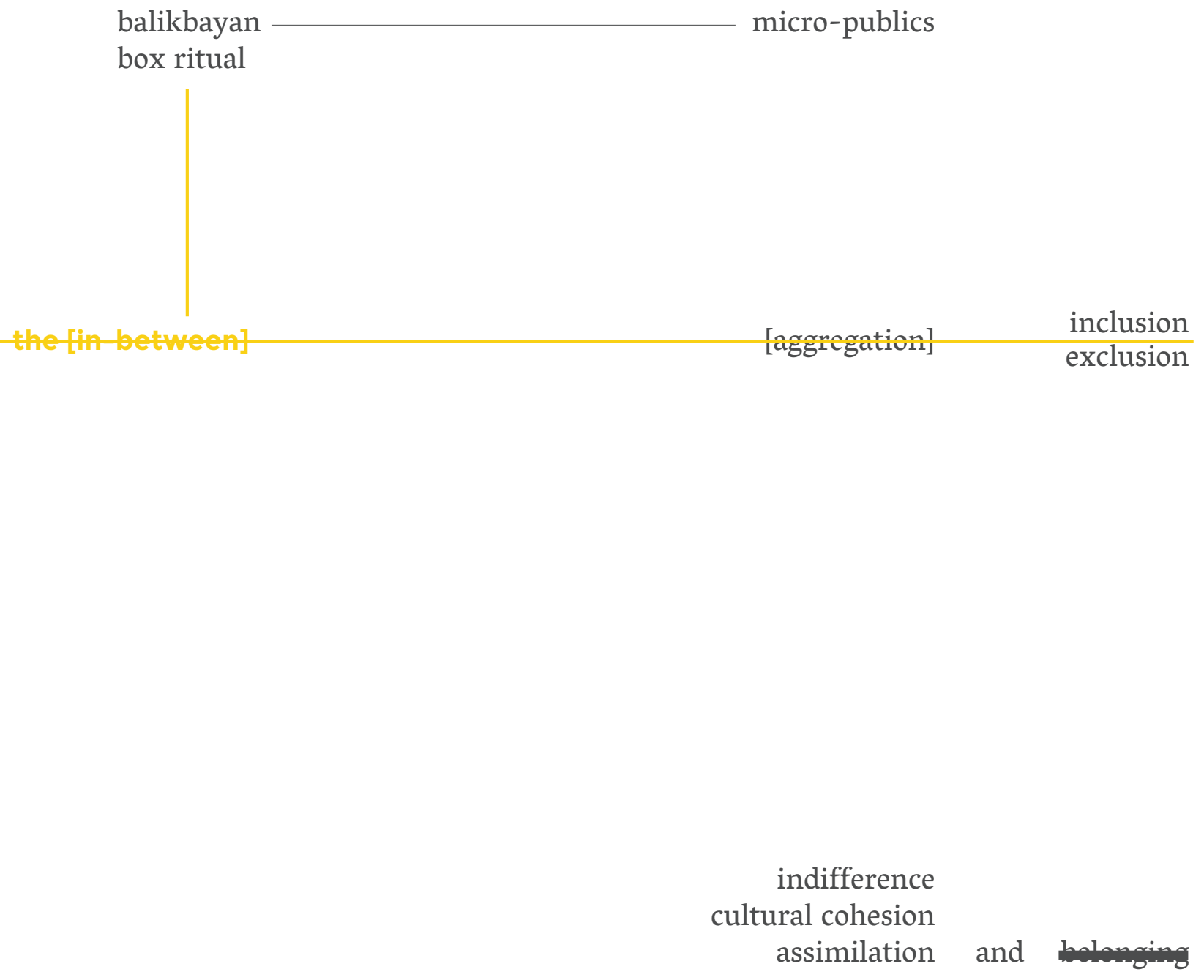

fear. 


\section{both.}

San Francisco Bay Blues

"...liminal phenomena ... we are presented, in such rites, with a 'moment in and out of time', and in and out of secular social structure, which reveals, however fleetingly, some recognition (in symbol if not always in language) of a generalized social bond that has ceased to be and has simultaneously yet to be fragmented into a multiplicity of structural ties."

- Victor W. Turner ${ }^{1}$

Diasporic identities are inherently liminal, in their deterritorialized state they are betwixt and between; never enough for both "home" or "here" as stated in the fourth line of Diaspora Blues. Author Victor Turner in the book The Ritual Process: Structure and Anti-Structure describes the liminal phenomena inherent in the global processes of migration as a "moment in and out of time, and in and out of secular social structure, which reveals some recognition of a generalized social bond that has ceased to be and has simultaneously yet to be fragmented into a multiplicity of structural ties." What is clarified here is that although the link between geographic space and social identity has been disrupted within the context of their host society, it still exists as a temporal spatial dimension within the social networks of transnational migrant groups. 
The diasporic individual then often has a double consciousness 3 , shaped through their multilocality, a transnational sense of self and an understanding of ethnicity that breaches boundaries both real and imagined. Transmigrants, in their multiple positionings within urban life "here", contribute actively to facilitating, legitimizing, and contesting both global and local processes ${ }^{4}$, while simultaneously having attachments and sentiments to "home". Thus, the social experiences and identities of transmigrants goes beyond the sum of the "home" and the "here", and in the processes of placemaking what is manifested is a transnational form of space . Thus, the role of transmigrants are not limited to spectacle, or even confined to either labor or culture; rather, they are rescaling cities and defining new conditions of space and place in their host localities through their hybrid existence.

Embedded in the core story of the Filipino diasporic community in San Francisco is the negotiation between "home" and "here". Thus, the cultural narrative of the SoMA urban landscape is informed by a state of liminality. Furthermore, Filipino immigrants commonly hold a "sojourner" mentality that is bound for, to and by "home", maintaining a transient attachment to their host localities. It is this state of mediated tension that defines their collective consciousness as transmigrants and at which the character of 
the Balikbayan originates, but it is the Balikbayan Box and the associated ritual that bridges the spatial abyss of the diaspora.

Conceived out of necessity as a means of transporting the "pasalubongs" (goods and remittances) that a Balikbayan would bring with them on their pilgrimage "home", the Balikbayan box ritual has become a tradition with ritualistic properties. By itself, a Balikbayan box is merely an artifact, "an object manufactured or modified by human hands". It is when a Balikbayan takes a carton and prepares it for transport to the Philippines does it communicate a social narrative based on familial ties and obligations, economics, space and place; subsequently become an index in understanding the unit of a Filipino household. ${ }^{6}$

The performance of the custom can then be interpreted as a rite of passage, not unlike the migrant journey from "home" to "here", which temporarily removes Balikbayans out of their liminality. Consequently, the exchange of remittances, is then representative of the final stage of the ritualistic journey - the aggregate state. However, it is the process of preparation, procurement and assembly of the "pasalubongs" which delimits the Balikbayans mediation of the liminal state. In a process termed "provisioning", alienable commodities become inalienable when imbued with 


\section{[ Act I ] - Separation}

The "balikbayan" program was devised by the Department of Tourism during the authoritarian regime of Ferdinand Marcos in 1973.

It was designed to entice overseas Filipinos to return to their homeland to observe the benefits of martial law, while simultaneously generating capital for the Philippine economy.

Balikbyayans brought with them a box of "pasalubongs" on their pilgrimage home. The 20 $\times 20 \times 20$ boxes and their contents are indices to a very specific segment of the Filipino population and represent a complex set of relationships to the Filipino homeland

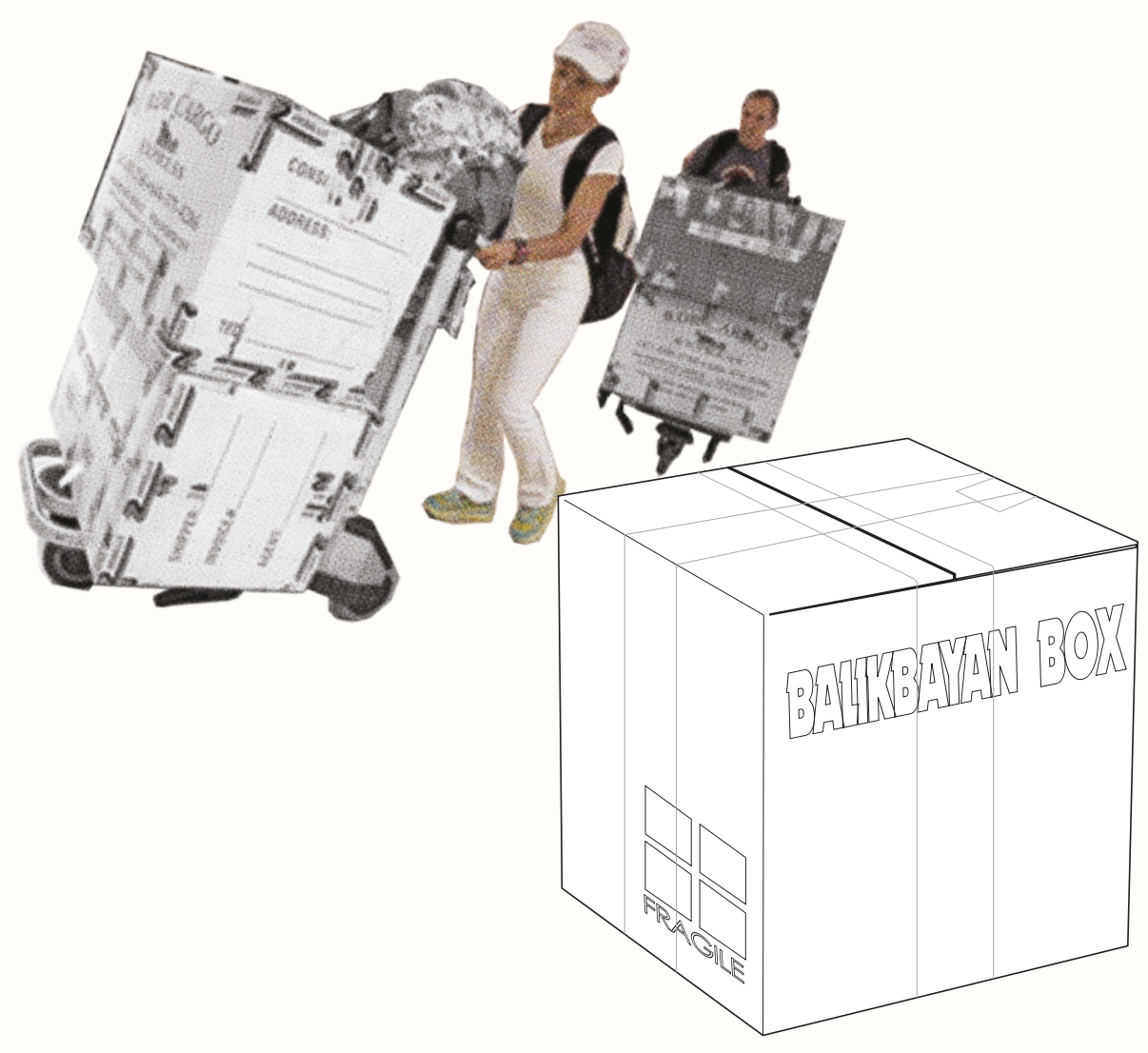




\section{[ Act II ] - Liminality}

What differentiates a plain utilitarian carton from a balikbayan box is the customary practice of its preparation.

Similar to an artifact, as it is modified by human hands it becomes a reflection of its manufacturer. Thus, the process of use becomes a process of creation.

The balikbayan box becomes a vessel of meaning for the balikbayans, recipients and other interpreters. Through the performance of the custom does the balikbayan become temporarily lifted out of their liminality.

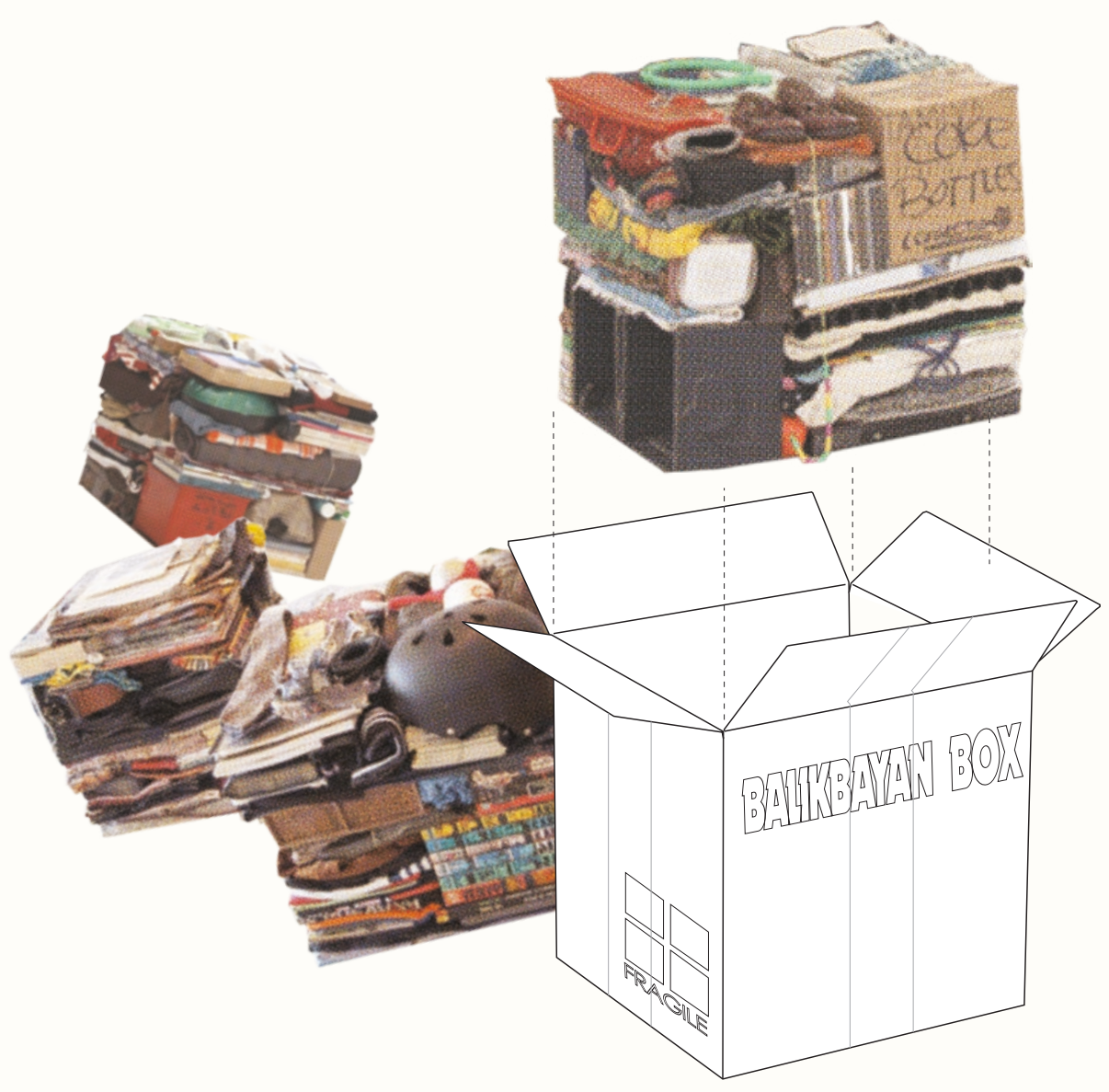




\section{[ Act III ] - Aggregation}

The commodities that are exchanged between balikbayan and recipient(s) are tangible connections between two places - the hostland and the homeland.

Thus, these balikbayan box represents a complex set of relationships, based upon kinship and obligation, economics, space and place, colonialism and hegemony. Most importantly, the boxes are sites for the reaffirmation of affective ties in the Philippines.

However, just as the boxes themselves are temporary and disposable, such are the spaces of reconnection that they create.

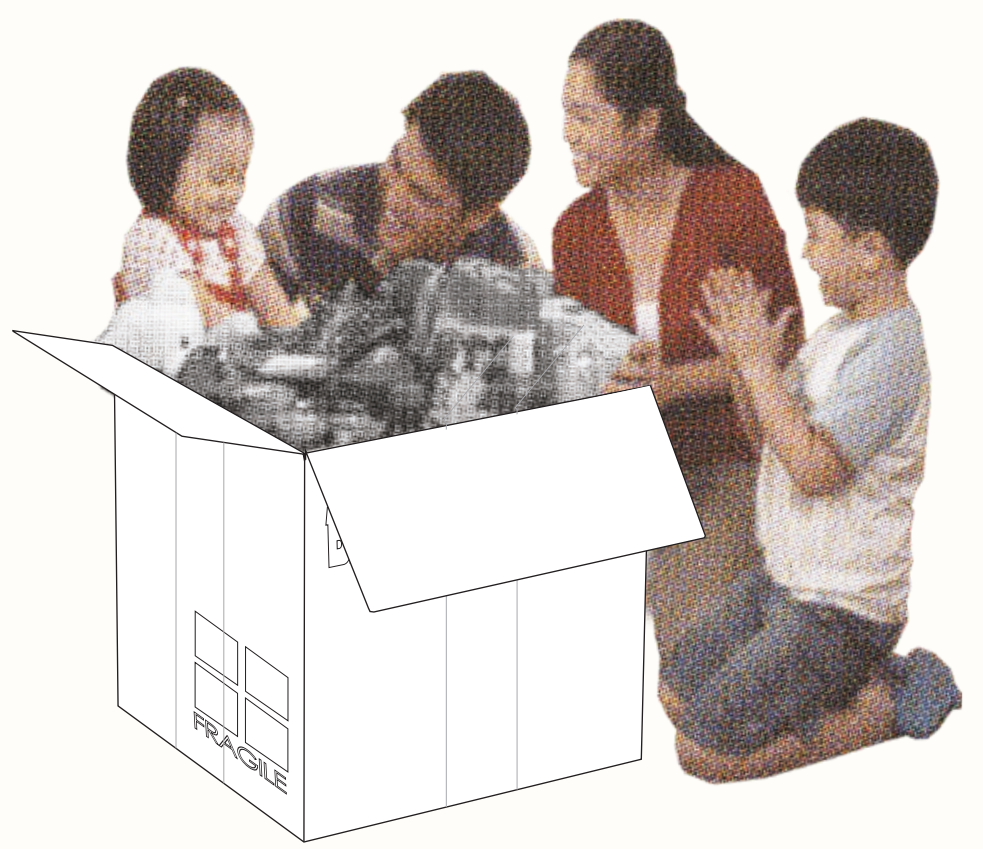


personal or social meaning and through consumption; objectifying the real and imagined ties of kinship that define that define them. It is through the commodification of care that "pasalubongs", as nonhuman entities, take on aspects of human action, intention, and judgement to participate in social and political life as coactants.

Balikbayans, through these packages are able to reaffirm the relationships that instigated the ritual, and briefly reprise their roles in these relationships 9 , figuratively returning them "home". In accordance to Bruno Latour in Where Are The Missing Masses, these "pasalubongs" are anthropomorphic, in that although made by humans they are now delegated to occupy the position of a human and shape human action ${ }^{10}$. Balikbayans, by the manner in which the remittances are chosen and then arranged within the Balikbayan box, are able to decipher the nuances and subtleties ${ }^{11}$ within their ties of kinship and their relationship to "home". The social narratives designated by the composition of the artifact then delineate a temporal re-constructing and reimagining of space. The action facilitates the space, rather than the space facilitating the action.

Through the exercise of the ritual, "home" then becomes a "mode of interpretive in-between, as a form of accountability to more than one location" ${ }^{12}$, as the carton itself embodies a transnational sense of space that mediates the collective consciousness of between "homeland" and "hostland". An analysis of Balikbayan Box's microhistory is an a expression of the social articulation of difference within a Filipino diasporic identity. When deciphered as a spatial metaphor, the negotiation of meaning and the creation of a narrative of difference involved within the process of assembly, can then be utilized as formal tactics for the urban landscape. While narrative is used to facilitate the process, the architecture then becomes a means of coordinating and consolidating moments of meaningful exchange. 


\section{Balikbayan Box Exercise}

This exercise was a means of clarifying the relationship between the single object and the composition of the overall box. Each specific placement delineated a specific negotiation of memory between the sender and receiver. The interaction between the object and the overall composition expressed information specific to that relationship.
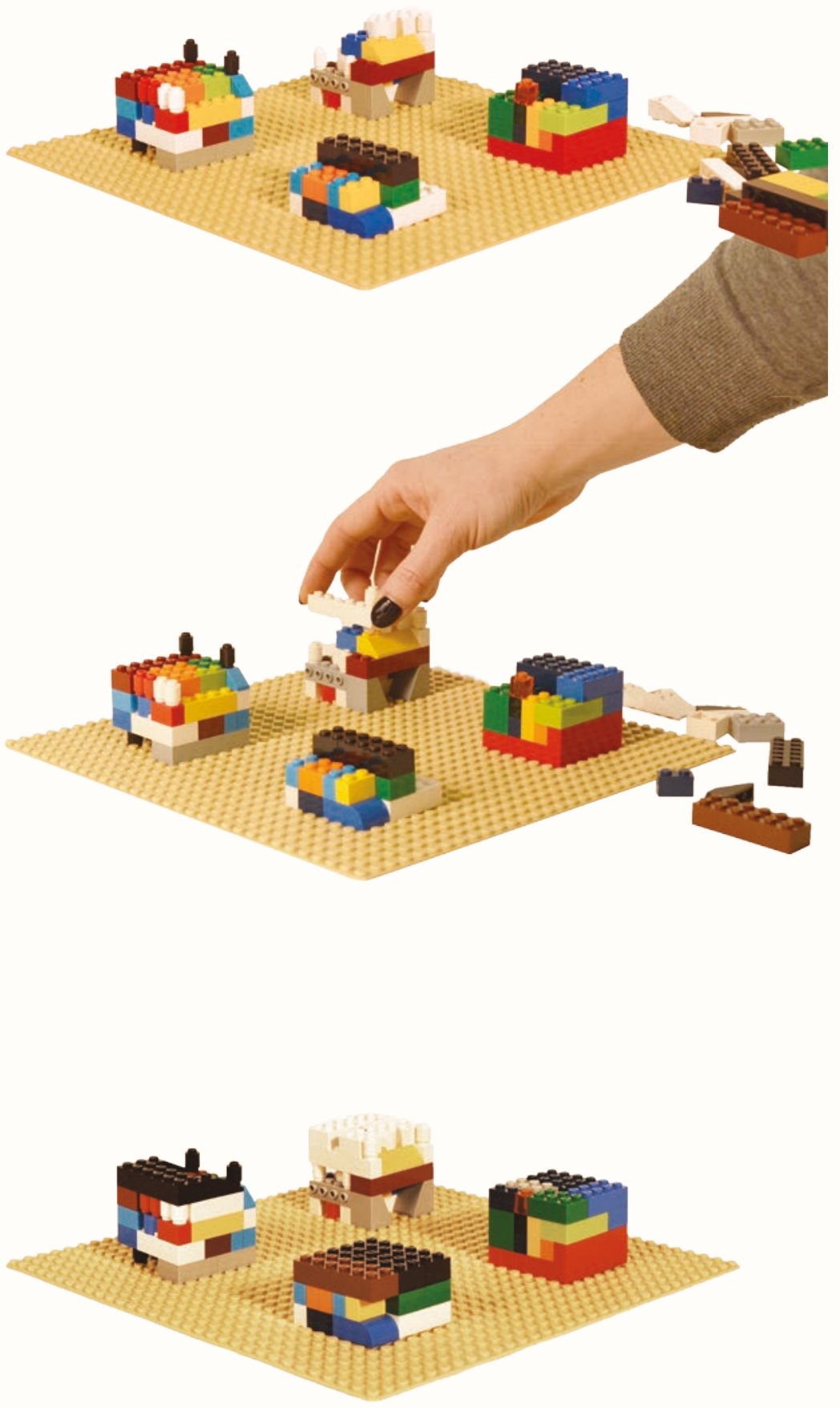
Unpacking the Balikbayan Box

\section{Unpacking the Ballkbayan Box}


imaginaries"16 within the urban landscapes that they occupy - in which they can deliberately construct self-identities that "evade, move beyond, and even invert" the "self-made" identities prescribed upon them.

When interpreting each action of exchange within the Balikbayan ritual as a form of "alternative imaginaries" ${ }^{17}$, the Balikbayan box then becomes a repository for exercises of "self-making". The collection of negotiated narratives between the here and there that make the composition of a balikbayan box can then be interpreted as an evolving photo-montage, an act of "creative miscegenation" - that can be described as a "cross breeding of forms from distant or apparently incompatible origins" ${ }^{\prime 18}$.

The process of decoupage/collaging within the context of this thesis then becomes a form of "self-making" - illustrating actions that may lack predetermination but then with discipline become an affirmative praxis within the process of place-making in SoMa. By interpreting each contrary piece of the decoupage as representation of the different relationships to home that each generation of Filipino-Americans has, the overall composition of the Balikbayan box, and the urban architectural proposal that it inspires, then becomes a transient space subservient to the substitution of "home".

The intimate life - which Hannah Arendt describes as "the passions of the heart, the thoughts of the mind, the delights of the senses"19 - are then brought from their "shadowy of existence"2o and into the public realm. By making the more domestic aspects of Filipino-American culture conspicuous, it encourages moments of intimate exposure - a means of engaging curiosity, encouraging a frank connectedness within an otherwise disengaged context and emphasizing the depth and density of the social aspects of a Balikbayan's life. 


\section{Endnotes}

01. Victor W. Turner, Ritual Process: Structure and Anti-Structure, (New Jersey: Aldine Transaction, 1969), p.96

02. The Ritual Process: Structure and Anti-Structure, p.96

03. Vijay Agnew, Diaspora, Memory and Identity: A Search for Home, (Toronto: University of Toronto Press, 2005), p.14

04. Ayse Caglar and Nina Glick Schiller, Locating Migration: Rescaling Cities and Migrants. (London: Cornell University Press, 2011), p.3

05. Alice Jade A. Alburo. Box Populu: A Socio-Cultural Study Of The Filipino American Balikbayan Box, (St John's: Memorial University of Newfoundland, 2002), p.7

06. Ibid, p. 9

07. Ibid.

08. Daniel Miller, Alienable Gifts And Inalienable Commodities, In The Empire of Things, (Sante Fe: School of American Research, 2001), p. 95

09. Alburo. Box Populu: Study Of Balikbayan Box, p.10

10. Bruno Latour, Where Are The Missing Masses?, (Cambridge: MIT Press, 1992), p.160

11. Miller, Alienable Gifts And Inalienable Commodities, p. 95

12. Agnew, Diaspora, Memory and Identity, p.195

13. Yen Le Espiritu. Home Bound: Filipino American Lives across Cultures, Communities, and Countries (Berkeley and Los Angeles: University of California Press, 2003), p. 179

14. Ibid, p. 215

15. Ibid.

16. Ibid

17. Ibid.

18. Marshall Brown. "Chimera: The Architecture of Creative Miscegenation." Journal of Architectural Education. 70, no.1 (2016): p. 22.

19. Hannah Arendt, The Human Condition, Chicago: University of Chicago Press, 1958. P. 50.

20. Ibid 
Proposal for the Liminal State 

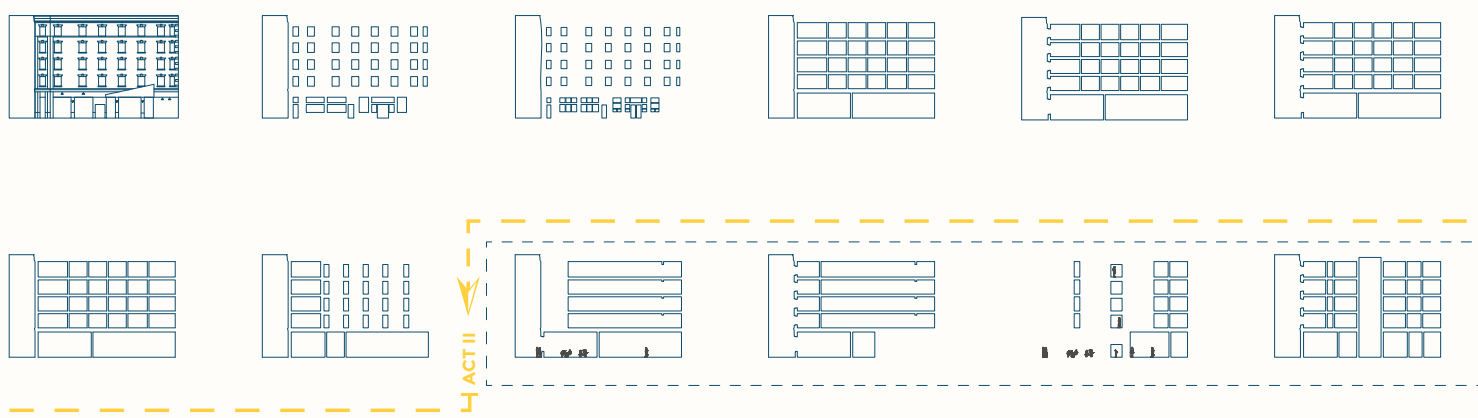

\section{围闻 \\ 罣围 围围 \\ 围围 \\ 国用

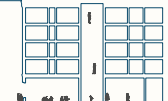

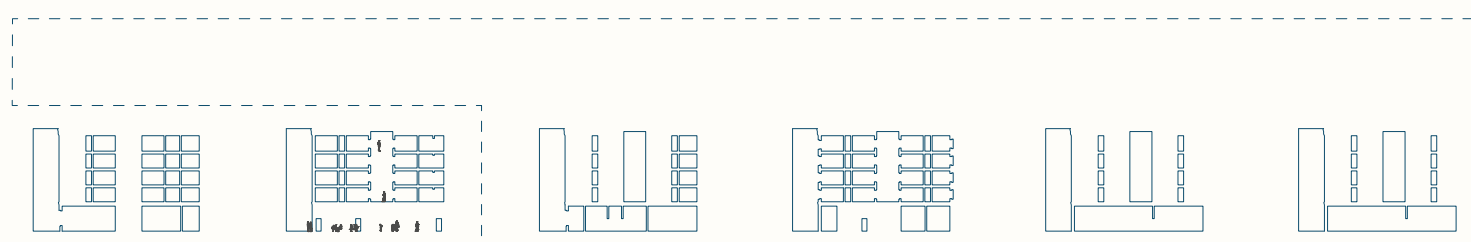

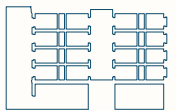

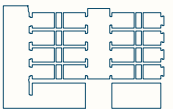

$\begin{array}{ll}\Gamma & ------- \\ 1 & 1 \\ 1 & 1 \\ 1 & 1\end{array}$

E푤

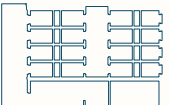

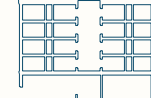

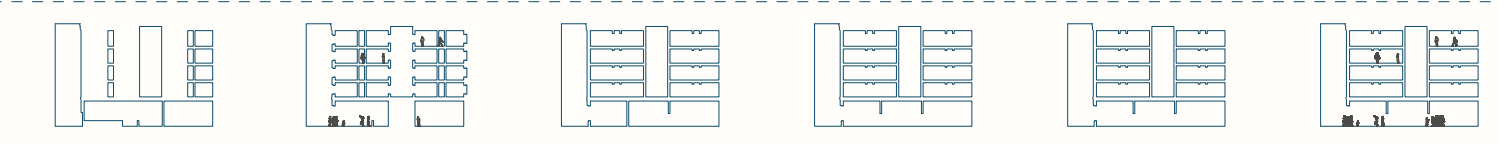

1

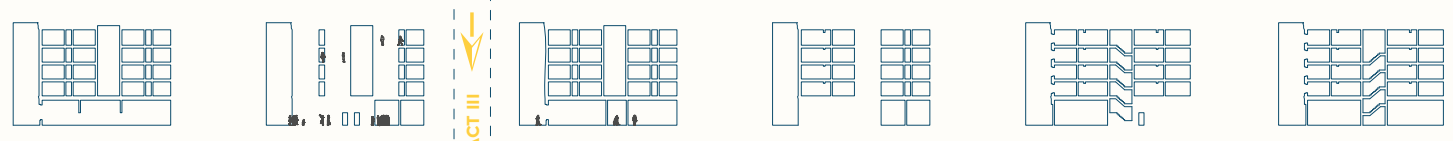
瞋目

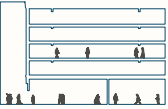
ए

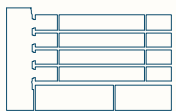
$\left[\begin{array}{llll}0 & & 0 \\ 0 & 1 & 0 \\ 0 & 1 & 0 \\ 0 & 1 & 1 & 1\end{array}\right.$
$\left[\begin{array}{ll}\square & \square \\ 0 & \square \\ \square & \square \\ \square & \square\end{array}\right.$

$\left[\begin{array}{lll}0 & 0 \\ 0 & 0 \\ 0 & 0 \\ 0 & 0 \\ & & 0\end{array}\right.$ 
[ Act I] Gen 1.5 \& 2.0

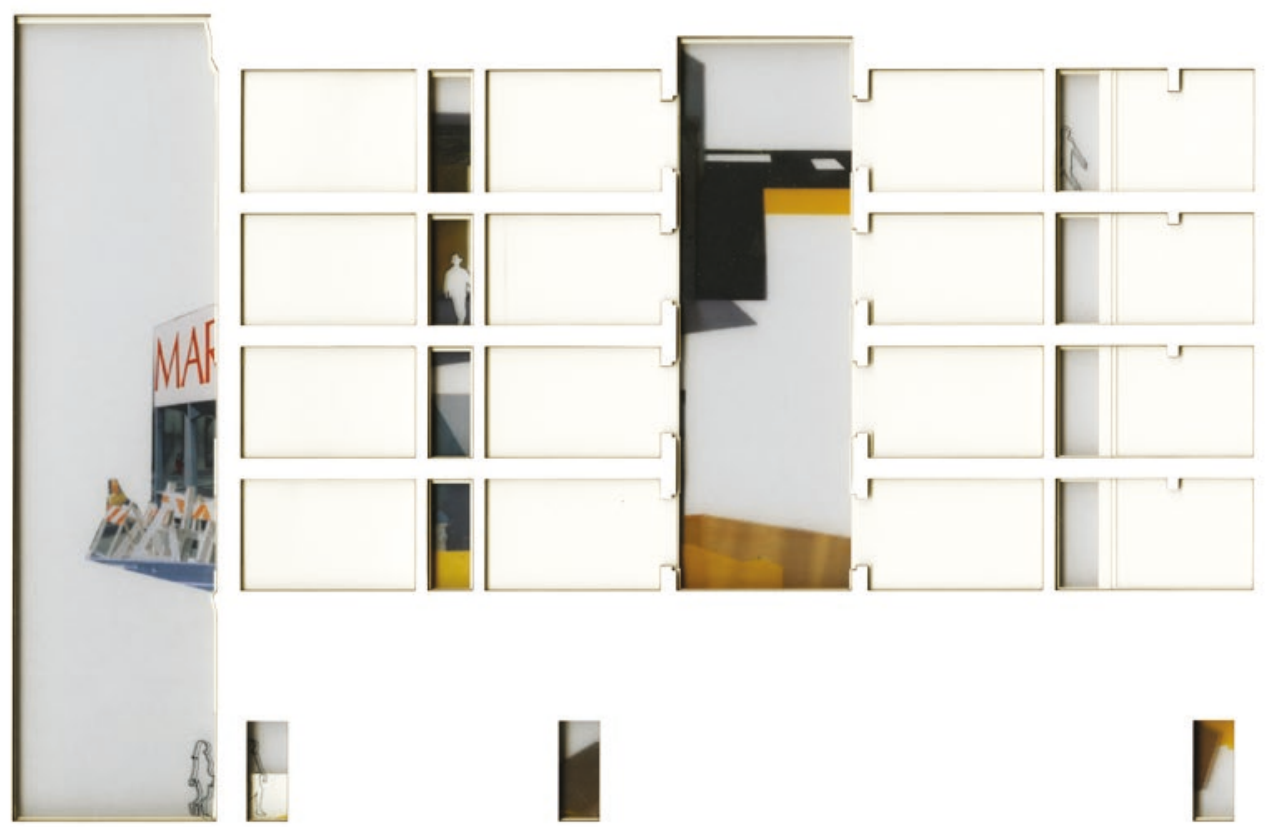

The Bayanihan Community Centre is the current centre of the SoMA Pilipinas - a building that facilitates interaction, negotiation and cultural expression between all the generations of FilipinoAmericans in the community. Similar to the Balikbayan Box, the Bayanihan Community Centre is defined by the ties of kinship of the three generations of Balibayans that inhabit it.

The " 1 to 50" exercise explores a narrative of cross-generational spatial narrative sectionally through the buiding. Distributed into three acts, each section of the community centre explores a conflict between two generations of Filipino-American transmigrants (extracted from my own subjective history). Possible architectural resolutions are explored using techniques from the process of collage/decoupage. These tactics are then applied to three sites in SoMA. 

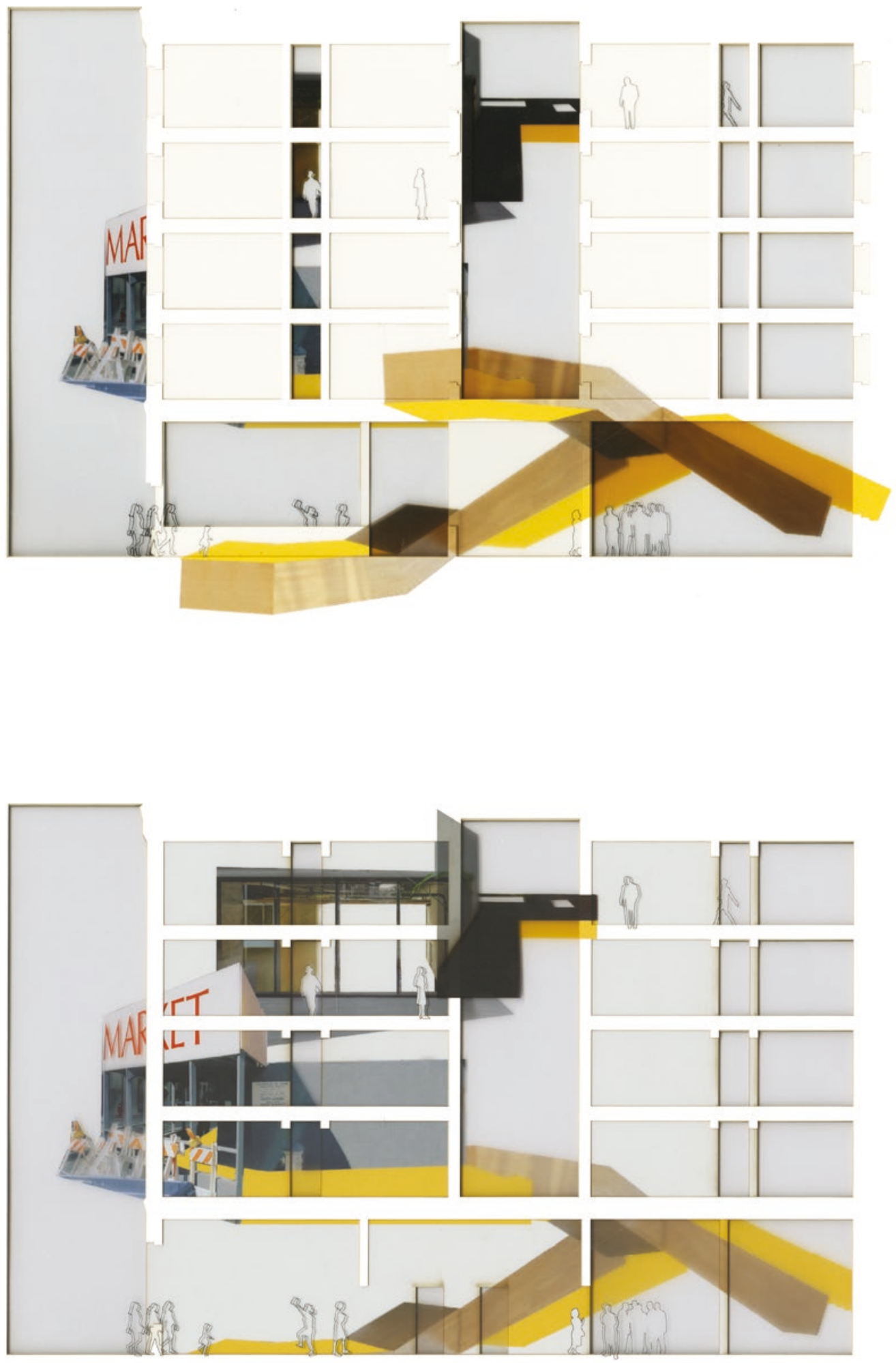

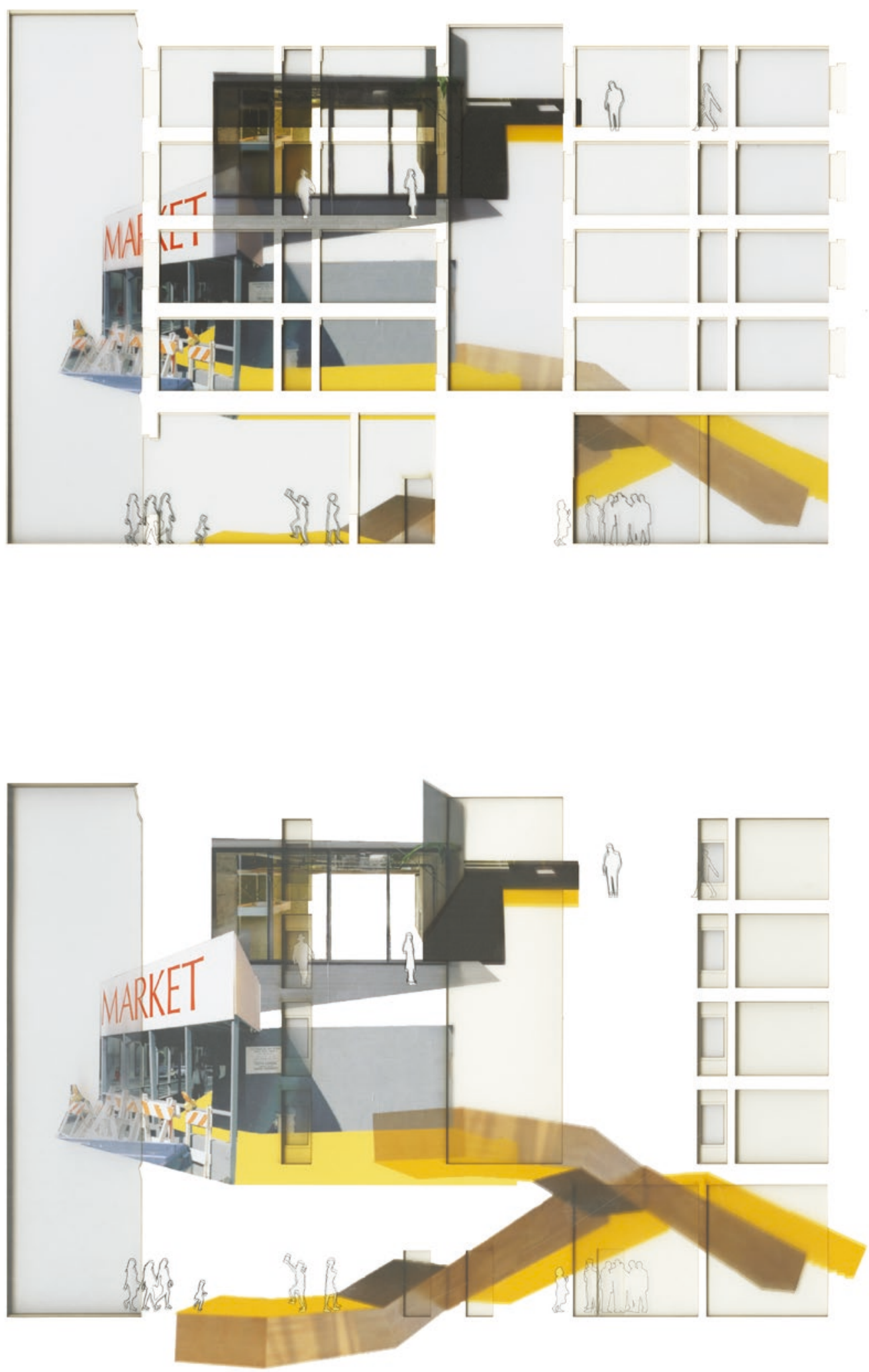
[ Act II ] Gen 1.0 \& 2.0

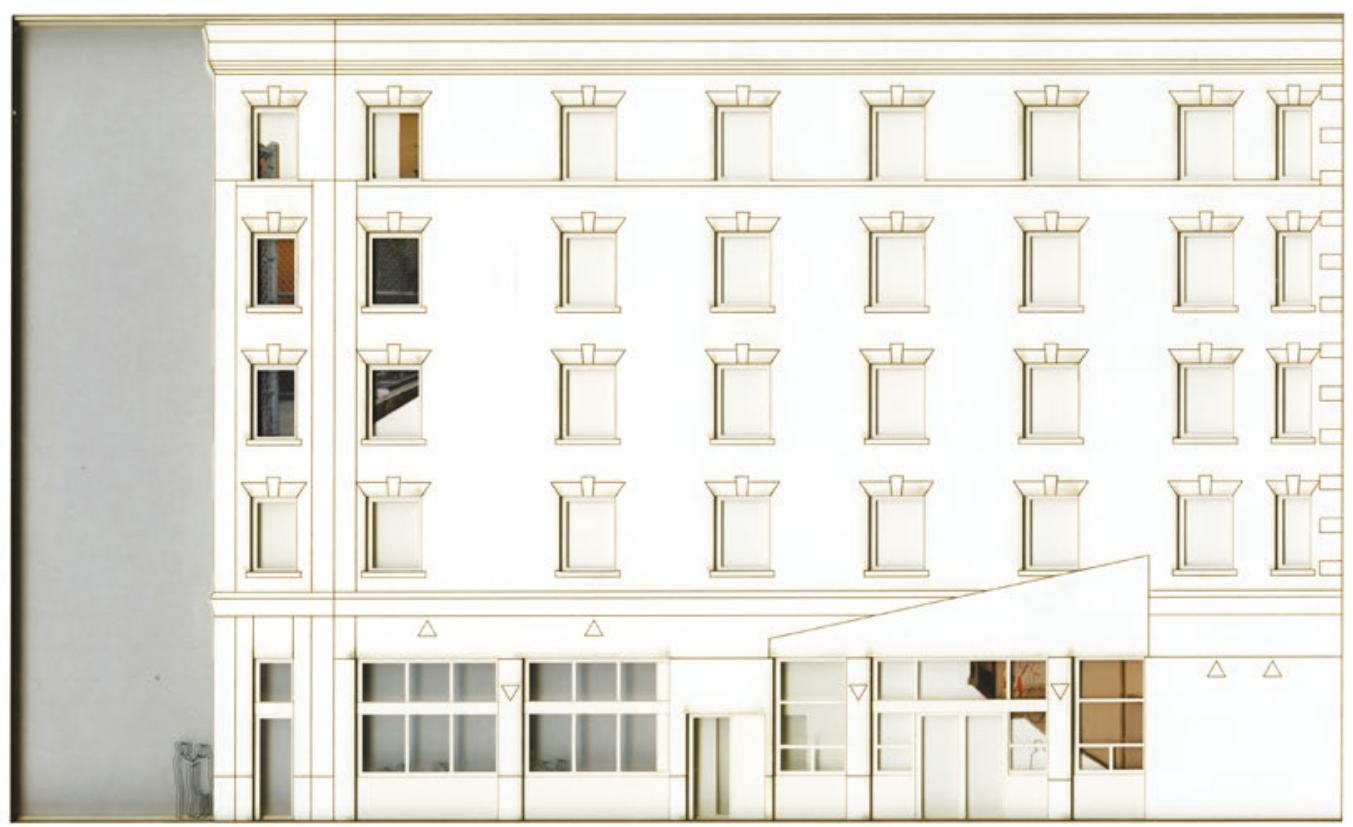



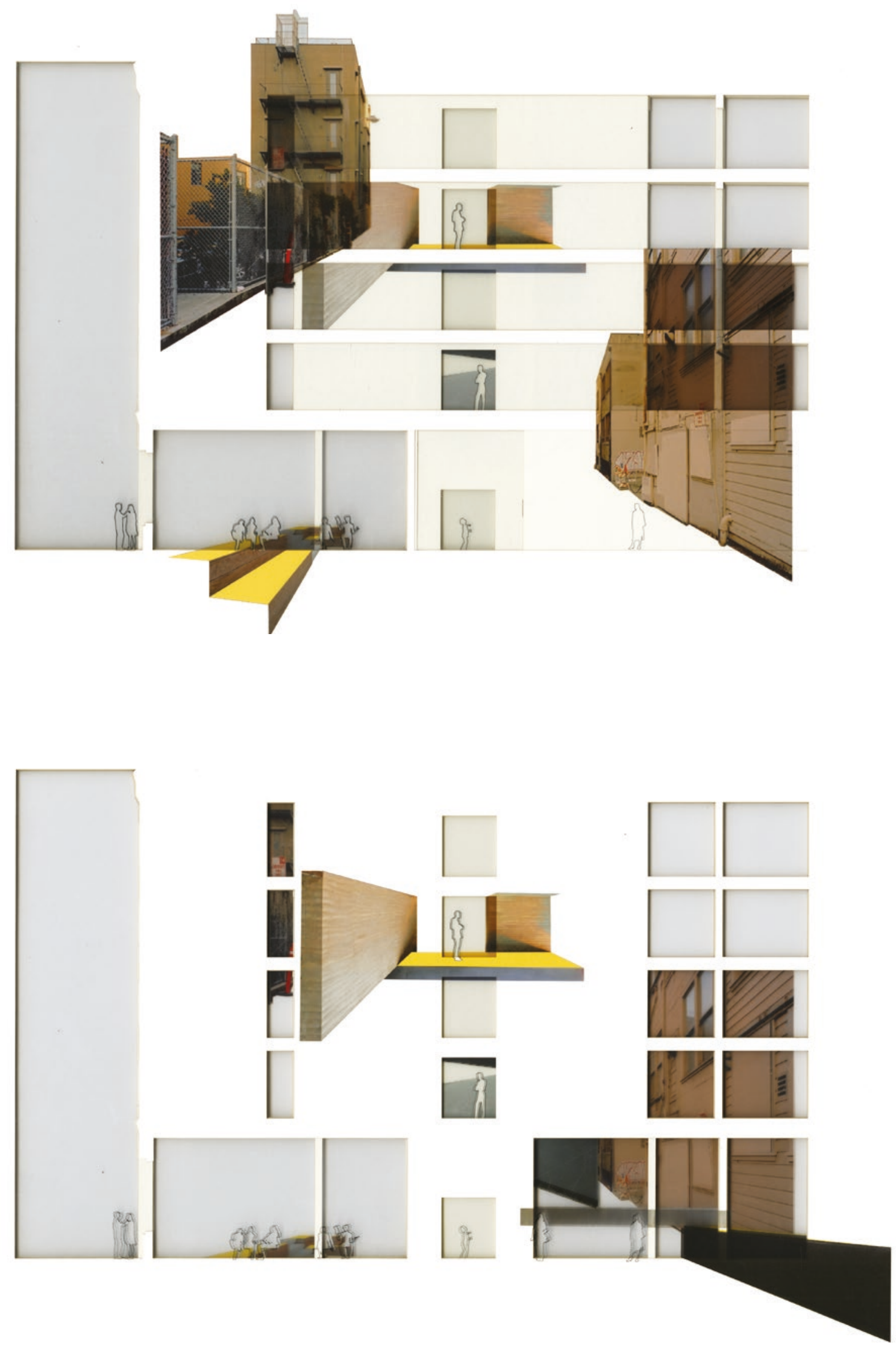

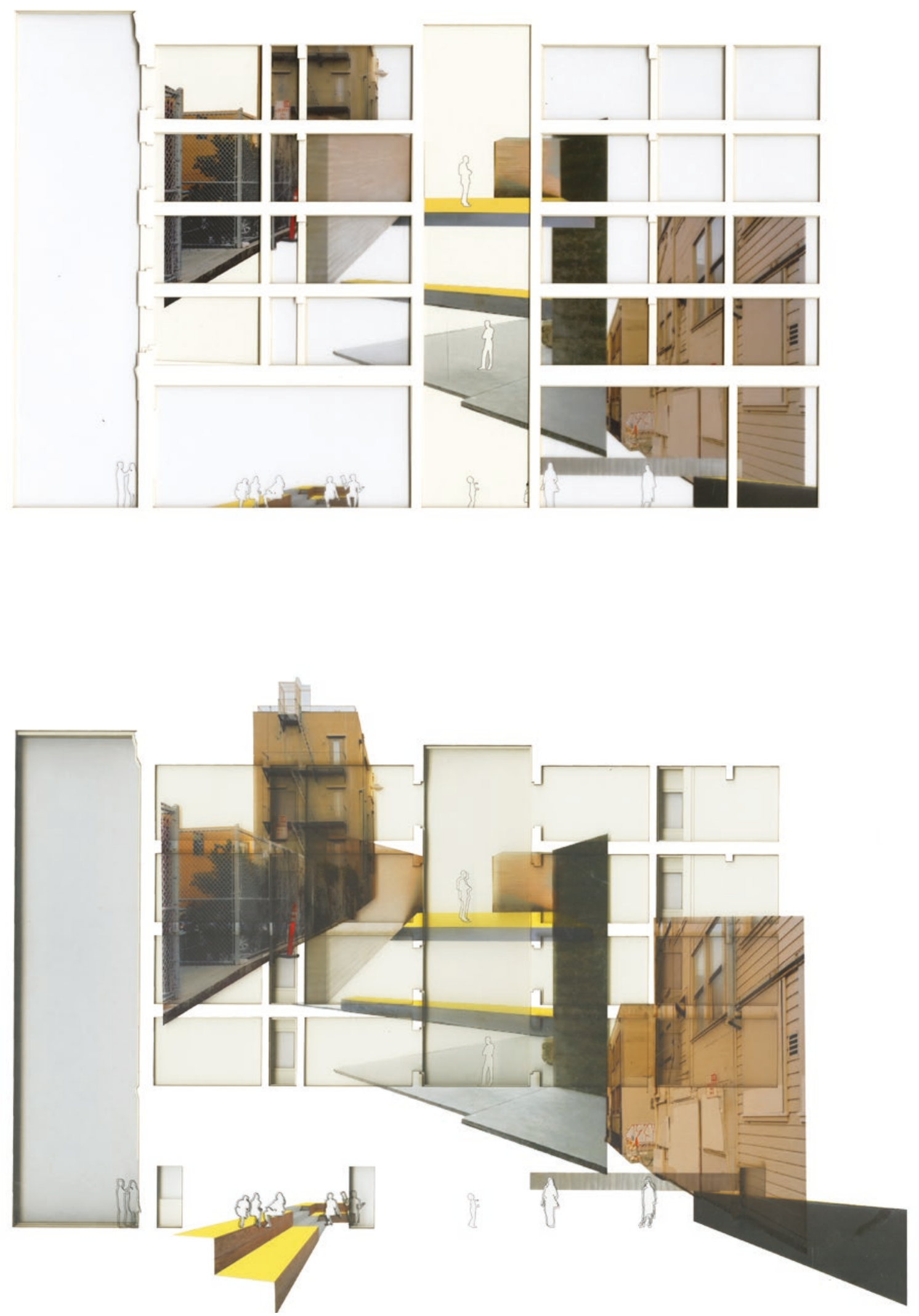
[ Act III] Gen 1.5 \& 1.0
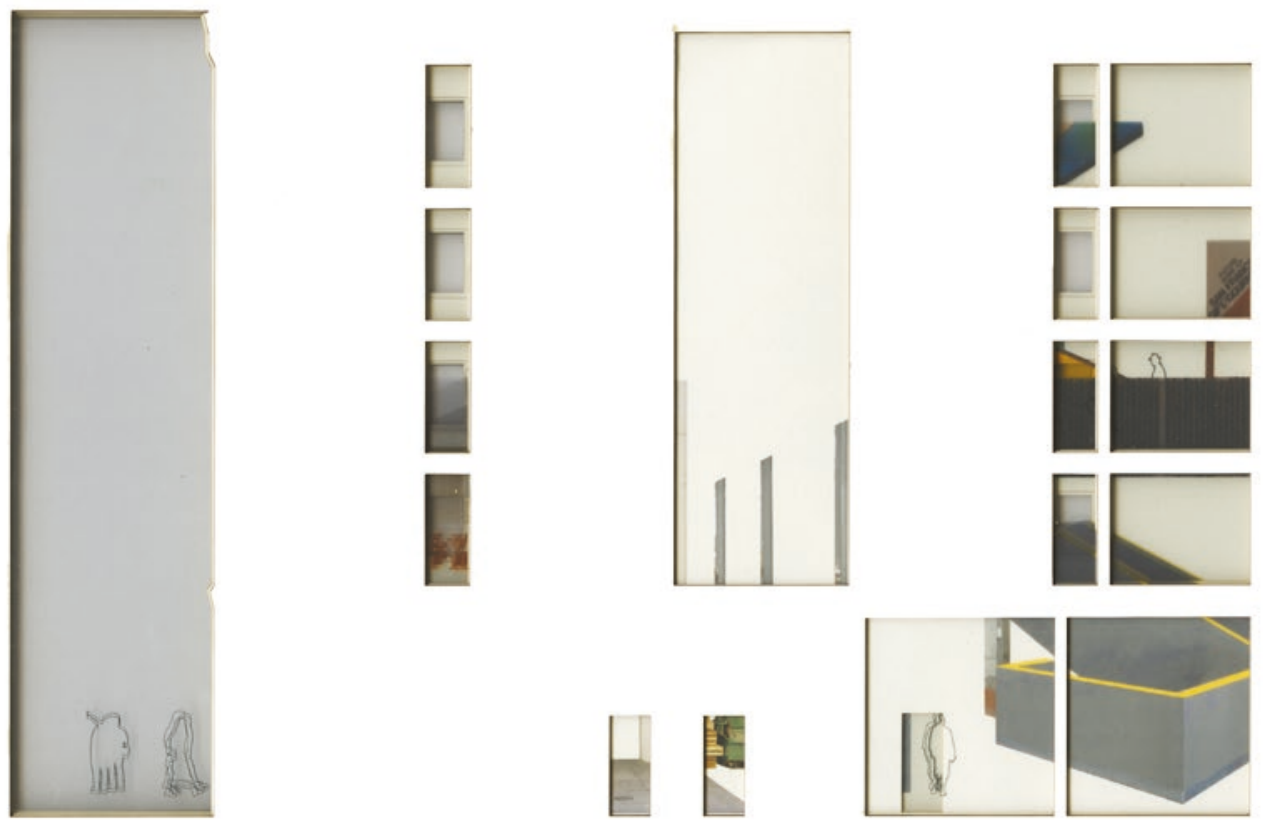

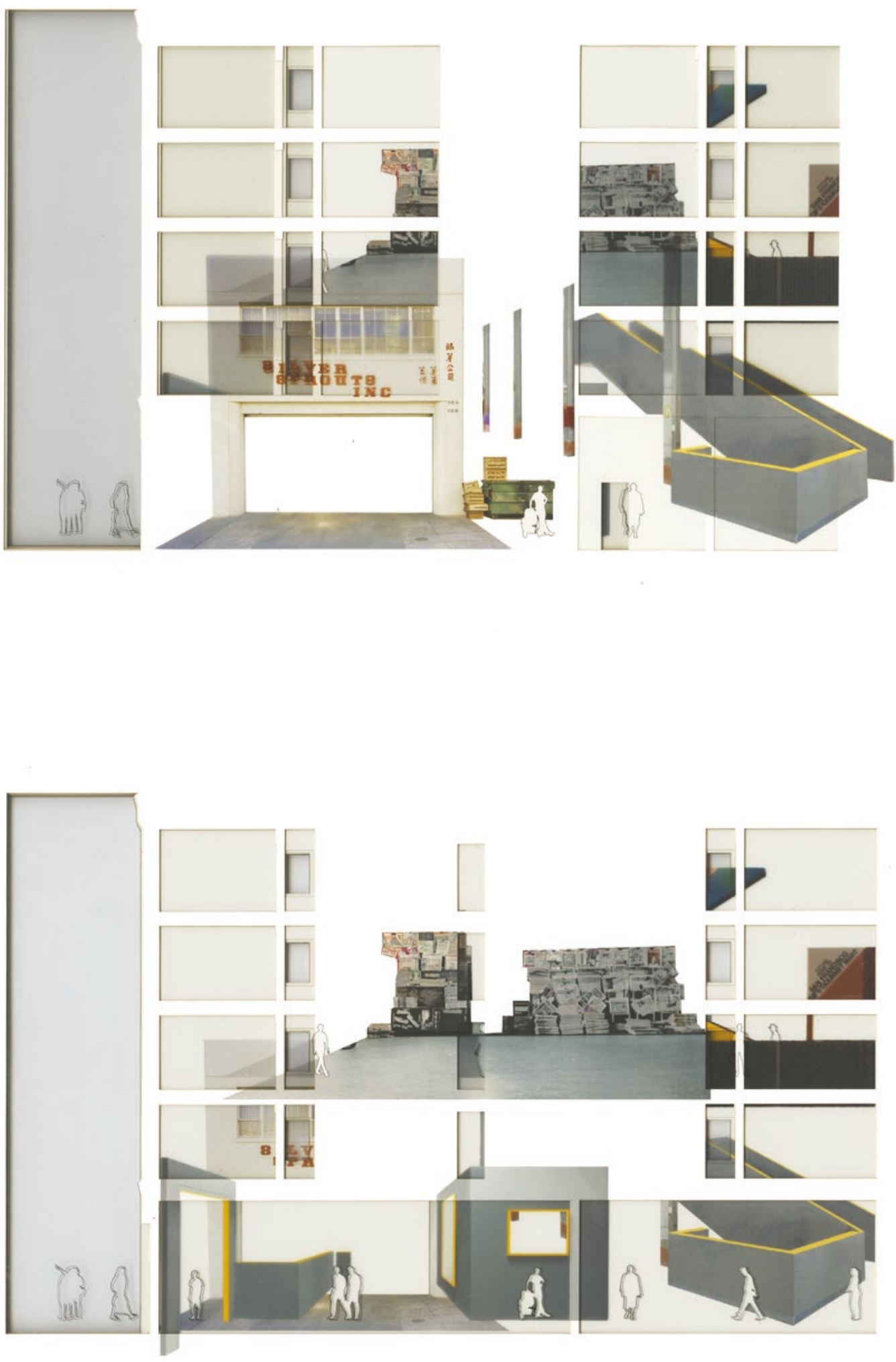

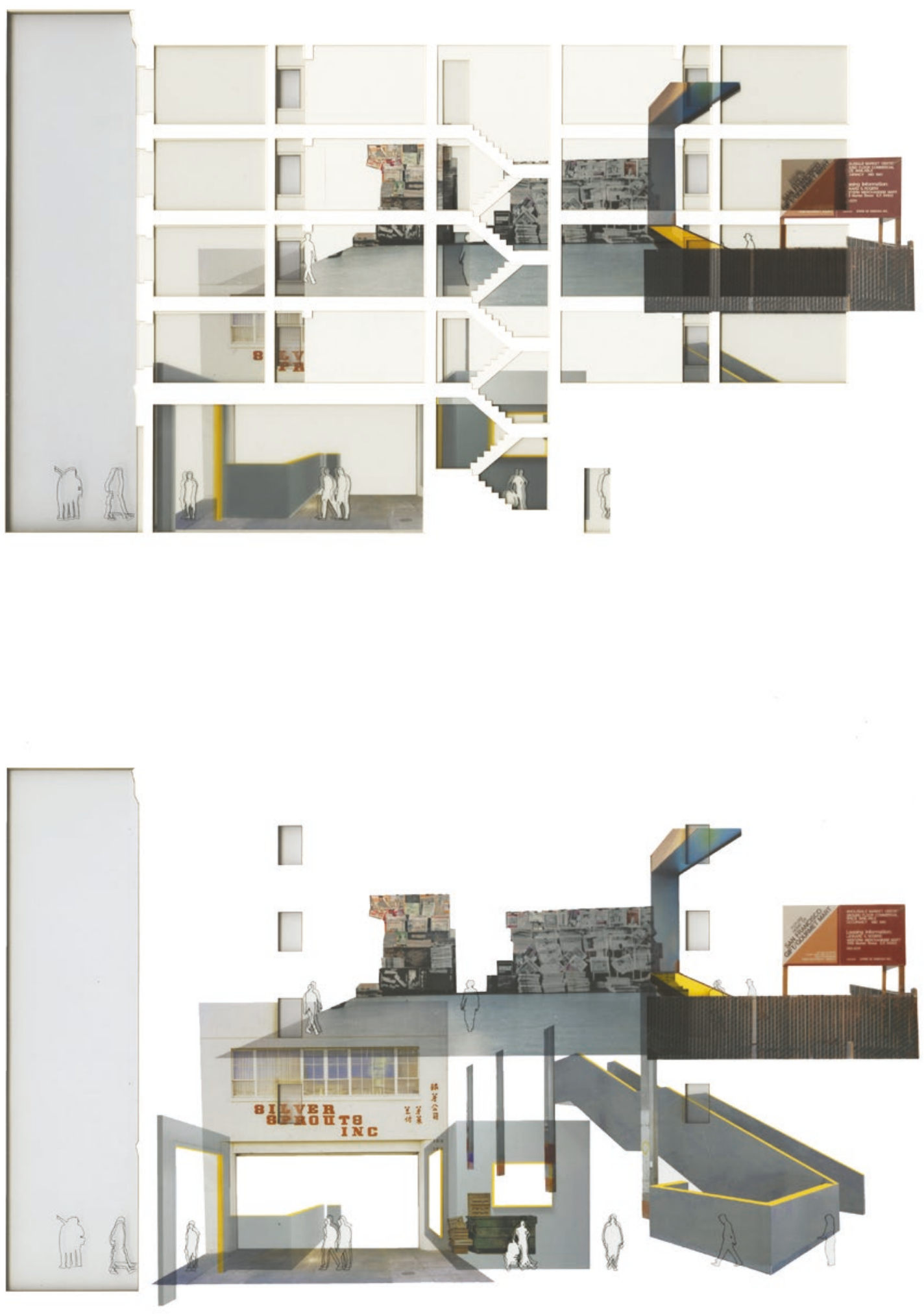
SoMa Sacred Spaces

1. UNION SQUARE

2. ST. PATRICKS CHURCH

3. YERBA BEUNA GARDENS

4. MINT MALL

5. BAYANIHAN CENTRE

6. BINDLESTIFF STUDIO

7. WESTBAY PILIPINO MULTISERVICE CENTER

8. YERBA BUENA \& MOSCONE CENTRE STATION

I SoMA Landmark/Organization/Business

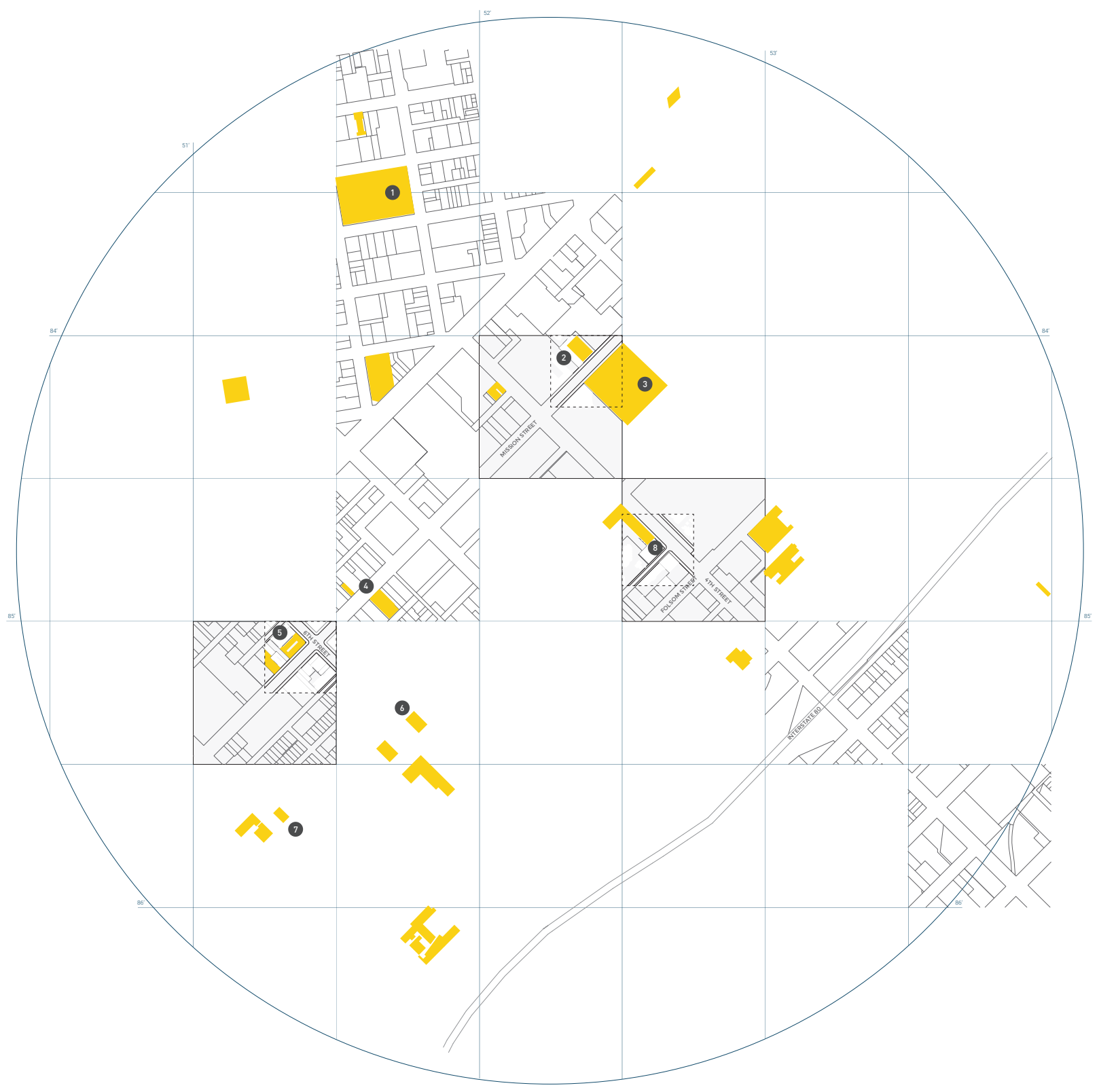




\section{Annual Ritual Paths}

1. PATH 1 / PAROL FESTIVAL (DECEMBER)

2. PATH 2 / KALAYAAN SF: INDEPENDENCE DAY FESTIVAL (JUNE)

3. PATH 4 / PISTAHAN PARADE AND FESTIVAL (AUGUST)

N YERBA BEUNA GARDENS

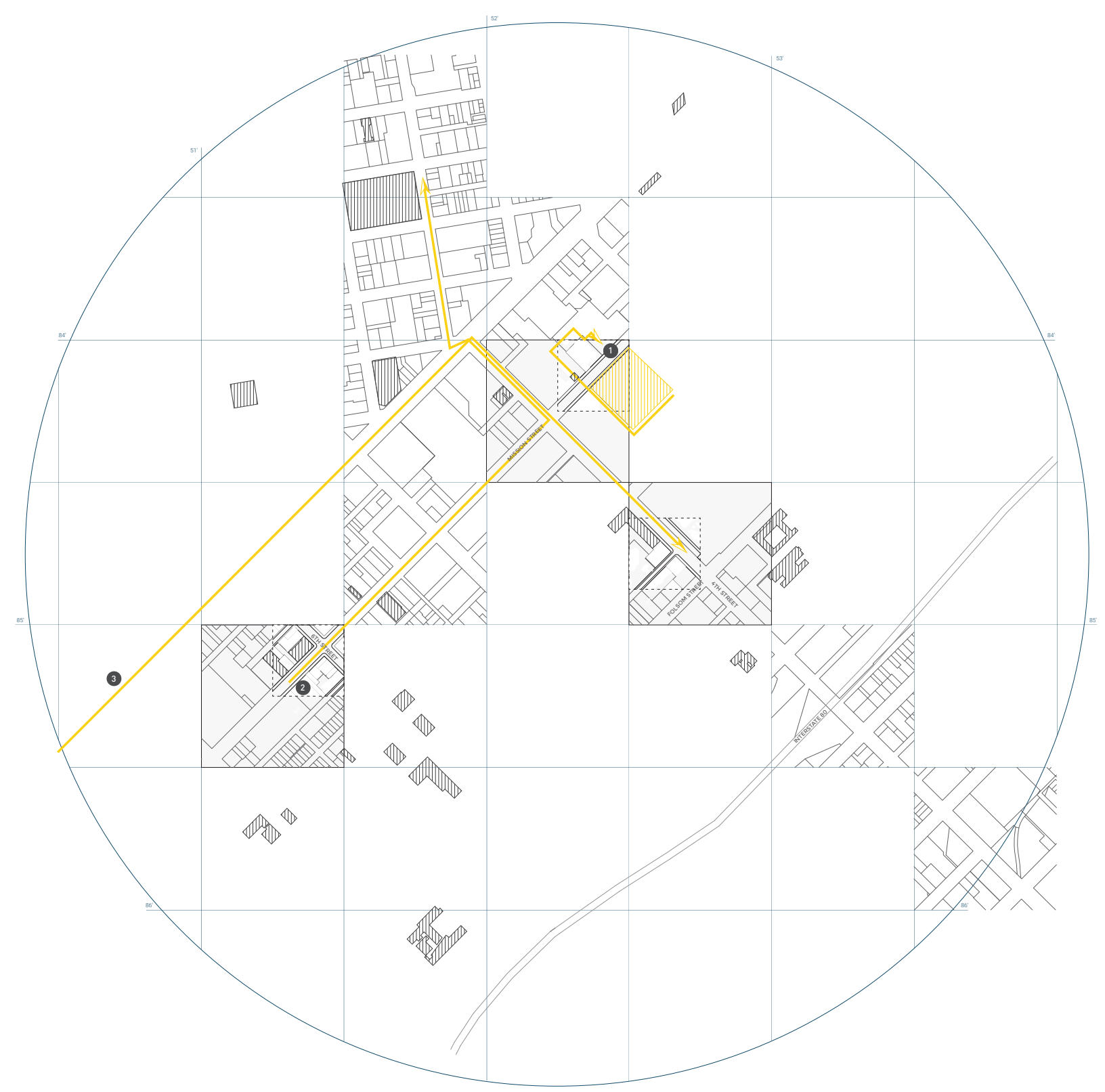




\section{Proposed Sites}

1. SITE 1 / SEPARATION - PLACE OF DEPARTURE OR ARRIVAL

2. SITE 2 / THE LIMINAL (IN-BETWEEN) - TRANSITION

3. SITE 3 / AGGREGATION - CONSUMMATION

Each circle is a $5 \mathrm{~km}$ walking radius

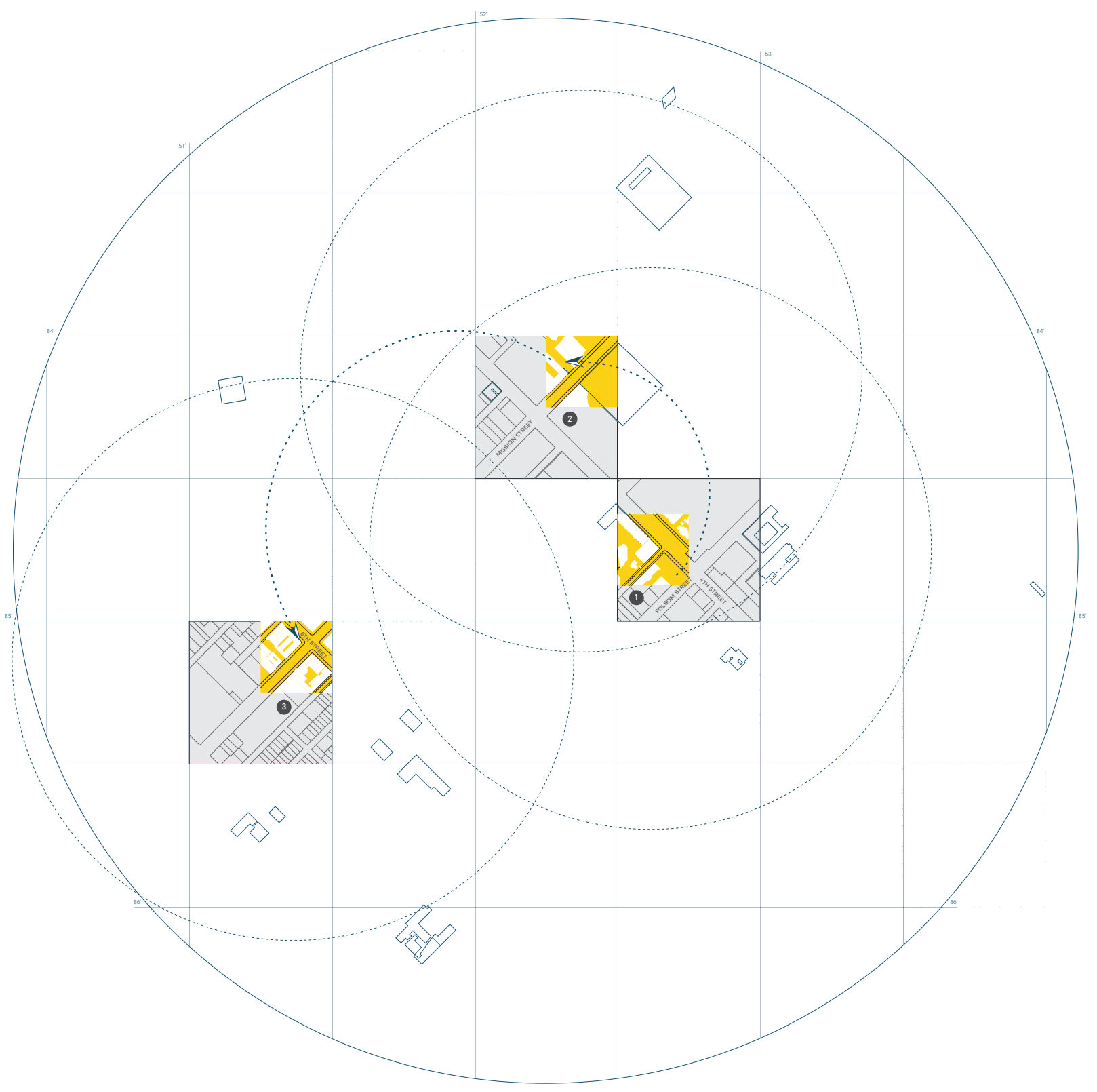




\section{Proposed Interventions}

1. SITE 1 / SEPARATION - PLACE OF DEPARTURE OR ARRIVAL

2. SITE 2 / THE LIMINAL (IN-BETWEEN) - TRANSITION

3. SITE 3 / AGGREGATION - CONSUMMATION

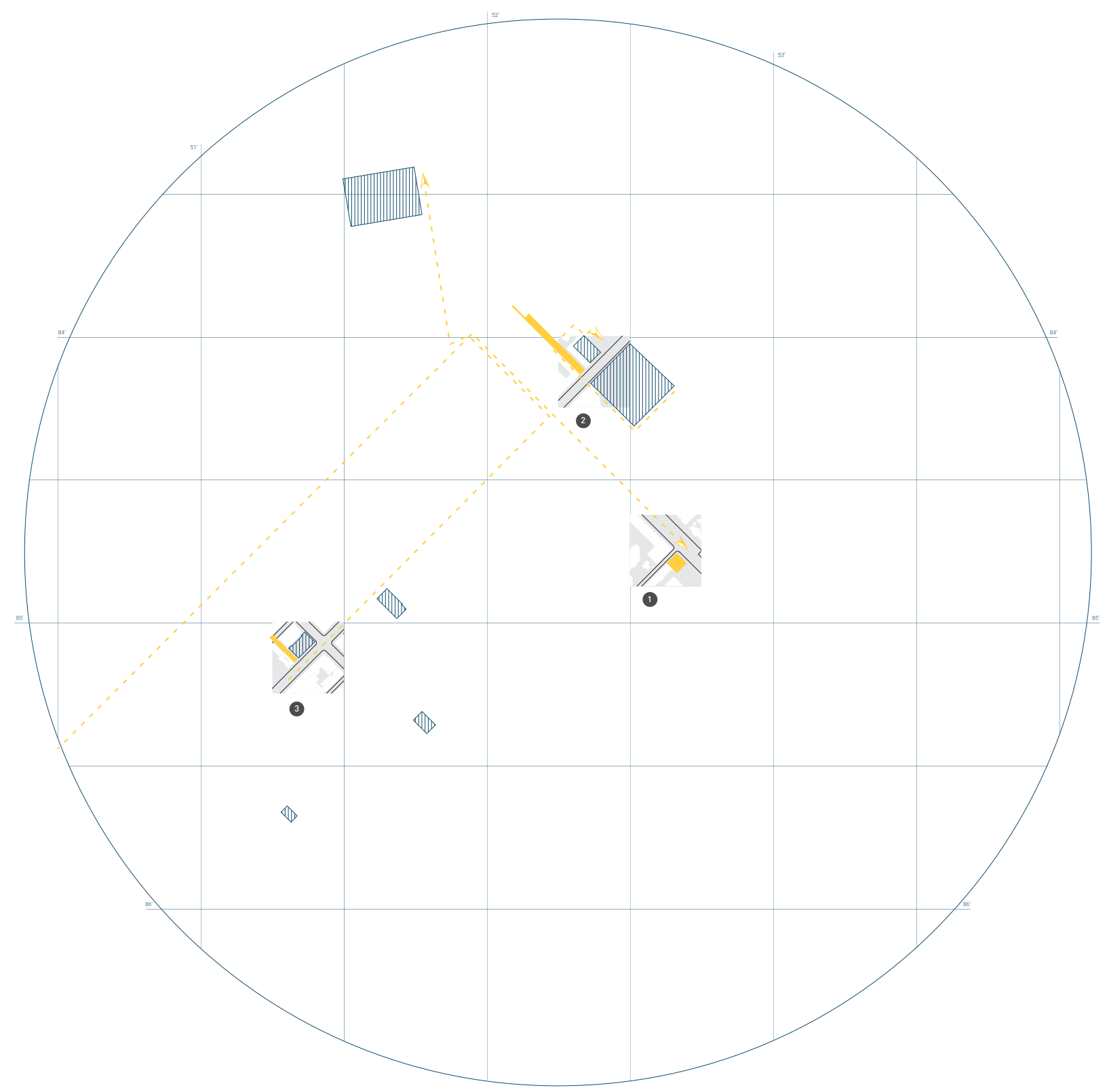


[ Act 1 ] - Separation / Arrival \& Departure

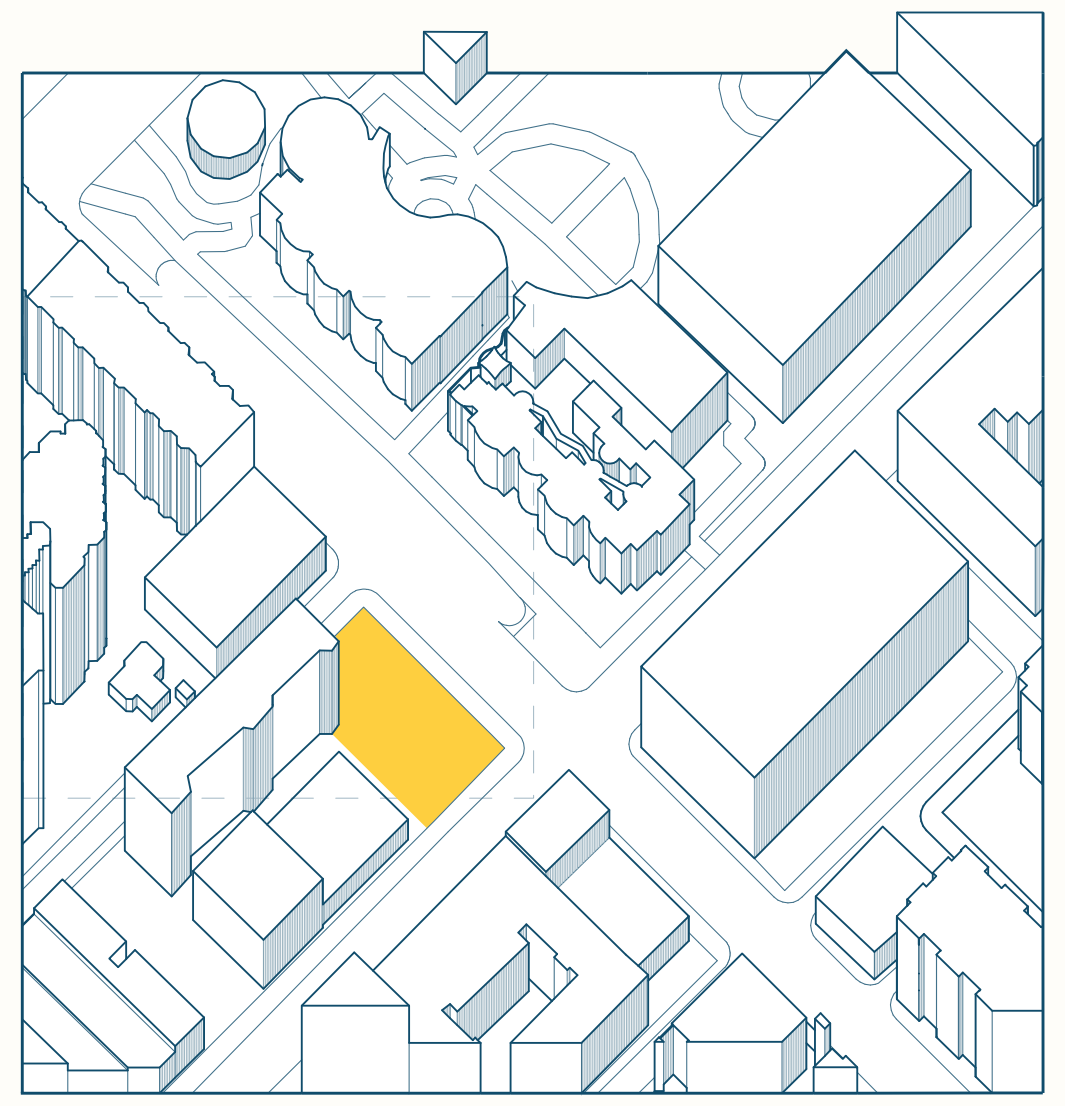




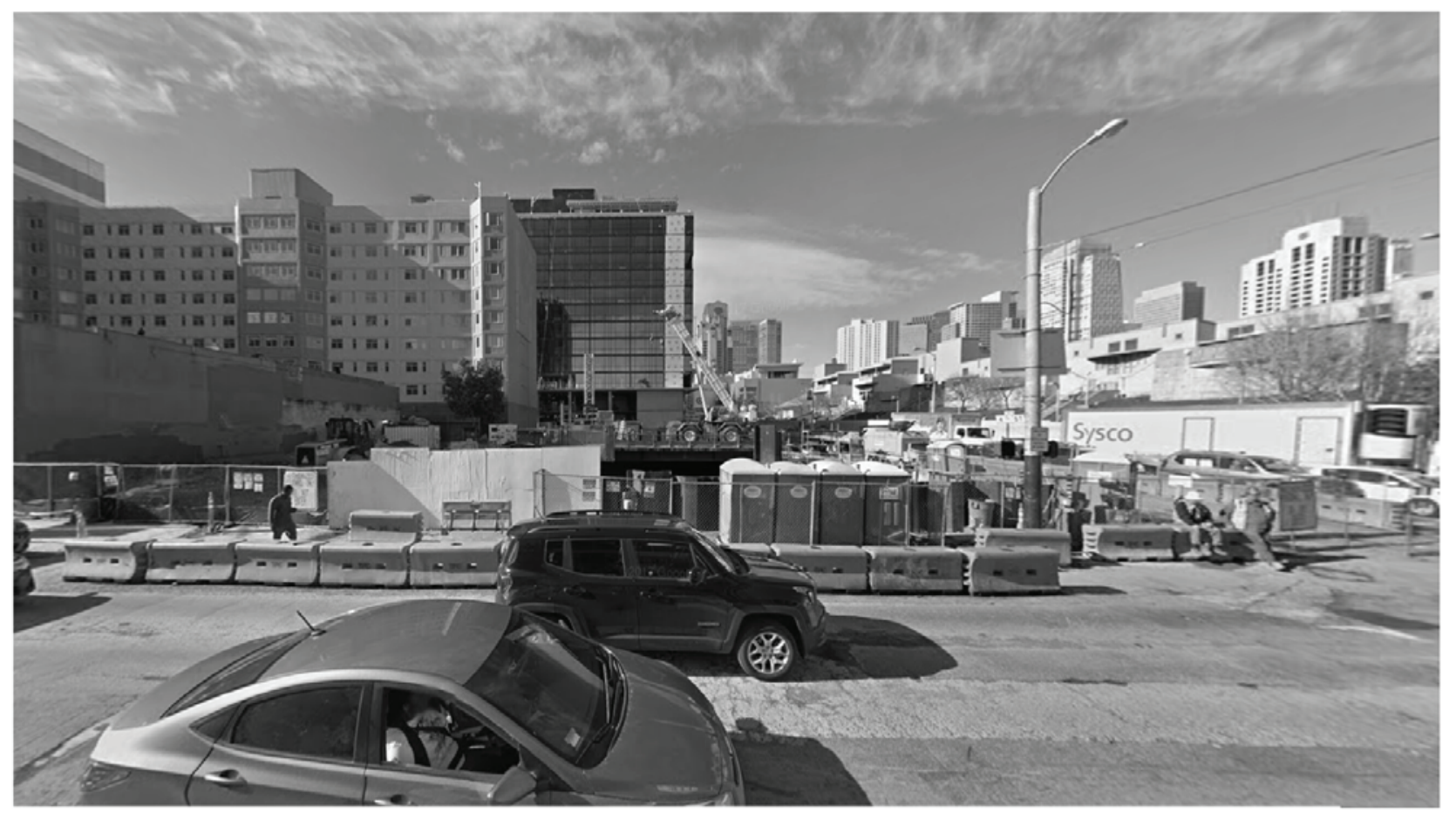


[ Act II ] In-Between / Transition

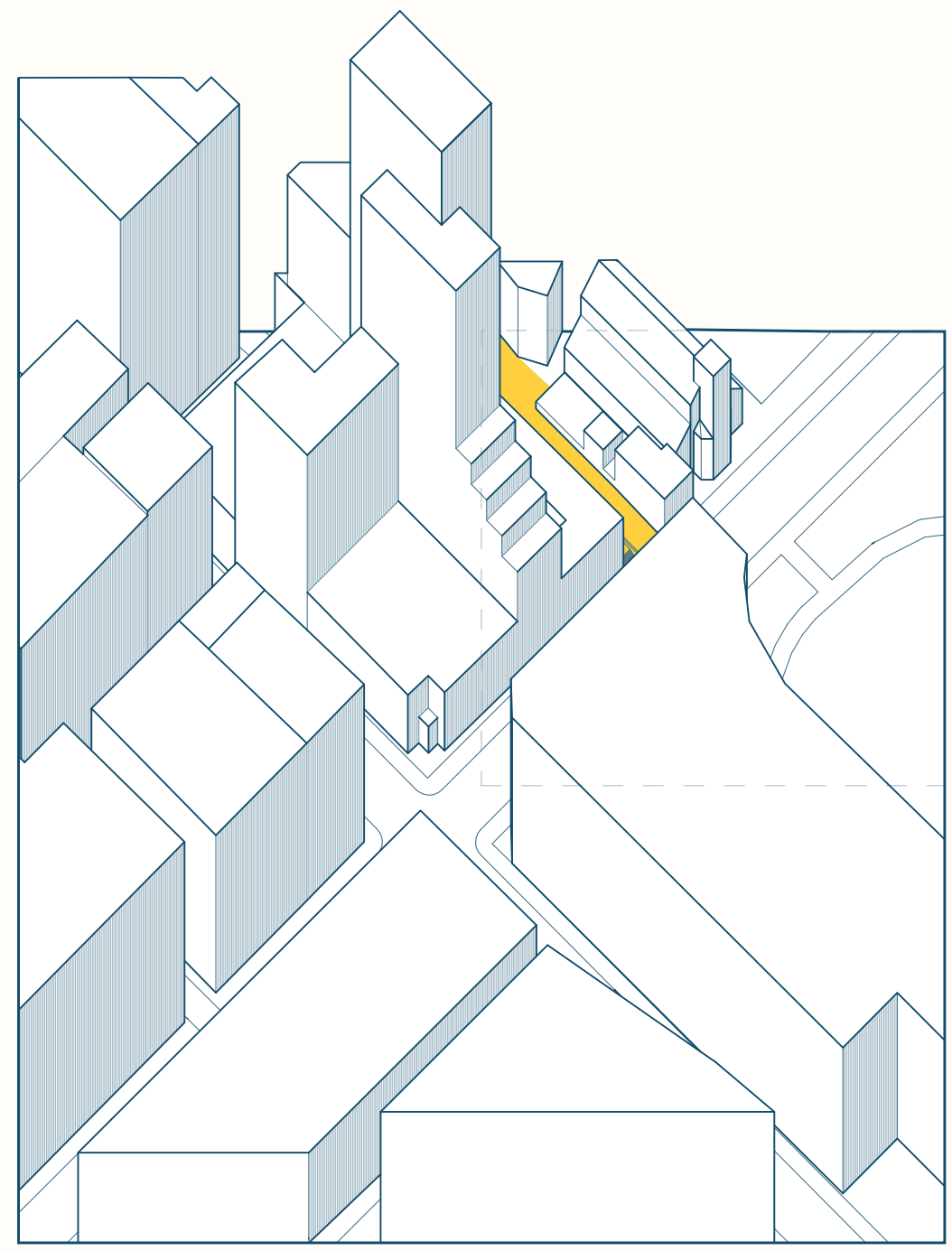




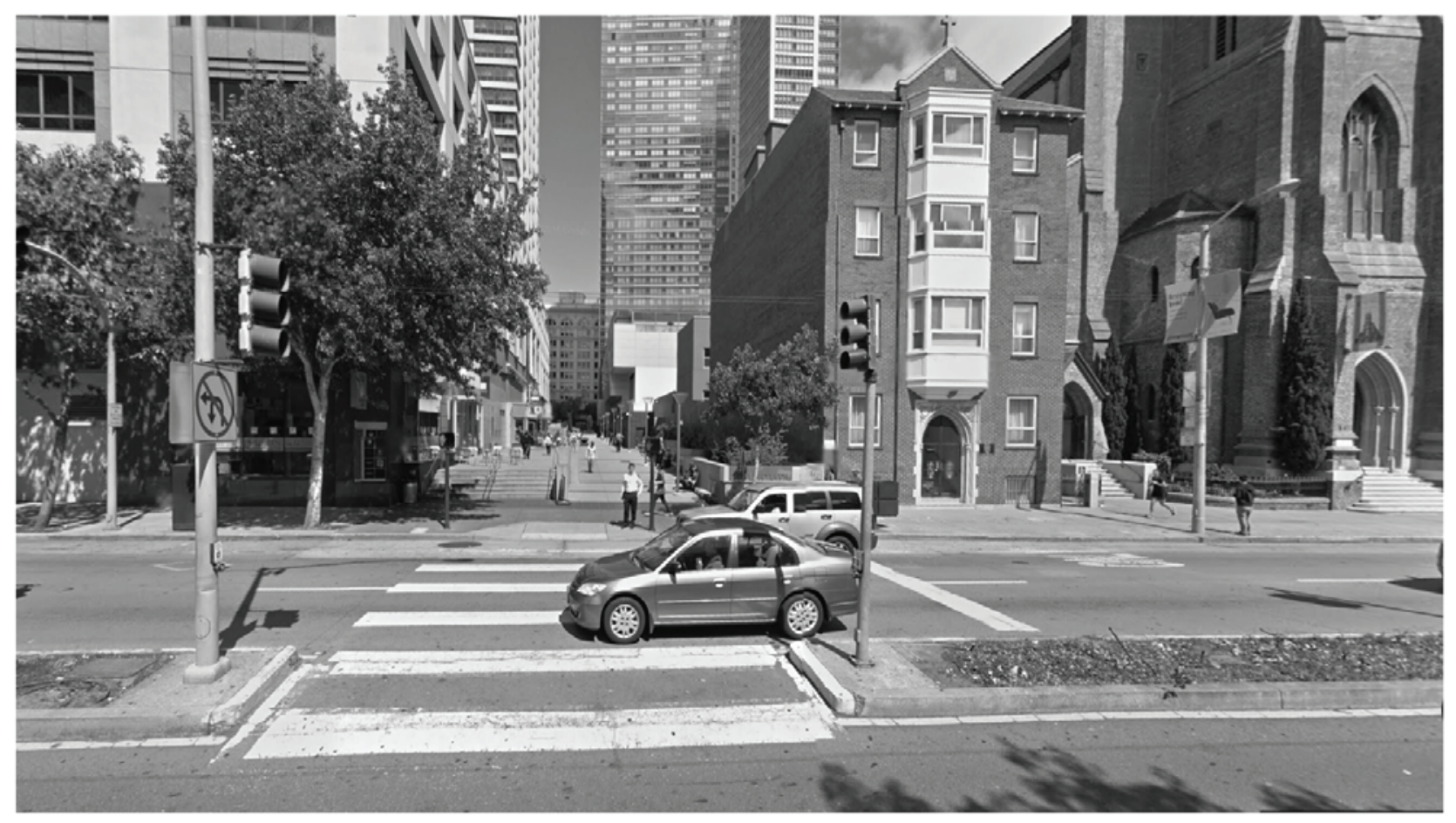


[ Act III ] - Aggregation / Consummation

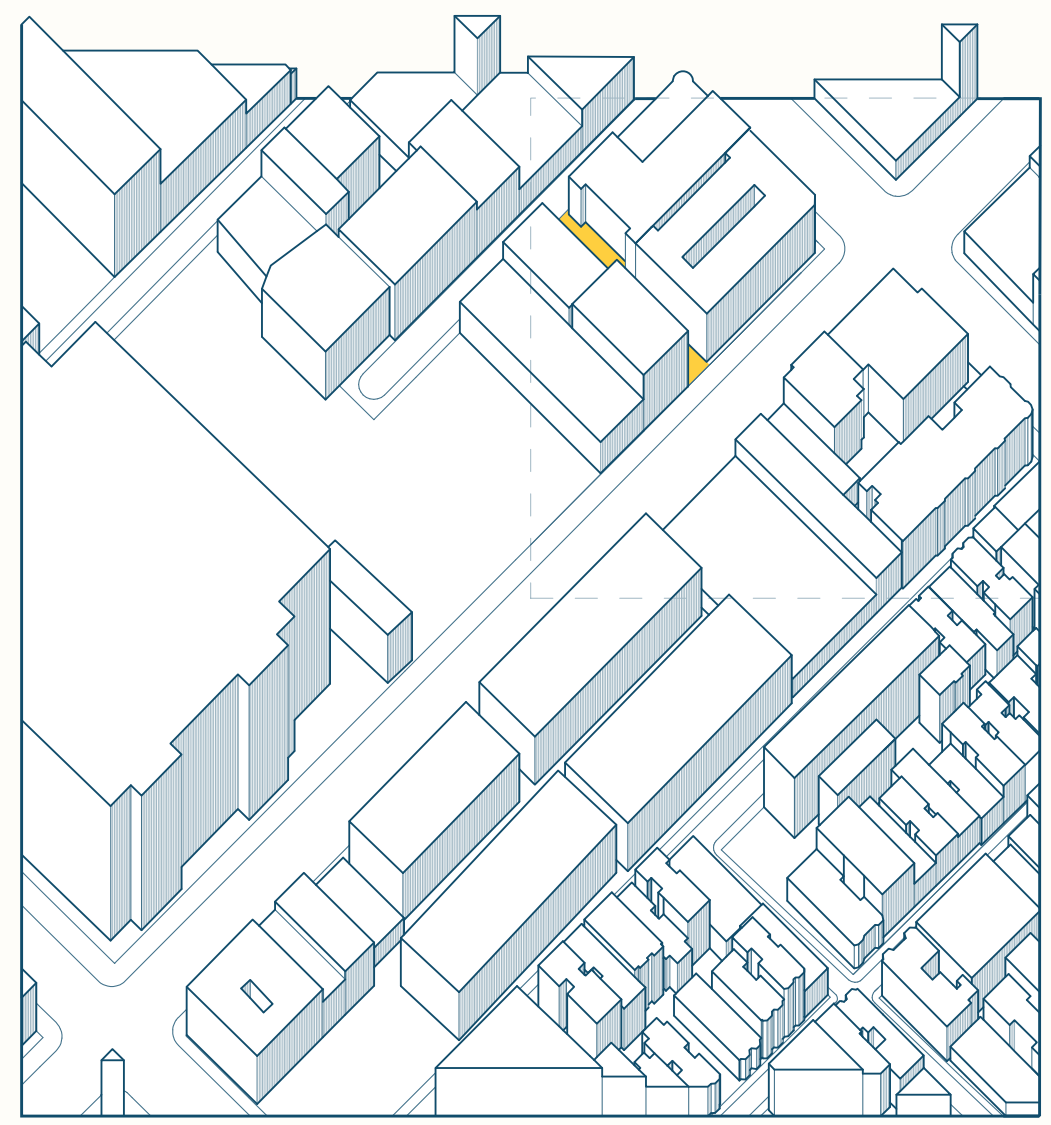




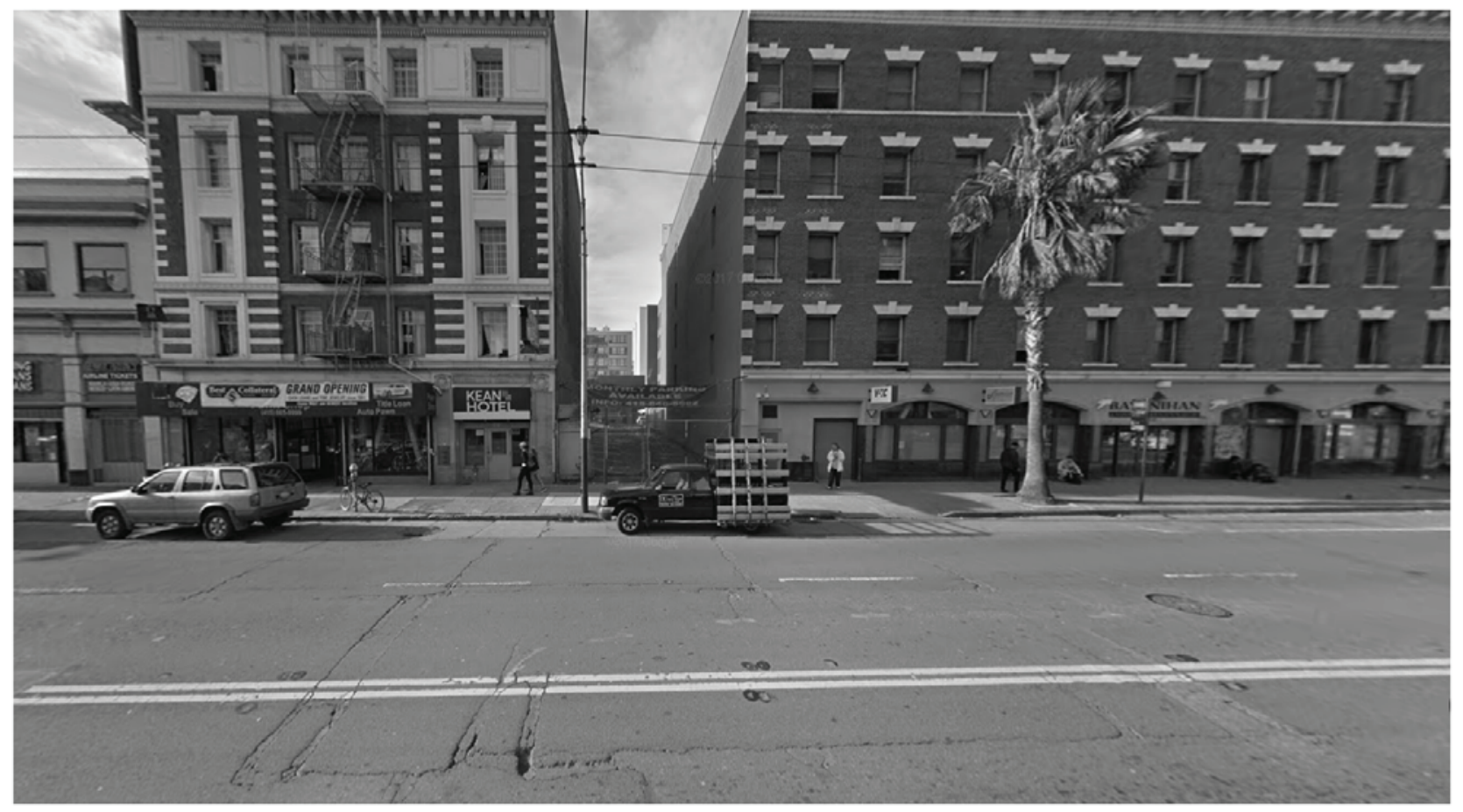




\section{Sites Before Proposals}

The three proposed sites are significant with the translocal cultural landscape of SoMA for their proximity to annual ritual paths and potential as public space.

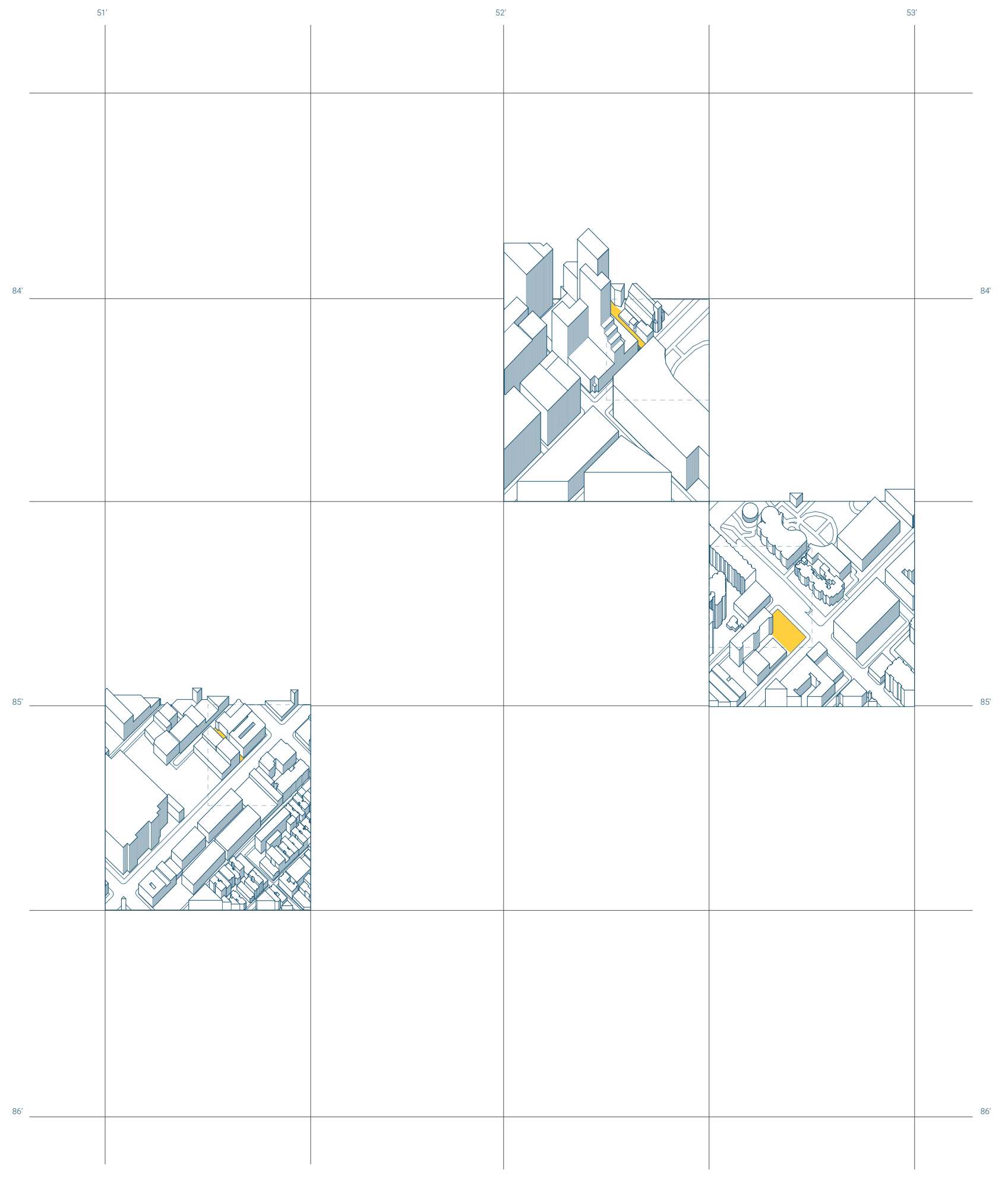


[ Act I] Gen 1.5 \& 2.0

Separation / Arrival \& Departure

Interstitial tactics:

Market

Lobby

Backstage / Front stage

Gate
The relationship between Gen 1.5 \& 2.0 is one defined by their relationship to the hostland and an abstracted notion of "home". Although their ties to the Philippines are less substantial in comparison to Gen 1.o, a contradiction still exists in how they identify with their immediate surroundings. Despite primarily identifying with the hostland they are still "Other" and therefore, "groundless". The proposed tactics is one based in experimentation and expression, as they move towards a new cultural narrative that is not necessarily associated with the homeland.

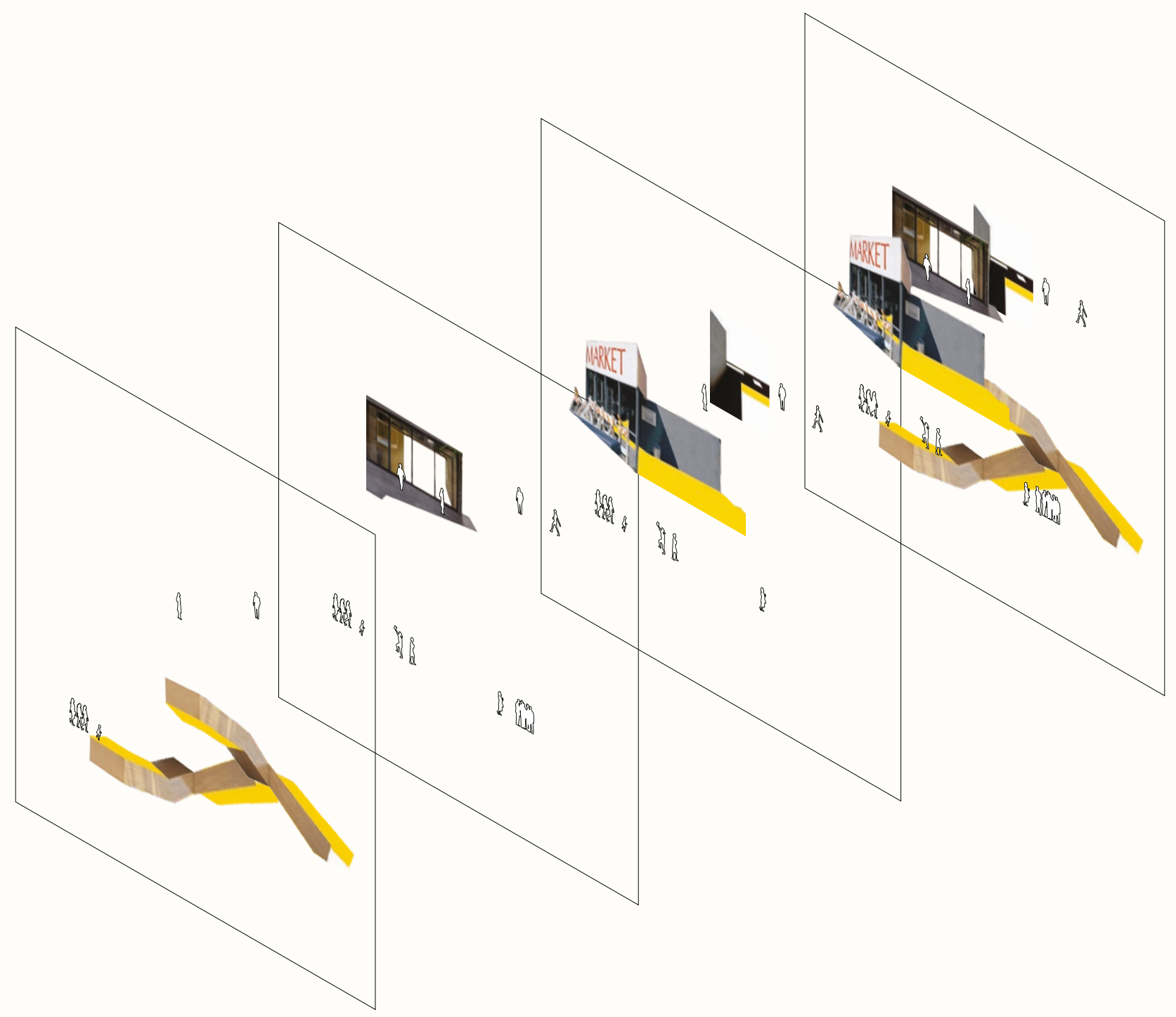


[ Act II ] Gen 1.0 \& 2.0

In-Between / Transition

Interstitial tactics:

Detour

Destination

Exhibit

Orchestra
The conflict between Gen 1.0 \& 2.0 is defined by a diametrically opposed understanding of "home" - both locationally and culturally. To mediate the gap of understanding the tactics that are proposed are based around the program of storytelling. As opposition is the expected behaviour between the generations, the montage expresses moments of both passage and pause.

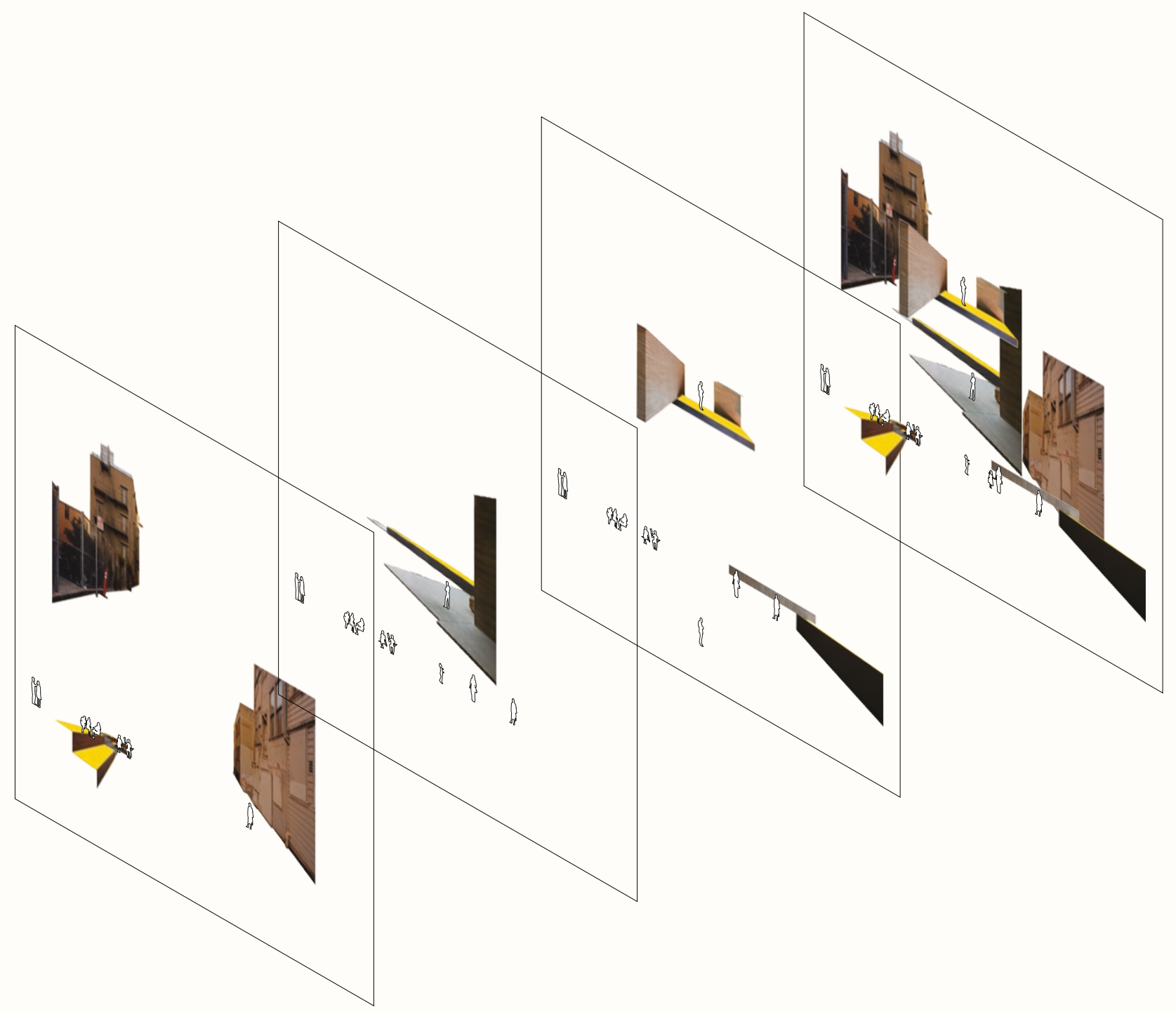


[ Act III ] Gen $1.5 \& 1.0$

Aggregation / Consummation

Interstitial tactics:

Frame

Archive

Confessional

Skene
The relationship between Gen 1.5 \& 1.0 is one rooted in nostalgia and the action of "remembering". The most insular out of the three generational relationships, their conflict is primarily situated in how to frame and distribute the memories of the homeland. Whereas the 1.o generation have a more essentialist perspective, the Gen 1.5 are adaptable in what constitutes Filipino culture. The least accessible of the three generational interactions, the tactics proposed are rooted in the program of viewing and listening, unless invited to engage.

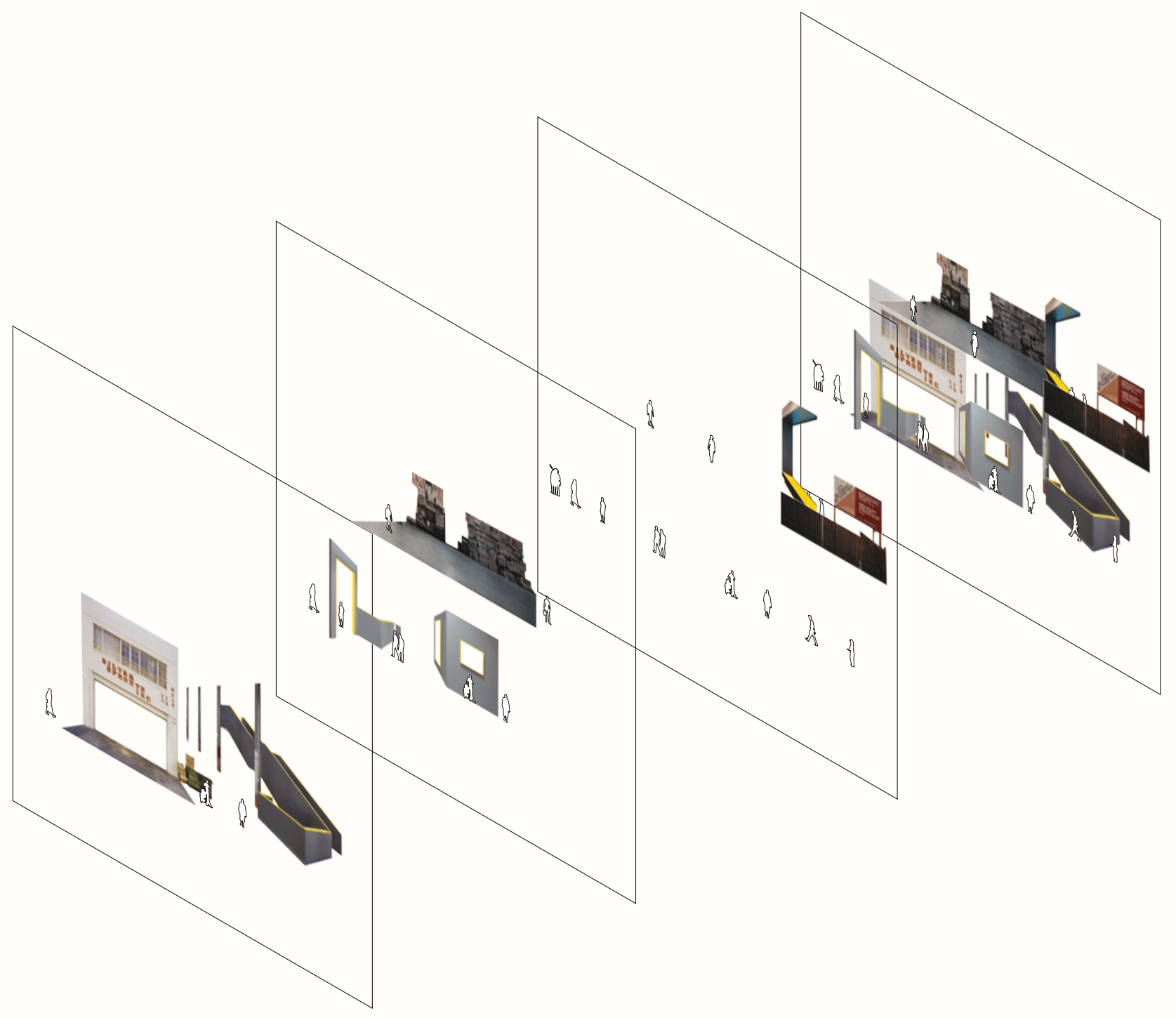




\section{Filipino American History Month}

The original intention of the architectural proposals would be to facilitate the collection and curation of narratives for Filipino American History month acting as a repository to incite dialogue.

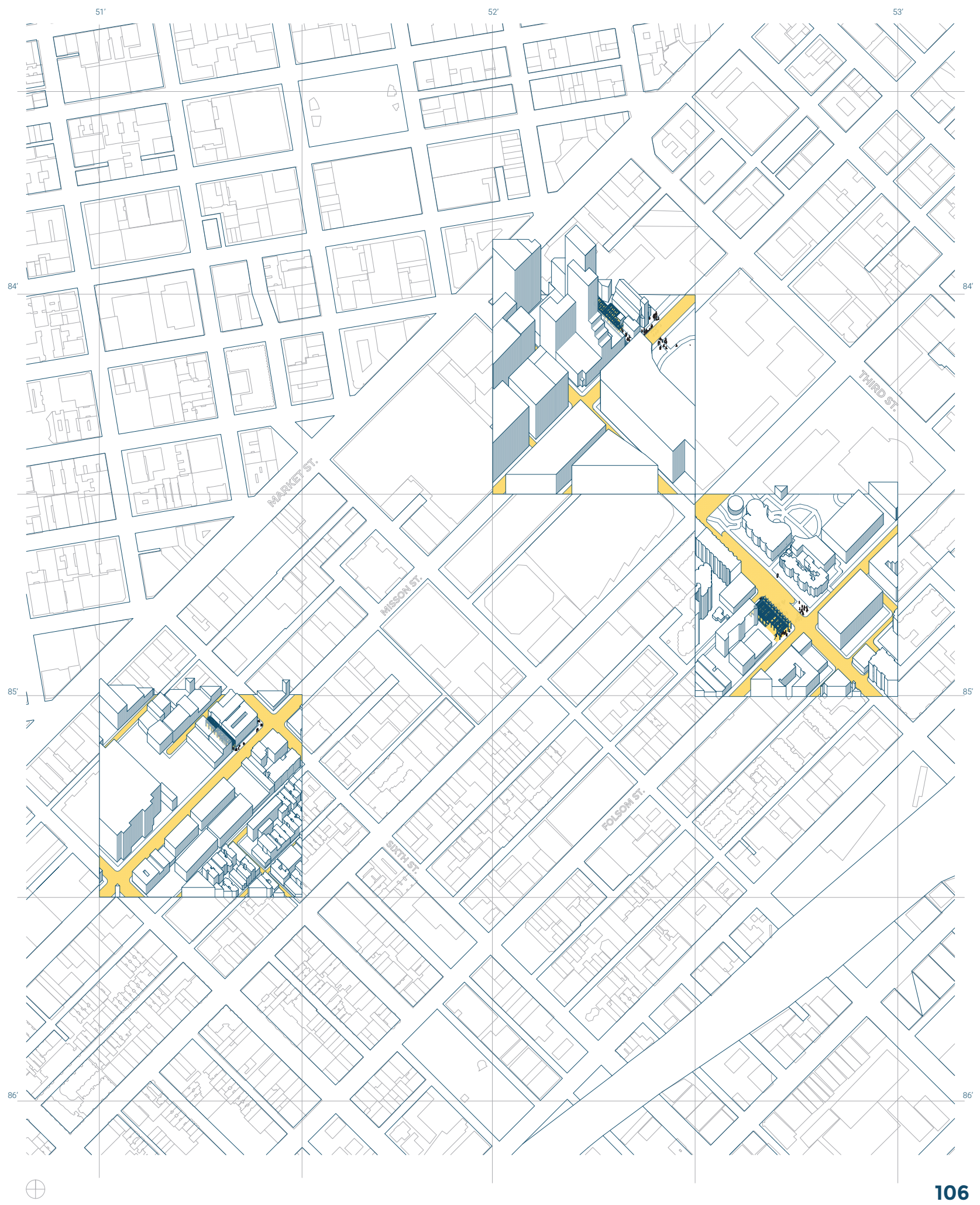




\section{Sites After Proposals}

After the Filipino-American history month celebrations, the structural frameworks would then be appropriated by the community and remain connected by the pre-existing annual ritual paths.

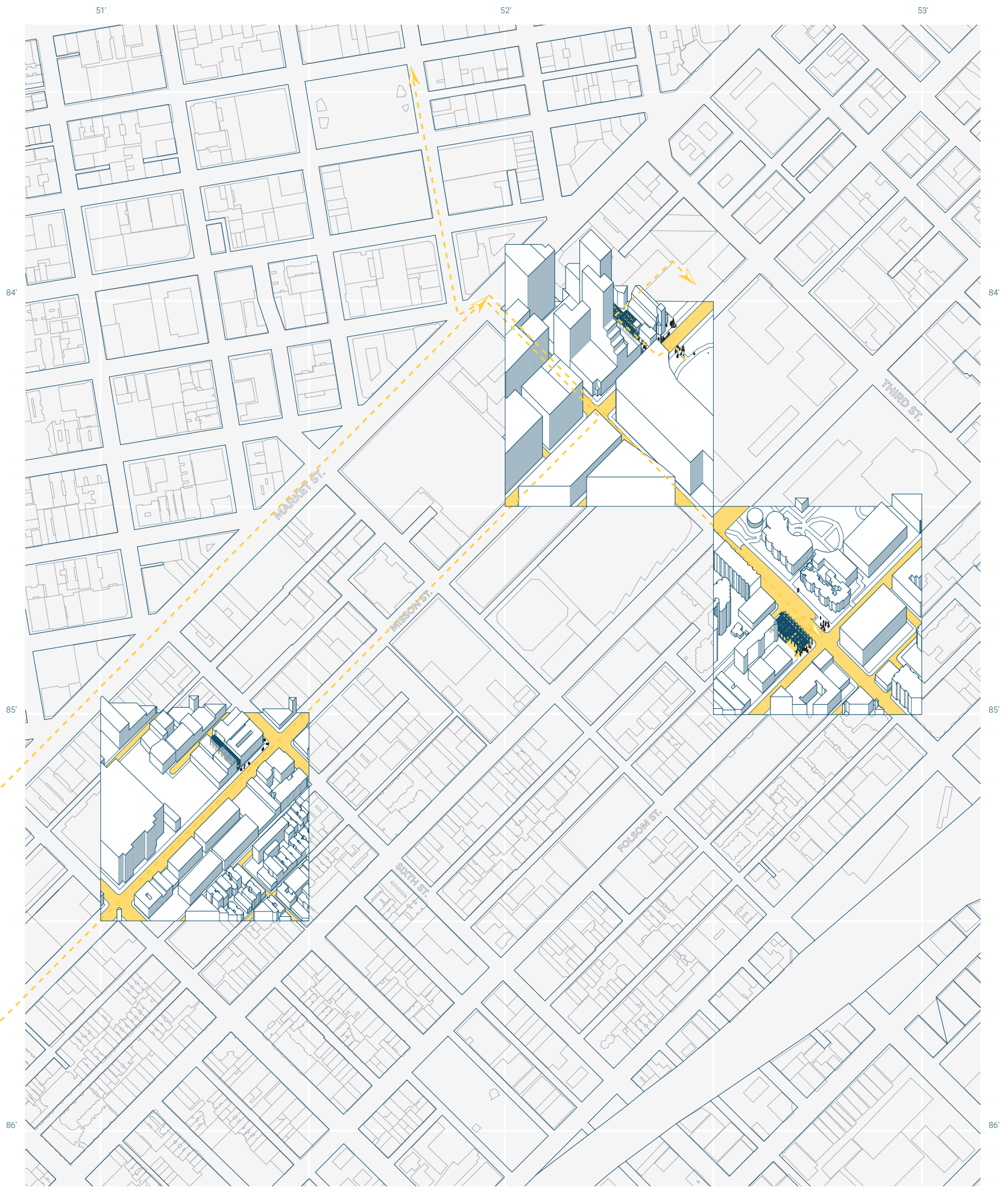


[ Act 1 ] Separation / Arrival \& Departure

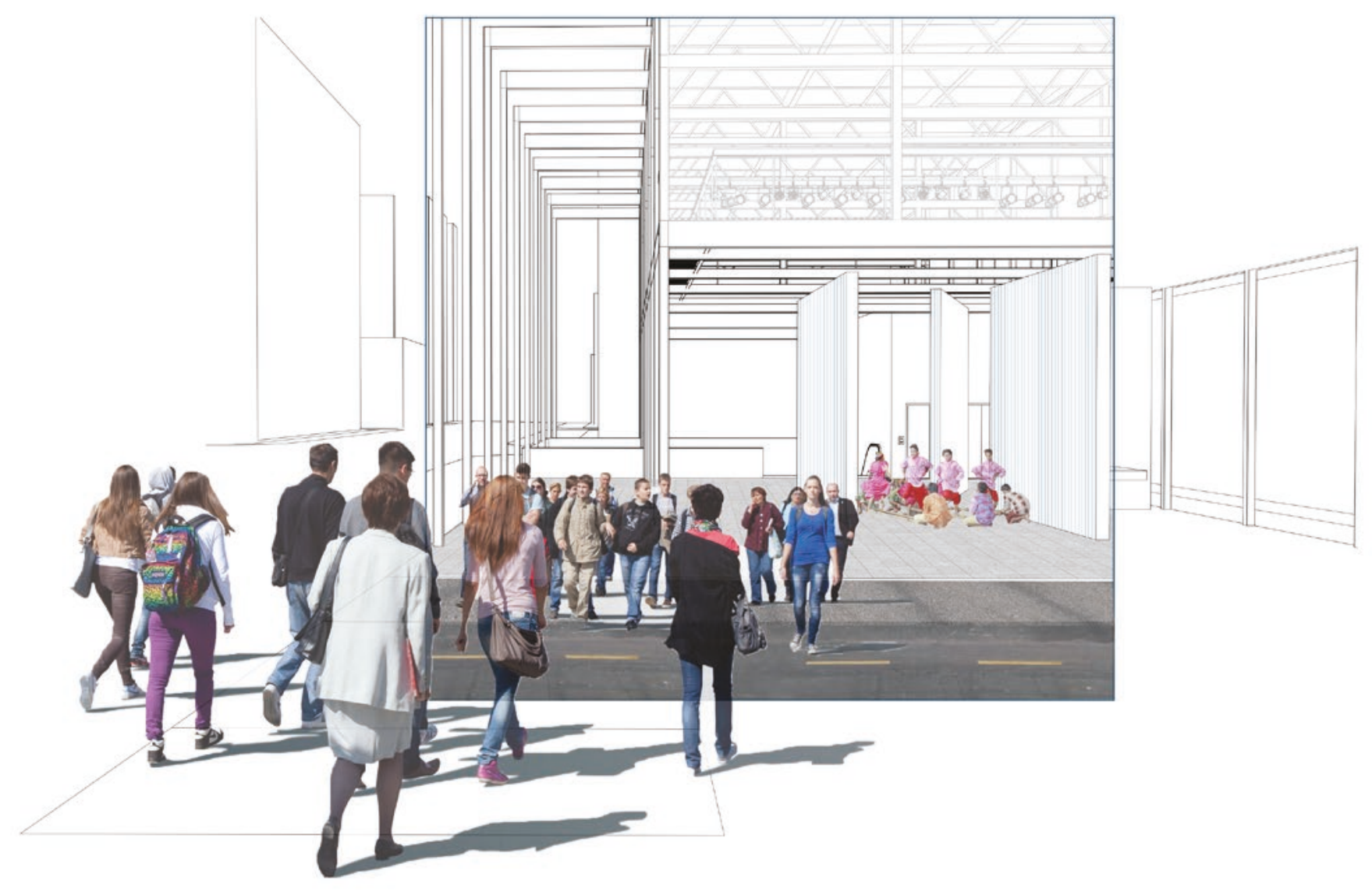


[ Act II ] In-Between / Transition

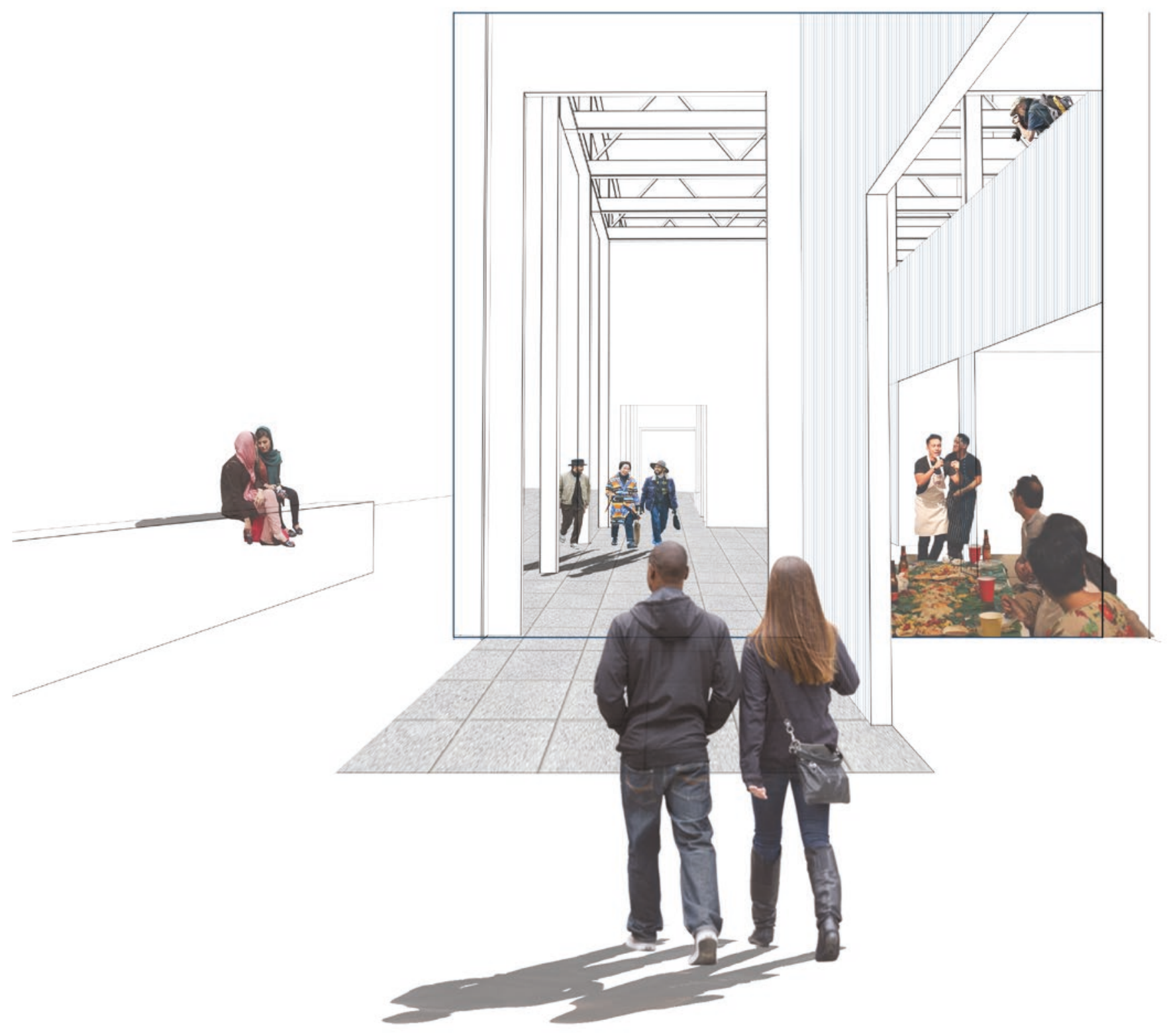


[ Act III ] Aggregation / Consummation

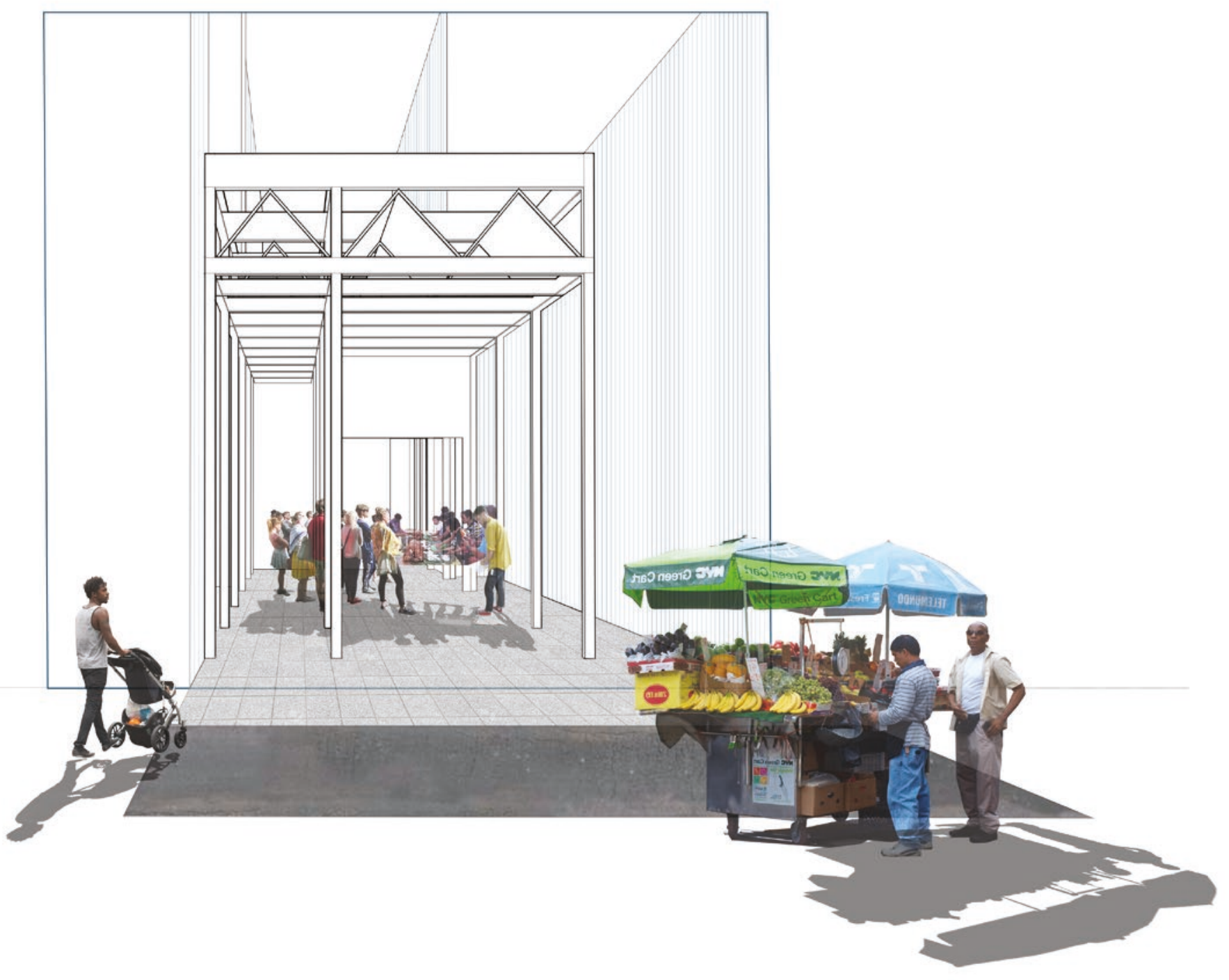




\section{appendix $\mathrm{A}$}




\section{Appendix A - Definitions}


communities will respond to crisis, or to public intervention.

Leonie Sandercock, Cosmopolis II: Mongrel Cities in the 21st Century, (London: Continuum, 2003), p. 188

\section{Cosmopolis}

A term coined by theorist Leonie Sandercock describing a utopian vision of the multi-ethnic, multicultural 21st century city. "...a construction site of the mind and heart, a city in which there is genuine acceptance of, connection with, and respect and space for 'the stranger' (outsider, foreigner...), in which there exists the possibility of working together on matters of common destiny, of forging new hybrid cultures and communities."

Leonie Sandercock, Cosmopolis II: Mongrel Cities in the 21st Century, (London: Continuum 2003), p. 1

\section{Cultural politics of difference}

Distinctive features of the new cultural politics of difference are to trash the monolithic and homogeneous in the name of diversity, multiplicity, and heterogeneity; to reject the abstract, general, and universal in light of the concrete, specific, and particular; and to historicize, contextualize, and pluralize by highlighting the contingent, provisional, variable, tentative, shifting, and changing. The new cultural politics of difference are neither simply oppositional in contesting the mainstream (or malestream) for inclusion, nor transgressive in the avant-gardist sense of shocking conventional bourgeois audiences. Rather, they are distinct articulations of talented (and usually privileged) contributors to culture who desire to align themselves with demoralized, demobilized, depoliticized, and disorganized people in order to empower and enable social action and, if possible, to enlist collective insurgency for the expansion of freedom, democracy, and individuality.

Cornel West, "The New Cultural Politics of Difference," The Humanities as Social Technology, 53 (1990), p.93-94. doi: 10.2307/778917

\section{Diaspora}

The movement, migration, or scattering of a people away from an established or ancestral homeland. Discourses on diaspora use the term in three distinct but related ways:

1. As a social form: refers to individuals who live in different parts of the world but identify collectively with one another; 2 . As a type of social consciousness: refers to individuals who live in a variety of societies and cultures and who emphasize their sense of belonging or exclusion, their states of mind, and their sense of identityl 3. As a mode of cultural production: refers to the reproduction of cultural 
phenomena through creolization and hybridization.

Vijay Agnew, Diaspora, Memory and Identity: A Search for Home, (Toronto: University of Toronto Press, 2005), p.5

\section{Ethnocultural differences}

Ethnocultural differences are used to ascribe dominant- and nondominant-group membership status. The dominant group may then use its power to determine access to things of value in the society. This differential access, based in part on cultural characteristics, maintains and reinforces boundaries between distinct groups and hence creates an "us-them" mentality. This in turn becomes critical in the development of interethnic tensions, stereotyping, racism, and discrimination.

Howard C. Blue and Carlos A, Gonzalez, The Meaning of Ethnocultural Difference: Its Impact on and Use in the Psychotherapeutic Process, 55 (1992), p. 74. doi: 10.1002/yd.23319925508.

\section{Governmentality}

A three fold-concept introduced by Michel Foucault:

1. The ensemble formed by institutions, procedures, analyses and reflections, calculations, and tactics that allow the exercise of this very specific, albeit very complex, power that has the population as its target, political economy as its major form of knowledge, and apparatuses of security as its essential technical instrument; 2 . The tendency toward preminence of "government" in the west over other forms of power (sovereignty, discipline, etc), leading to the creation of specific governmental apparatuses and knowledges; 3 . The gradual governmentalization of the administrative state.

Michel Foucault, Security, Territory, Population: Lectures at the College de France 1977-1978. (Surrey: Picador Publishing, 2009), p.108

\section{Homeland/hostland}

One of the three dualities that lie at the heart of the inherent betweenness of diaspora according to sociologist Anne-Marie Fortier. The other two are "here and there" and "indigenousness and foreignness".

Anne-Marie Fortier, Migrant Belongings: Memory, Space, Identity, (London: Bloomsbury Academic, 2000), p. 160

\section{Intercultural co-existence}

The willingness of host society and immigrant groups and individuals to work together across cultural divides without the fear of losing their own identity [...] one of the roles of urban policy and urban planners is to create the physical and discursive spaces for such debates and renegotiations of collective identity." 
Leonie Sandercock, Cosmopolis II: Mongrel Cities in the 21st Century, (London: Continuum, 2003), p. 151.

\section{Indigenous/foreigness}

One of the three dualities that lie at the heart of the inherent betweenness of diaspora according to sociologist Anne-Marie Fortier. The other two are "here and there" and "homeland/ hostland".

Anne-Marie Fortier, Migrant Belongings: Memory, Space, Identity, (London: Bloomsbury Academic, 2000), p. 160.

\section{Living together}

Conceptualization, rationalization and management of cultural difference, reflects a notion of culture as 'national cultural of difference'. They reflect processes of categorization based on the nation-state as a fundamental cultural 'container' that can be represented by such markings of 'difference' as national costume, cuisine or decorative styles. Such national categorizes [...] are inadequate to describe the differences that exist on the ground.

Greek Colombijn and Aygen Erdentug, Urban Ethnic Encounters: The Spatial Consequences, (London: Routledge Publishing, 2002), p. 189.

\section{Locality}

The socio spatial dimension of human experience. Speaking of locality highlights the processes of the restructuring and rescaling of capital production that [...] must be addressed in examining migrants' processes of settlement and transnational connection.

Ayse Caglar and Nina Glick Schiller, Locating Migration: Rescaling Cities and Migrants, (London: Cornell University Press, 2011), p.63.

\section{Mahiya}

Tagalog. Someone who feels embarrassment or shame.

\section{Micro-publics}

The contact spaces of housing estates and public places fall short of nurturing inter-ethnic understanding, he argues, 'because they are not spaces of interdependence and habitual engagement ... sites for coming to terms with ethnic (and surely other) differences are the 'micro-publics' where dialogue and prosaic negotiations are compulsory (workplace, schools, colleges, youth centres, sports clubs, community centres, neighbourhoods houses, and the 'micro-publics' of banal transgressions (community gardens, childcare facilities, neighbourhood watch schemes, youth projects, regeneration of derelict spaces. A term coined by geographer Ash 
Amin.

Leonie Sandercock, Cosmopolis II: Mongrel Cities in the 21st Century, (London: Continuum, 2003), p. 94.

\section{Migration}

Within the scope of research in this thesis a cultural model of migration is used. A cultural mode of migration [...] emphasizes the dynamics of a culture of migration (not the decisions of individual migrants - what is best thought of as a micro-level approach nor a focus on national outcomes - a macro-level analysis). We attempt to understand migration - or, better put, mobility - from the perspective of cultural and social practices... It is critical to realize that regardless of the moves a migrant makes, the decision are framed within a larger social field than the individual - and for us that is the household.

Jefferey H. Cohen and Ibrahim Sirkeci, Cultures of Migration,. (Austin: University of Texas Press, 2011), p. 17.

\section{National cultural difference}

See "Living together".

\section{New Society}

A term used by authoritarian dictator Ferdinand Marco's as a form of propaganada to describe Philippine society under Martial Law. In contrast to the pre-Marcos "Old Society".

Alice Jade A. Albur, Box Populu: A Socio-Cultural Study Of The Filipino American Balikbayan Box, (St John's: Memorial University of Newfoundland, 2002), p. 66

\section{"The Other"/"Self"}

The binary of self and other is perhaps one of the most basic theories of human consciousness and identity, claiming, in short, that the existence of an other, a not-self, allows the possibility or recognition of a self. In other words: I see you. I do not control your body or hear your thoughts. You are separate. You are not me. Therefore, I am me. The self/other binary seems to be an accepted division of how the modern individual comprehends who s/he is, by recognizing what $s /$ he is not. Origin of self/other binary rooted in school of phenomenology and philosopher Edmund Husserl.

Sami Shalk, "Self, Other and Other Self: Going Beyond the Self/Other Binary in Contemporary Consciousness", Journal of Comparative Research in Anthropology and Sociology. 2, no. 1. (2011), p.1. ISSN $2068-0317$.

\section{Pasalubongs}

Tagalog. Gifts given when returning from a trip 


\section{Proxemic}

The study of how human beings communicate through their use of space. Coined by anthropologist Edward T. Hall. The spatial dimension of nonverbal behavior.

Edward T. Hall, The Hidden Dimension, (New York: Anchor Books, 1969), p, 122.

\section{Pure Identity}

Identity and difference than are an intertwined and always historically specific system of dialectical relations, fundamental to which is inclusion, and its opposite exclusion [...] The politics of pure identity seeks to eliminate the Other, the politics of difference seeks recognition and inclusion.

Leonie Sandercock, Cosmopolis II: Mongrel Cities in the 21st Century, (London: Continuum, 2003), p. 98.

\section{Rational city/Mongrel city}

[Mongrel Cities] refer to the demographic restructuring which many cities and regions in the industrialized countries have been experiencing for the past several decades and [...] four major sociocultural factors which have been and will continue to re-shape cities and regions in the 21 st century.

1. International migration - politics of 'multicultural citizenship'

2. Discourse of postcolonialism and unresolved postcolonial condition in the West

3. Resurgence of indigenous people and associated politics of reclaiming their land

4. Rise of organized civil society and the new politics of social movements.

Contributes to a new cultural politics of difference that is undermining the rational city - which represents modernist notions of technical rationality providing order, coherence, regulation, homogeneity.

Leonie Sandercock, Cosmopolis II: Mongrel Cities in the 21st Century, (London: Continuum, 2003), p. 3

\section{Sacred spaces}

Identifying sacred spaces in the urban landscape ... reveals the connections between place and collective identity, which are at the heart of [the other] experience of the city.

Leonie Sandercock, Cosmopolis II: Mongrel Cities in the 21st Century, (London: Continuum, 2003), p. 226

\section{Spaces of insurgent citizenship}


These struggles over belonging take the form of struggles over citizenship, in its broadest sense, of rights to and in the polis ... these sites of these struggles [are called] "spaces of insurgent citizenship"

Leonie Sandercock, Cosmopolis II: Mongrel Cities in the 21st Century, (London: Continuum, 2003), p. 21.

\section{South of Market}

South of Market can refer to the sixth supervisorial district of San Francisco (which includes the neighbourhoods of the Tenderloin, Mission Bay and South of Market) or the relatively large neighbourhood of the same name (which contains subneighbourhoods including South Beach and Rincon Hill)

\section{Translocal social spaces}

Translocal social space result from new forms of delimitation that consist of but also reach beyond geographic or national boundaries. These spaces become the new sources of identification and action within specific local and global reference systems. However, this does not imply a local determinist position that denies agency to migrants. It is the migrants who also shape the conditions of the local. They contribute to the upgrading of certain cities and certain urban districts and zones.

Leonie Sandercock, Cosmopolis II: Mongrel Cities in the 21st Century, (London: Continuum 2003), p. 171

\section{Transmigrants}

Transmigrants as agents of change "across entire transnational fields" - effecting transformations across a wider transnational social field.

Leonie Sandercock, Cosmopolis II: Mongrel Cities in the 21st Century, (London: Continuum, 2003), p. 13

\section{Transnationalism}

Process at which migrants create social fields that cross national boundaries.

Leonie Sandercock, Cosmopolis II: Mongrel Cities in the 21st Century, (London: Continuum, 2003), p. 12

\section{Transnational migrant groups}

Transmigrants migrant groups are confronted with and engaged in nation-building processes of two or more nations as the link between geographic space and social identity has been disrupted. 
Leonie Sandercock, Cosmopolis II: Mongrel Cities in the 21st Century, (London: Continuum, 2003), p. 12.

\section{Treaty of Paris}

A formalized agreement signed between the United States and Spain in December 1898 which ceded the Philippines to the United States after the Spanish-American War.

Alice Jade A. Albur, Box Populu: A Socio-Cultural Study Of The Filipino American Balikbayan Box, (St John's: Memorial University of Newfoundland, 2002), p. 27

\section{Urban Cultural Landscape}

Urban cultural landscapes are storehouses for individual and collective social memories. Moving beyond the familiar architectural approach to cultural heritage which favors individual buildings, a deeper understanding of the entire urban cultural landscape as an important part of American history, emphasizes the social and political meanings of vernacular buildings; ending the invisibility of the history of all but the white Anglo occupiers; and connecting the history of struggle over urban space with 'the poetics of occupying particular places.

Leonie Sandercock, Cosmopolis II: Mongrel Cities in the 21st Century, (London: Continuum, 2003), p. 12. 
appendix B 
[ Ritual Process Postcards ]
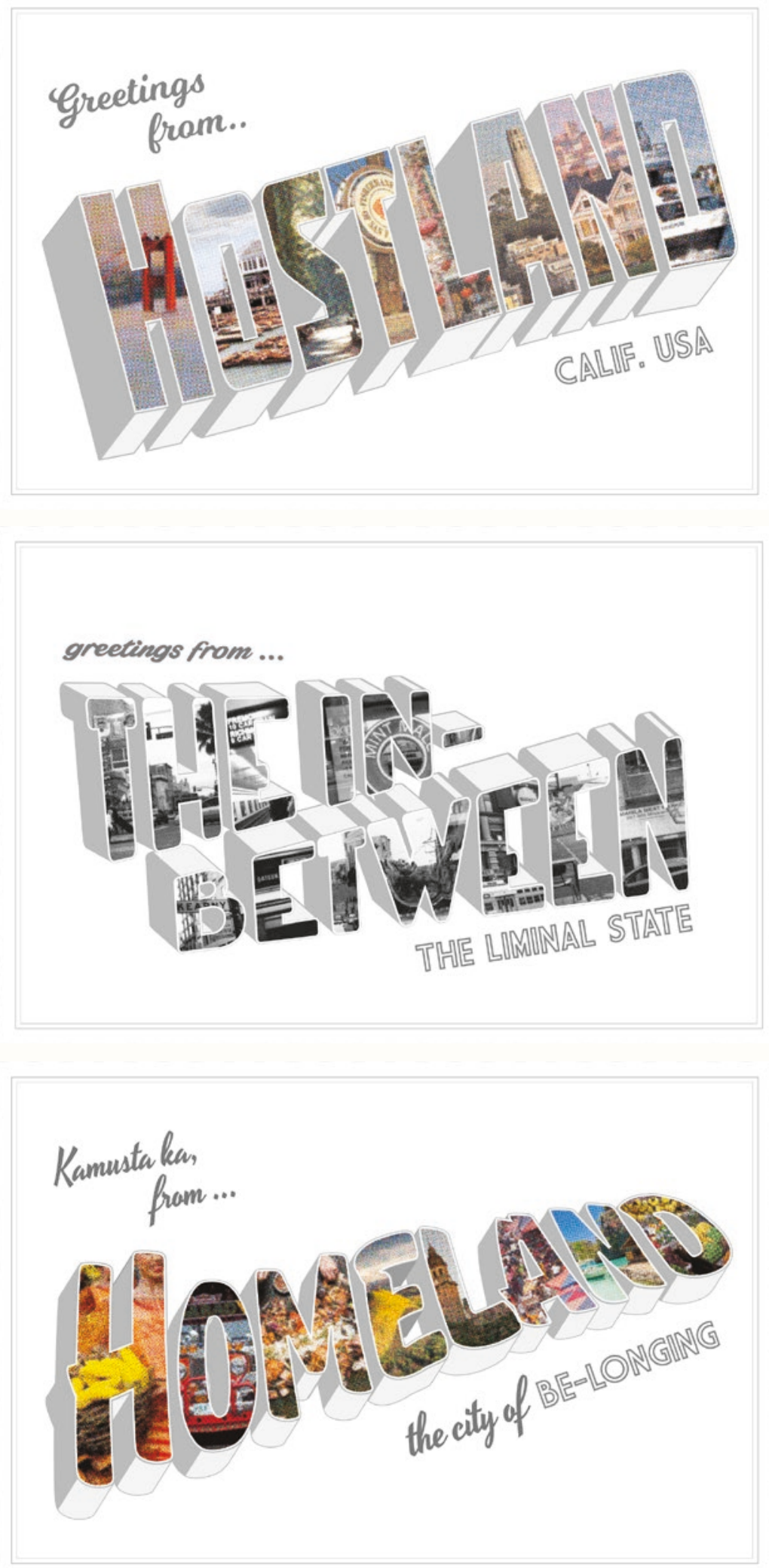


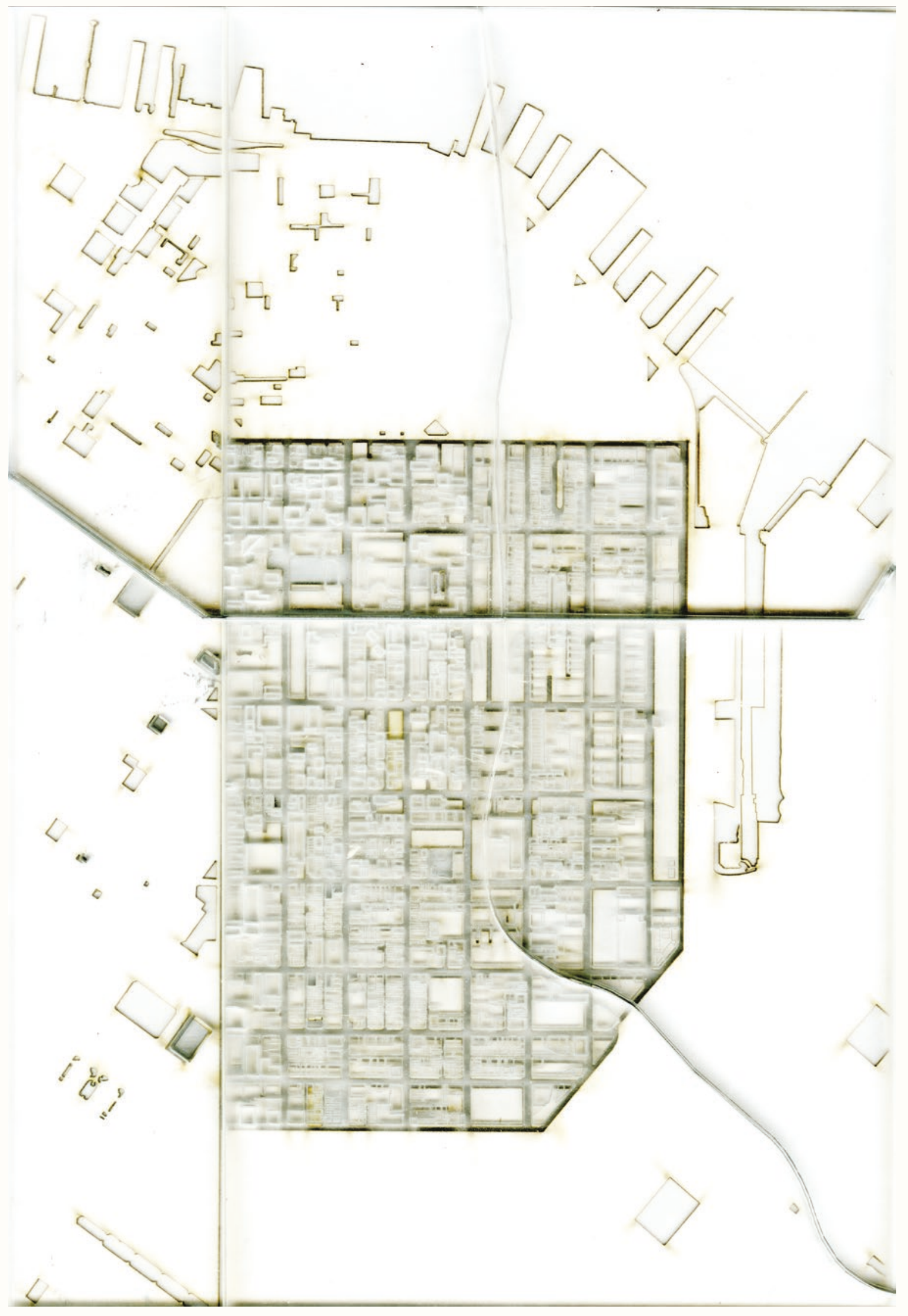




\section{[ 1 to 50 ] Collage/Decoupage Process}

In assembling the three photomontages for the "1 to 50" exercise, I utilized photographs from an exhibition by Janet Delaney - a Berkeley based photographer. Janet's series of images captured the South of Market neighbourhood at a point of significant transition - making use of contrast to do so. In assembling the decoupage, I utilized architectural aspects from these images to construct new spaces, informs the seams inbetween and to maintain a consistant morphology without accentuating a specific location.

The additional collage pieces were collected from contemporary architectural works within and around the Bay Area in an effort to maintain a consistent morphology
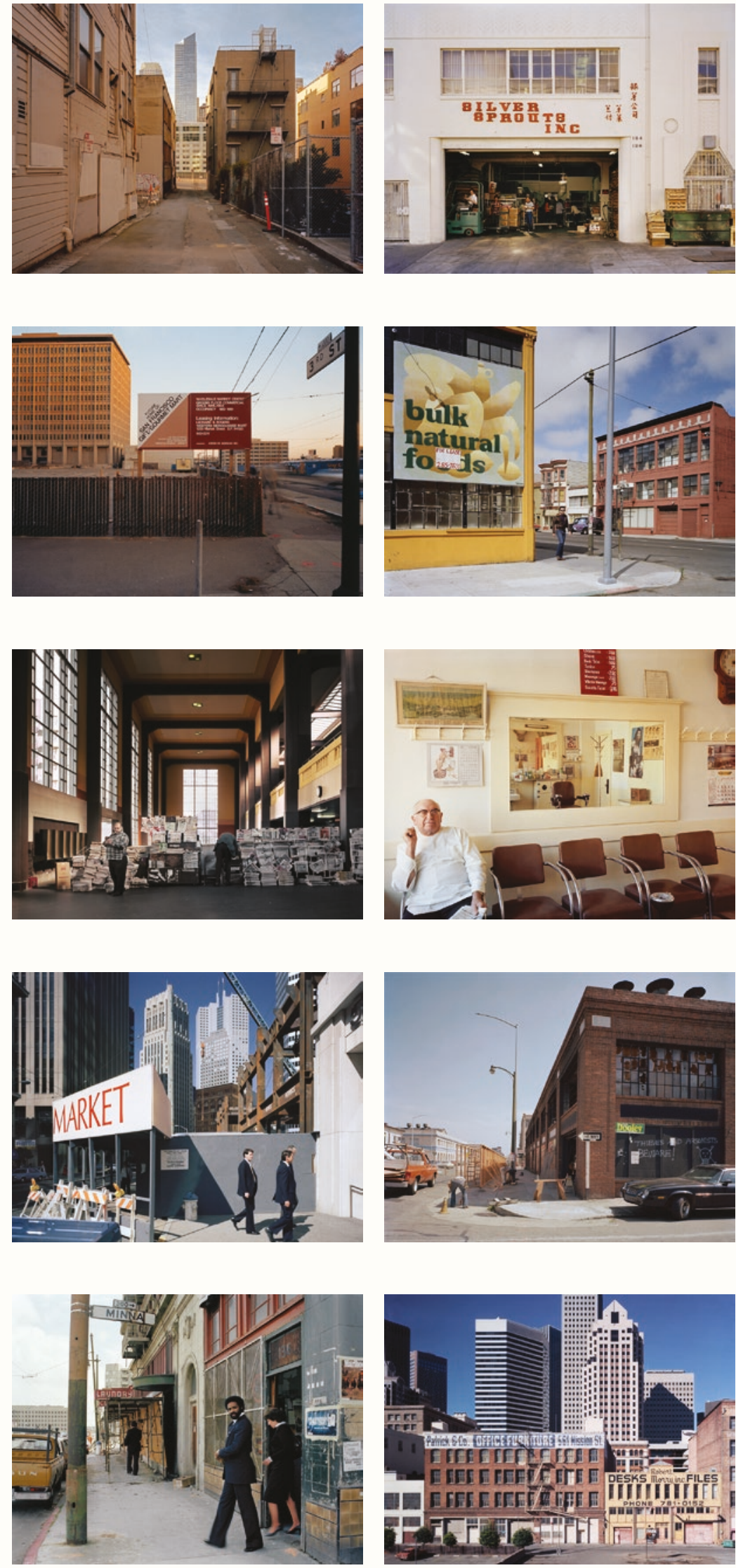


\section{bibliography}

"Filipino Americans Make a New Name for Their San Francisco Neighbourhood." Centre for Asian American Media. Last modified Oct 6, 2016., http://caamedia.org blog/2016/10/05/filipino-americans-make-a-new-name for-their-san-francisco-neighborhood/.

"Images of America Series: Filipinos in San Francisco." Filipino American National Historical Society. Mount Pleasant: Arcadia Publishing, 2011.

"SoMA, Tenderloin Activists Suing San Francisco over 5M Project Approvals". Hoodline San Francisco. Last modified Jan 7, 2016. http://hoodline.com/2016/01/soma-tenderloin activists-suing-san-francisco-over-5m-project-approvals.

"SoMA Filipino Community Divded on Costs, Benefits of 5M Development", Hoodline San Francisco. Last modified Jan. 10, 2016. http://hoodline.com/2016/01/soma filipino-community-divided-on-costs-benefits-of-5m development.

"South Of Market (SOMA) Neighborhood in San Francisco, California (CA), 94103 Detailed Profile." City-Data com, Accessed March 20, 2017. http://www.city-data $\mathrm{com} /$ neighborhood/South-Of-Market-San-FranciscoCA html.

"San Francisco Neighbourhoods Socioeconomic Profiles 2011." San Francisco Planning Department. Accessed March 20, 2017. http://sf-planning.org/sites/default/files FileCenter/Documents/8501 SFProfilesByNeighborhoodForWeb.pdf.

Alice Jade A. Alburo. Box Populu: A Socio-Cultural Study Of The 
Filipino American Balikbayan Box. St John's: Memorial University of Newfoundland, 2002.

Alison B. Hirsch and Aroussiak Gabrielian. "Grounding

Diaspora: Negotiating Between Home and Host.

"Journal of Architecture Education. 70, no.1 (2016): 116

131. doi: 10.1080/10464883.2016.1122468.

Ayse Caglar and Nina Glick Schiller. Locating Migration: Rescaling Cities and Migrants. London: Cornell University Press, 2011

Benito Vergara. Pinoy Capital: The Filipino Nation in Daly City. Philadelphia: Temple University Press, 2008.

Bruno Latour. Where Are The Missing Masses? Cambridge: MIT Press, 1992.

Charles Joyner. Shared Traditions: Southern History and Folk Culture. Urbana: University of Illinois, 1999.

Daniel Miller. Alienable Gifts And Inalienable Commodities, In The Empire of Things. Sante Fe: School of American Research, 2001.

Edward T. Hall. The Hidden Dimension. New York: Anchor Books, 1969.

Filomeno V. Aguilar Jr. "Is the Filipino Diaspora a Diaspora?." Critical Asian Studies. 47. No. 3 (2015): 440-461. doi: 10.1080/14672715.2015.1057392.

Greek Colombijn and Aygen Erdentug. Urban Ethnic Encounters: The Spatial Consequences. London: Routledge Publishing, 2002.

Gregorio C. Borlaza and Caroline G. Hernandez, "Philippines: Pre-Spanish History", Encyclopaedia Britannica. Encyclopaedia Britannica, inc, 2016. Accessed on March 20, 2017. https://www.britannica.com/place/Philippines Pre-Spanish-history.

Hamid Nacify. Exile, Homeland Film, Media, and the Politics of Place. New York: Routeledge, 1998.

Hannah Arendt, The Human Condition, Chicago: University of Chicago Press, 1958.

Henri Lefebvre. State, Space, World: Selected Essays. Mankota: University of Minnesota Press, 2009.

Ijeoma Umebinyuo. Questions for Ada. CreateSpace Independent Publishing Platform, 2015 
Janet Delaney. "South of Market 1978-1986." Janet Delaney. Accessed March 20, 2017. http://www.janetdelaney.com/ south-of-market/

Jefferey H. Cohen and Ibrahim Sirkeci. Cultures of Migration. Austin: University of Texas Press, 2011.

Kathryn Terzano. "Commodification of Transitioning Ethnic Enclaves." Journal of Behavioral Sciences. no. 7 (2014): 341-351. doi:10.3390/bs4040341.

Katie Worth, "San Francisco Neighborhoods Have Changed Faces Over Two Decades." San Francisco Examiner. Last modified March 20, 2011. http://www.sfexaminer com/local/development/2011/03/san francisconeighborhoods-have-changed-faces-over-last two-decades.

Leonie Sandercock. Cosmopolis II: Mongrel Cities in the 21st Century. London: Continuum, 2003

Lucy K. Phillips, Revitalized Streets of San Francisco: A Study of Redevelopment and Gentrification in SoMA and the Mission. Masters Thesis, Scripps College, 2012.

Luisa A. Igloria. Not Home but Here: Writing From the Filipino Diaspora. Pasig City: Anvil Publishing, Inc. 2003.

Marshall Brown. "Chimera: The Architecture of Creative Miscegenation." Journal of Architectural Education. 70, no.1 (2016): 22-27. doi:10.1080/10464883.2016.1122468.

Michel De Certau. The Practice of Everyday Life. Berkley: University of California Press, 1984.

Peter Brook. The Empty Space. New York: Touchstone Publishing, 1968.

Philip Chang, Claire Dwyer and Peter Jackson. Transnational Spaces. London: Routledge, 2004.

Sam Greenspan and Roman Mars. "Pagodas and Dragon Gates". 99\% Invisible Podcast. 192. Podcast audio. 99\% Invisible: Cities. MP3, 23:59. Accessed April 26, 2016. http://99percentinvisible.org/episode/pagodas dragon gates/.

Vijay Agnew, Diaspora, Memory and Identity: A Search for Home, Toronto: University of Toronto Press, 2005..

Yen Le Espiritu. Home Bound: Filipino American Lives across Cultures, Communities, and Countries. Berkeley and Los Angeles: University of California Press, 2003. 
Maraming Salamat! 